San Jose State University

SJSU ScholarWorks

Dissertations

Master's Theses and Graduate Research

Spring 2019

\title{
Superintendent Beliefs About the Assessment and Use of School Climate Data for Continuous Improvement
}

Anji Buckner-Capone

San Jose State University

Follow this and additional works at: https://scholarworks.sjsu.edu/etd_dissertations

\section{Recommended Citation}

Buckner-Capone, Anji, "Superintendent Beliefs About the Assessment and Use of School Climate Data for Continuous Improvement" (2019). Dissertations. 28.

DOI: https://doi.org/10.31979/etd.qawf-e9xs

https://scholarworks.sjsu.edu/etd_dissertations/28

This Dissertation is brought to you for free and open access by the Master's Theses and Graduate Research at SJSU ScholarWorks. It has been accepted for inclusion in Dissertations by an authorized administrator of SJSU ScholarWorks. For more information, please contact scholarworks@sjsu.edu. 


\title{
SUPERINTENDENT BELIEFS ABOUT THE ASSESSMENT AND USE OF SCHOOL CLIMATE DATA FOR CONTINUOUS IMPROVEMENT
}

\author{
A Dissertation \\ Presented To \\ The Faculty of the Educational Doctoral Program in Educational Leadership \\ San José State University \\ In Partial Fulfillment \\ of the Requirements for the Degree \\ Doctor of Education
}

by

Anji Buckner-Capone

May 2019 
(C) 2019

Anji Buckner-Capone

ALL RIGHTS RESERVED 
The Designated Dissertation Committee Approves the Dissertation Titled SUPERINTENDENT BELIEFS ABOUT THE ASSESSMENT AND USE OF SCHOOL CLIMATE DATA FOR CONTINUOUS IMPROVEMENT

by

Anji Buckner-Capone

\section{APPROVED FOR THE EDUCATIONAL DOCTORAL PROGRAM IN EDUCATIONAL LEADERSHIP}

SAN JOSÉ STATE UNIVERSITY

May 2019

Brent Duckor, Ph.D.

Roxana Marachi, Ph.D.

Kathleen M. Roe, MPH, Dr.PH
Department of Teacher Education

Department of Teacher Education

Department of Health Science and Recreation 


\title{
ABSTRACT \\ SUPERINTENDENT BELIEFS ABOUT THE ASSESSMENT AND USE OF SCHOOL CLIMATE DATA FOR CONTINUOUS IMPROVEMENT
}

\author{
by Anji Buckner-Capone
}

Academic outcomes and health outcomes are interconnected and reciprocal and school climate has emerged as a way to capture some of this relationship. An increasing trend in education policy is using multiple measures of school success, including school climate, such as California's Local Control Funding Formula (LCFF). As school climate evolves as a critical component in state accountability there is a need to better understand the role of leaders in facilitating the implementation processes for school climate assessment accountabilities, including their beliefs and their practices. This mixed methods study explored the practices and beliefs of California Superintendents in their efforts to meet Priority 6 (school climate) of the LCFF. The study used an explanatory sequential mixed methods design to query 298 superintendents who participated in an online survey and eight superintendents who were interviewed in the qualitative data collection phase. Findings suggested that superintendents largely believe that school climate assessment was important; they believe in their capacities to use the data for decision making; and they believe that using quality instruments are important. However, there was variation in their responses suggesting the need for further exploration. These varied beliefs impact how local leaders interpret and implement assessment strategies, which influence the data that are received and the subsequent decisions that are made. In the conclusion, the researcher offers recommendations for policy, practice, and future research. 


\section{DEDICATION}

I dedicate this dissertation to the journey for equal rights and social justice and to all of the people (past, present and future) who work to sustain the momentum. 


\section{TABLE OF CONTENTS}

List of Tables................................................................ ix

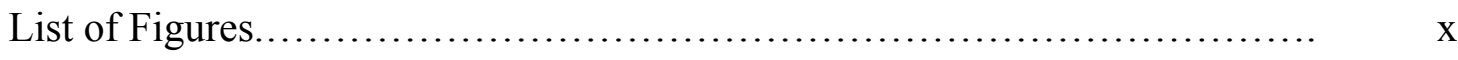

List of Abbreviations....................................................... xi

Chapter One: Introduction................................................

The California Way.................................................... 6

Significance of the Problem................................................ 7

Research Questions................................................... 9

Key Definitions................................................ 9

Chapter Two: Literature Review................................................ 12

Health, Academics, and School Climate.................................. 12

The relationships between health and education outcomes.............. 12

School climate outcomes and underlying beliefs....................... 17

Assessing School Climate............................................. 21

Considerations for school climate assessment............................. 26

Education Policy Reform......................................... $\quad 30$

School conditions and climate work group........................ 32

Data driven decision making in K-12 education....................... 34

Implications for Superintendents as Decision Makers................... $\quad 36$

Research Gaps and Opportunities...................................... $\quad 40$

Chapter Three: Methodology and Research Design.......................... 44

Research Methodology and Study Design............................. 45

Research methods.............................................. 47

Study population............................................... 48

Sampling ......................................................... 48

Instrumentation................................................. 49

Survey design................................................ 49

Construct maps........................................... 49

Items design.......................................... 50

Semi-structured interview protocol............................. 51

Data collection procedures...................................... 52

Data analysis.................................................... 53

Quantitative data analysis.................................... 54

Outcome space........................................... 54

Mathematical modeling.................................... 55

Qualitative data analysis.................................... 58

Evidence for Validity and Reliability................................. 60

Evidence for validity ........................................... 60

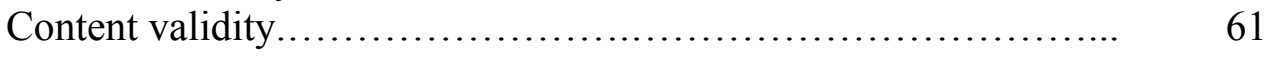


Response process validity.................................. 61

Internal structure validity.................................... 62

Relations to external variables and consequences................. 62

Evidence for reliability........................................ 63

Internal consistency...................................... 64

Alternate forms, test retest, rater reliability...................... 64

Random errors........................................... 65

Credibility, consistency, and transferability........................ 66

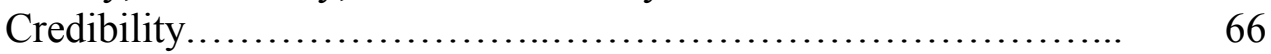

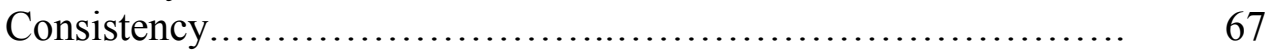

Transferability........................................... 68

Response bias.............................................. 69

Ethical Considerations................................................ 71

Chapter Four: Findings............................................ 74

Profile of the Participants........................................ $\quad 75$

Analysis of the quantitative findings............................. 75

Analysis of the qualitative findings............................... 78

Analysis of the quantitative and qualitative findings.................. $\quad 79$

Research Question One............................................ 79

Analysis of the quantitative findings: Instruments and practices in use. $\quad 80$

Analysis of the qualitative findings: Instruments and practices in use... $\quad 82$

Analysis of the quantitative and qualitative findings: Instruments and

practices in use................................................. 85

Research Question Two........................................... 86

Analysis of the quantitative findings: Importance.................. 87

Analysis of the qualitative findings: Importance .................... 90

Analysis of the quantitative and qualitative findings: Importance ...... 97

Analysis of the quantitative findings: Capacity..................... 99

Analysis of the qualitative findings: Capacity...................... 101

Analysis of the quantitative and qualitative findings: Capacity......... 105

Analysis of the quantitative findings: Trustworthiness................ 107

Analysis of the qualitative findings: Trustworthiness................. 110

$\begin{array}{ll}\text { Analysis of the quantitative and qualitative findings: Trustworthiness.. } & 113\end{array}$

Research Question Three........................................... 114

Importance construct......................................... 115

Capacity construct............................................ 117

Trustworthiness construct........................................ 118

Chapter Five: Discussion............................................ 121

Summary of the Study.......................................... 121

Summary of RQ1: Implications.................................... 122

Summary of RQ2: Implications.................................... 123

Summary of RQ3: Implications................................... 124 
Discussion............................................................ 125

Assessment literacy............................................ 128

Power dynamics.............................................. 131

Resources......................................................... 133

Study Limitations................................................. 133

Conclusion.......................................................... 135

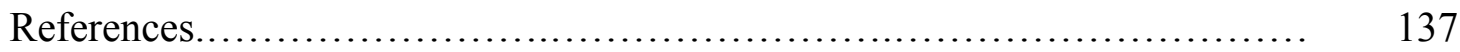

Appendices.............................................................. 149

Appendix A. Visual Depiction of the Gaps in the Research................ 149

Appendix B. Construct Maps........................................... $\quad 150$

Appendix C. Survey Instrument....................................... 156

Appendix D. Semi-Structured Interview Protocol....................... 164

Appendix E. Recruitment Emails................. 167

Appendix F. Wright Maps............................................. 173

Appendix G. Regression Analysis Questions............................. 176

Appendix H. Approved IRB........................................ 178

Appendix I. Survey Consent Notification............................... $\quad 180$

Appendix J. Interview Consent Form................................. 182 


\section{LIST OF TABLES}

Table 1. Domains Measured in the School Climate Research......... 23

Table 2. Comparison of Instrument Characteristics.................. 25

Table 3. Data Analysis Summary............................... 53

Table 4. Survey Participant Personal Demographics................. 75

Table 5. Survey Participant District Demographics................. 77

Table 6. Importance Construct Summary Statistics................ 88

Table 7. Capacity Construct Summary Statistics................... 99

Table 8. Trustworthiness Construct Summary Statistics............. 107

Table 9. Trust in Using Data for Continuous Improvement........... 109

Table 10. High Uncertainty in Trustworthiness of Data................ 110

Table 11. Regression Summary for Importance Construct............. 116

Table 12. Regression Summary for the Capacity Construct............ 117

Table 13. Regression Summary for the Trustworthiness Construct....... 119 


\section{LIST OF FIGURES}

Figure 1. Overview of school climate research..................... 19

Figure 2. Common definitions citied in school climate research....... 22

Figure 3. California SCCWG recommendations to the state and local... 33

Figure 4. Explanatory sequential mixed methods design visual........ 47

Figure 5. Visualization of email components used to increase response $\quad 70$

Figure 6. Instruments used by districts for school climate assessment... 80

Figure 7. Frequency of data disaggregation by student population...... 81

Figure 8. Frequency of data disaggregation by level................ 82

Figure 9. Side-by-side data analysis of importance of evaluation........ 97

Figure 10. Side-by-side data analysis of importance of standardization... $\quad 98$

Figure 11. Side-by-side quantitative and qualitative data showing....... 106

Figure 12. Side-by-side quantitative and qualitative data visualizing.... 113 


\section{LIST OF ABBREVIATIONS}

EAP - Expected A Posterior

EL - English Learner

FRPM - Free and Reduced Price Meal

SPED - Special Education 


\section{Chapter One: Introduction}

Historically, the United States (US) public school system has been characterized by a commitment to wellbeing and citizenship. The concept of providing universal education reflected a social ideal of a standard level of academic proficiency, and an investment in future generations' ability to fully engage in a democratic system. As a public sponsored system, the formal and informal evaluation of how well public schools are doing has long been a focus of the schools directly, the general public, scholars, and politicians.

Unfortunately, these judgments have not always been positive. Public and political indignation towards the education system was heightened with the Reagan Administration's 1983 report, A Nation at Risk. In this work, the commission proposed that the education system was failing, supported by evidence that suggested a decline in academic achievement among US students (National Commission on Excellence in Education, 1983). The authors further proposed that the national trends would negatively impact the nation's long-term economic and global productivity.

In the four decades that followed, these considerations led to high levels of criticism and waves of education reform efforts. One result was a shift in educational accountability, and by early the early 2000's standardized achievement tests emerged as the primary metric for success. In the years following, the debate over standardized exams and school accountability has been closely intertwined. As schools across the country have made efforts to improve assessment and evaluation expectations, it has become clear that the system is indeed in need of change. However, the change is not as the Nation at Risk had proclaimed or predicted. On the contrary, the US education system 
has been a model for the rest of the world and we continue to educate some of the world's brightest and most innovative global contributors. Simultaneously, when compared to other wealthy nations, the US has some of the highest rates of child poverty and widest gaps in achievement (Berliner \& Glass, 2014). The extreme outcomes are not well captured in statistical averages, thus inaccurately portraying both the strengths and the weaknesses of our system.

As a result of misleading portrayals, the national perception of public schools has remained under constant attack. Political and social attacks on the education system open the doors for reform efforts. Currently, reform efforts are both supporting and resisting school choice, privatization, and standardized academic achievement testing. At the same time, there is a growing interest in multiple measures of success, including an emergent focus on non-academic and out-of-school factors that contribute to learning and school outcomes. These influences include environmental factors, such as poverty and neighborhood conditions, and individual factors such as health, relationships, and resilience. Education scholar David Berliner has presented research on the influence of out-of-school variables on academic outcomes, claiming that upwards of $60 \%$ of the range in student achievement could be attributed to out of school factors (Berliner, 2014). Berliner, who has focused on socioeconomic status, claims that the most effective school reform movement would be to eliminate poverty and improve neighborhood conditions (Berliner, 2009, 2013, 2014).

To further support Berliner's claim valuing the role of influences outside of school, public health researchers and practitioners have consistently documented a synergistic 
relationship between health outcomes and education outcomes. Academic attainment is a social determinant of health, which means that health outcomes are directly and indirectly shaped by educational experiences and outcomes. One of the ways this relationship is observable is through epidemiological studies, where researchers have documented lower mortality and morbidity rates as years of education increase.

The relationship between health and education is evident in both chronic and acute conditions. For example, the age adjusted mortality rate among high school dropouts is almost twice that of people with some college, and the risk of heart disease is reduced by $2.2 \%$ among adults who have four additional years of education beyond high school (Telfair \& Shelton, 2012). Furthermore, early educational experiences serve a purpose in helping children develop knowledge, skills, and habits that will promote good health throughout life. The magnitude and scope of the influence of these potentially positive health-promoting experiences, however, are subject to community circumstances and contexts in which the children live and go to school.

In addition to health outcomes that are influenced by academic attainment, school success is influenced by health. According to Charles Basch, healthy students are more capable and motivated to learn. Basch argues that eliminating health disparities could be an effective strategy to close the achievement gap in US education outcomes (Basch, 2011). Ultimately, it is in the interest of public health to ensure that all students have school-based opportunities to develop healthy cognitive, social, and health-promoting knowledge and skills and are prepared for college or career pathways. Similarly, it is in 
the interest of public schools to help promote both pupil and school health to maximize the positive impact of teaching and learning.

One area where the relationship between health and learning has emerged is through contemporary scholarship, practice, and policies that have been directed at improving school climate. School climate broadly refers to the culture of the school and is inclusive of the environment, attitudes, and behaviors of students, school personnel, and the broader community. According to many scholars, it is the organizational character that establishes the school behaviors and practices - the norms, values, rules, and expectations (Hopson \& Lee, 2011; National School Climate Council, 2017; Sheldon, Epstein, Galindo, 2010; Thapa, Cohen, Guffey, \& Higgins-D’Alessandro, 2013).

Understanding the climate of a particular school is important because a positive perception of school is directly and indirectly associated with a number of educational outcomes. For example, according to Thapa et al.'s (2013) meta-analysis of school climate, there are prolific data documenting the impact of a positive school climate on academic success, motivation, health, and general wellbeing.

The concept of school climate is not new to education scholarship. In fact, it appeared a century ago in Arthur Perry's book, Management of a City School (Perry, 1908). Perry, a school principal, claimed that an important role of a principal was in ensuring that school conditions would be favorable to students, parents, teachers, the public, and the authorities (1908). The concept has been studied to various degrees in the century that followed Perry's assertion, with a recent surge influencing both policy and practice. 
In education practice, increased attention is being devoted to surveillance and descriptive processes as school personnel set out to characterize the climate at their schools, identify needs, and strategize programs (and services) to improve organizational health. Educational scholarship defends that non-academic factors (Farrington et al., 2012) make a difference in student outcomes including college and career readiness. Now, many policy makers and advocacy groups are calling for multiple measures to ensure a more equitable education for children, particularly those in high need schools as defined by the Every Student Succeeds Act (ESSA).

In education policy, the trend to include non-academic influences on student growth and school development in state benchmarks and accountability processes is increasing. For example, all 50 states articulate preschool benchmarks for social and emotional developmental competencies and a growing number of states are exploring expectations beyond preschool (Dusenbury \& Weissberg, 2017).

Even with increasing interest, and despite the invitation under the federal ESSA, few states have incorporated non-academic indicators in state accountability systems. In fact, according to a policy report by the Center for American Progress, only four states have included school climate specifically, five have included chronic absenteeism as a proxy for climate, and one has included parent engagement directly (Martin, Sargrad, \& Batel, 2016). California is one of the four states in the nation to include school climate as one of the multiple measures in school accountability. The 2013 revised state funding system, Local Control Funding Formula (LCFF), drastically shifted attention to local leadership and expanded accountability to include measures of growth in engagement and school 
climate. This move signaled a growing concern regarding the reliance on standardized achievement tests to evaluate school success.

\section{The California Way}

The implementation of the LCFF marked a radical shift in California education accountability and politics. "The California Way," a term that was popularized by education leaders, researchers, and policy makers, is the blueprint for change and it is characterized by multiple measures of accountability and local control, or "leading from the middle" (LftM). LftM, an idea that was coined by Hargreaves (2015) and openly endorsed by international scholar Michael Fullan, emphasizes the role and capacity of the more than 1000 district and county Superintendents to effectively lead local schools through a process of continuous improvement. As previously stated, the LCFF has broadened the measures of school accountability resulting in increased attention on school climate. As a result, California has begun to discuss how to best support schools in assessing school climate. There is a need to ensure that assessment processes are accurate and effective in guiding meaningful change that can improve school climate and conditions.

Many instruments have been developed to assess school climate, but these tools are inadequate for state accountability for several reasons. First, there is little consistency in the definition and operationalization of variables. Second, the tools need improved rigor in psychometric testing to be used in practice, particularly state accountability and decision making. Third, underlying theoretical foundations are predominantly absent in the majority of tools. Fourth, there is a lack of discussion in terms of the purpose and 
usability of the instruments. Lastly, little attention is being paid to the interpretation and future planning for improvement of school climate following assessment (Berkowitz, Astor, Pineda, DePedro, Weiss, \& Benbenishty, 2016; Konold et al., 2014; Lee et al., 2017; Thapa et al., 2013; Wang \& Degol, 2016; Zullig et al., 2015).

\section{Significance of the Problem}

School climate is increasingly believed to be important in shaping school experiences. Simultaneously, advocates and policy makers are looking for ways to explain the widening gap in academic achievement, and hold schools accountable. As the attention towards school climate increases among advocates, reformers, policy makers, and practitioners, it is imperative that we critically analyze the ways in which schools are assessing school climate and the accompanying beliefs about school climate amongst education leaders. California, as the nation's front runner in school climate assessment as an accountability measure, offers a compelling opportunity to explore leader beliefs and local practices.

School environments that foster, condone, ignore, or perpetuate behaviors that pose risks to healthy development are deeply in need of greater understanding, just as environments that foster positive health and quality of life are in demand. School climate, if adequately understood and assessed, can facilitate interactions between key stakeholders and school systems. If school climate is not well understood or is poorly assessed, the emergent data cannot adequately guide change and may not accurately represent the dynamic complexity of the factors that influence healthy school environments. 
The extant literature clearly indicates the importance of school climate on academic and health outcomes, and furthermore, the state of California is committed to ensuring that schools work to continuously improve school climate and conditions. A current challenge is that school climate is not consistently defined and/or measured, thus impacting the use and applicability of assessment tools and the potential for change in local and state education policy and practice (Duckor, 2017; Maul, 2017). While school climate is a state priority, it remains unclear how local education agencies are collecting and using data and whether or not school climate assessment is practically useful in informing local changes to improve academic outcomes for all learners.

This interdisciplinary study draws from and blends the perspectives and considerations from the scholarship of both public health and education, to situate and contextualize the meaning and significance of school climate assessment and the impacts that leaders' beliefs may have on assessment practices. The purpose of this study was to explore superintendent beliefs and local district practices in school climate assessment throughout the state of California. Knowing what schools are doing and how superintendents perceive the importance of school climate, their trust in the data, and their capacity to use data to influence change will help statewide leaders, policy makers, researchers, and school personnel improve their efforts to support local school improvement plans. 


\section{Research Questions}

The following research questions were explored in this study that aimed to contribute to the scholarship of school climate and school climate assessment in California's public schools.

1. What instruments and practices are currently being used by California public schools to assess and use school climate data for continuous improvement?

2. What are superintendent beliefs regarding the importance of school climate assessment, their perceived ability to use school climate data for decision making, and their trust in the data?

3. What is the relationship (if any) between superintendent beliefs towards school climate data and other personal factors or school contexts?

\section{Key Definitions}

There are a number of discipline-specific terms that were important in this study. The following definitions were used.

Academic outcomes: Academic outcomes pertain to individual or school based measures of learning or performance (Glossary of Education Reform, 2014).

Assessment: Assessment is any process that seeks to obtain information or measure performance in order to draw inferences about the characteristics people, objects, or programs (American Educational Research Association, 2014, p. 216).

Continuous improvement: Evidence demonstrating that a school is getting better and better at developing capacities in relationships, pedagogy for diversity, assessment, and leadership (Fullan, 2005; Fullan, 2011). 
Health: Health is "not merely the absence of disease" but a "state of complete physical, mental, and social wellbeing" (World Health Organization, 2017, para 1).

Leadership from the Middle: LftM is focused on the capacity of leaders at the county and district level to use policy in ways that will support continuous local improvements to teaching and learning (Fullan, 2014).

Non-academic skills: Non-academic skills is a term that will be used in place of the outdated, but still existent term - non-cognitive skills. These skills are characterized by individual "patterns of thought, feelings, and behaviors that are socially determined and can be developed throughout the lifetime to produce value" (Zhou, 2016, p. 2). These skills are inclusive of terms such as personality traits, attitudes, motivation, grit, perseverance, mindset, and self-efficacy. Non-cognitive skills have become increasingly conflated with social and emotional learning and the two terms are sometimes used interchangeably and synonymously, despite differences.

Public health: Public health includes any strategic effort that "promotes and protects the health of people and the communities where they live, learn, work, and play" (American Public Health Association, 2017, para 1).

Quality of life: Quality of life is simply defined as "the degree to which a person enjoys the important possibilities of his or her life" (Quality of Life Research Unit, 2017, para. 4).

School climate: "School conditions and climate refers to the character and quality of school life" (California Department of Education, 2017, screen 11). 
Social and emotional learning: Social and emotional learning is "a process through which children and adults acquire and effectively apply the knowledge, attitudes, and skills necessary to understand and manage emotions, set and achieve positive goals, feel and show empathy for others, establish and maintain positive relationships, and make responsible decisions" (Collaborative for Academic, Social, and Emotional Learning, 2017, para. 1). SEL practitioners and advocates have long objected to the synonymous use of non-cognitive factors because social and emotional capacity very clearly require cognitive thought and skill. 


\section{Chapter Two: Literature Review}

As an interdisciplinary study, this review included an analysis of extant literature across both public health and education disciplines, synthesizing the perspectives across four topic areas. First, the relationship between health, academics and school climate was explored. This topic included the synergistic relationship between health outcomes and education outcomes, shared inequities, and the influence of school climate. The second topic area explored research on school climate assessment instruments, including evidence of validity and reliability and practices. Education policy reform, including an historical overview leading up to contemporary trends and California's LCFF, followed by data-driven decision making were captured in the third topic area. Finally, the role of superintendents in shaping and implementing education reform policy was explored in the fourth topic area. A summary of gaps in the literature and opportunities for research concludes this chapter.

\section{Health, Academics, and School Climate}

The available literature on the interconnections and relationships between health, education, and school climate was robust. This section explores the synergistic relationship between health and education outcomes and the related outcomes and underlying beliefs regarding school climate research.

The relationship between health and education outcomes. The evidence pointing to a correlation between academic attainment and personal health is substantial. Public health epidemiologists have consistently documented a relationship between the number of years of schooling completed and rates of morbidity and mortality. Such evidence 
informs the rationale for public health labeling education as a social determinant of health, which is a social-environmental context that contributes to population health outcomes. In addition to education, other social determinants include neighborhood conditions, economic stability, and discrimination (Office of Disease Prevention and Health Promotion ((ODPHP), 2017).

Public health research abundantly illustrated the impact of education on health. Analysis of mortality data show an increase in death rates among populations with the lowest education levels; a trend that is recognized in the US as well as globally (Adler et al., 2016; Pomeranz \& Chang, 2017; Venkataramani, Chatterjee, Kawachi, \& Tsai, 2016; World Health Organization ((WHO), 2017). Researchers in the US have suggested that nearly two decades of life are lost for people who have not graduated high school (Telfair \& Shelton, 2012). The relationship also appears to be gradient. As schooling increases, mortality decreases (Krueger, Tran, Hummer, \& Chang, 2015; Olshansky, 2012). For example, mortality risk was $6 \%$ lower for individuals with some college and $25 \%$ lower for those with a college degree (Krueger et al., 2015).

The correlations are so strong, in fact, that some researchers have adopted language of causation, claiming that the impact of education on mortality is akin to other behavioral causes of death, such as smoking (Galea, Tracy, Hoggatt, DiMaggio, \& Karpati, 2011; Krueger et al., 2015). In one US study, the researchers suggested that 145,245 deaths in 2010 were attributed to not having earned a high school diploma or the equivalent (Krueger et al., 2015). 
It has been proclaimed that educational opportunities enable individuals to obtain higher paying jobs, and increased opportunities for access to healthcare, social mobility, improved relationships, and the development of healthy habits and behaviors. Thus, an underlying moral argument in the literature on the relationship between health and education was the valuing and promotion of quality educational opportunities for all (Adler et al., 2016; Basch, 2011; ODPHP, 2017a; WHO, 2017).

Researchers, in congruence with epidemiologists and public health professionals, have suggested that increasing attention, in both policy and practice, to reducing educational gaps and increasing completion rates would lead to drastic improvement on premature death and overall health status (Adler et al., 2016; Basch, 2011). While there was a clear relationship between educational attainment and health, the inverse was also consistently supported in the literature.

Researchers have evidence suggesting that health impacts both learning and academic outcomes. Education researchers have led efforts exploring factors outside of school that impact education, and many researchers have proposed increased attention to social and health related issues to improve academic success (Basch, 2011; Berliner, 2009, 2013, 2014). Basch's extensive research suggested that improving student health can help reduce achievement gaps, because, "Healthier children learn better" (2011). To support this claim Basch, and others, take an in-depth look at "educationally relevant health disparities" including visual impairments, asthma, teen pregnancy, and physical activity (Basch, 2011; Berliner, 2014). 
Taken in its entirety, Basch's scholarship has exposed the ways in which health can (and does) impede academic outcomes and student capacities. In his research, he claimed that sensory perceptions, cognition, school connectedness, absences, disruptive classroom behavior, and dropping out are all related to specific health problems that are prevalent among children and school-aged youth.

More broadly, environmental factors that negatively impact quality of life have also been implicated as contributing to the academic achievement gap. In his research, Berliner points to non-genetic prenatal influences, healthcare access, environmental pollutants, food insecurity, and family and neighborhood stress as directly impacting the academic and learning potential of many children; factors that are all significantly exacerbated by poverty (Berliner, 2009, 2013, 2014). He has suggested that these out ofof-school factors are attributable to nearly $60 \%$ of the variance in test scores (2009). Berliner's research parallels the research on student health by Basch. Both have recognized that the work of schools, which is to educate children, has been impeded by exogenous factors related to health, wellbeing, and economics.

The extant literature generously supported the synergistic relationship between health and education and a closer look revealed that similar populations are disproportionately burdened by these relationships. Disparities, which are the result of systematic and population based inequities and injustices (Braveman et al., 2011), persist across and within both education and health systems. For example, in health, life expectancy is lower among low income adults and African Americans, Latinos, and Native Americans (Lu et al., 2010; Telfair \& Shelton, 2012). Insurance rates and healthcare access are 
lowest among Latinos and people who are low in socio-economic status (ODPHP, 2017b). Members of the LGBTQ population disproportionately report high levels of stress and suicidal ideation (Jackson, Agénor, Johnson, Austin, \& Kawachi, 2016; ODPHP, 2017b), and people with disabilities are at risk of victimization and violence (Krahn, Walker \& Correa-De-Araujo, 2015). In education, researchers have documented lower rates of achievement in math by gender (Cimpian, Lubienski, Timmer, Makowski \& Miller, 2016); and graduation rates are significantly lower among students with disabilities, low income students, and black and Latino youth (DePaoli, 2015; DePaoli, 2017; Hemphill \& Vanneman, 2011).

The relationships between these two disparately functioning systems have led some practitioners to collaborate to improve the overall health of the school environment and it has led researchers to further understand the role of the environment in academic outcomes. School climate, a commonly used term to describe the school environment, is not synonymous with health, but does provide an opportunity to explore elements of school health.

School climate literature has suggested compelling and robust relationships between climate and a variety of important outcomes and contributing factors. The relationships have been explored for decades, but the current interest was heightened by rhetoric that has suggested that improving climate will help decrease the gaps in academic achievement. It is, therefore, important to understand how school climate influences education experiences and the underlying beliefs guiding school climate research. 
School climate outcomes and underlying beliefs. There have been multiple studies on school climate devoted to exploring how climate influences outcomes in health and academics. Additionally, researchers interested in closing the achievement gap have identified school climate as a variable that can potentially help schools improve equity across student groups. A synthesis of research spanning these three perspectives revealed an overarching trend that when perceptions of climate were positive, behaviors were also more positive and health promoting; alternatively, when climate perceptions were negative, high risk behaviors occurred more frequently (Benbenishty, Astor, Roziner, \& Wrabel, 2016; Doumas, Midgett, \& Johnston, 2017; Espelage, Polanin, \& Low, 2014; Hopson \& Lee, 2011; Karakos, Voight, Geller, Nixon, \& Nation 2016; O’Brennan, Bradshaw, \& Furlong, 2014; O’Malley, Voight, Renshaw, \& Eklund, 2015).

Researchers have explored specific school climate variables and corresponding outcomes. The most common variables studied were perceptions of safety, harassment, relationships, and academic and social engagement. The observed outcomes related to these school climate variables included attendance, health, violence, and academics. Among the findings, absenteeism and truancy crossed all of the variables. Chronic absenteeism was associated with negative perceptions of school climate (Van Eck, Johnson, Bettencourt, Johnson, 2017), and truancy decreased, for all students, when school climate perceptions were positive (Hopson \& Lee, 2010). Relative to LGBTQ students, there was a strong relationship between absenteeism and fear of being assaulted or harassed at school was evident (Burton, 2014). 
Health was another outcome that was observed. When students did not feel safe or were afraid of being harassed, substance use and rates of physical activity both emerged as negative outcomes (Doumas et al., 2017; Gase et al., 2017; Richmond, Milliren, Walls \& Kawachi, 2014). Similarly, lower rates of violence and harassment were related to overall favorable perceptions of school climate (Benbenishty et al., 2016; Espelage et al., 2014; Hopson \& Lee, 2011; Low \& Van Ryzin, 2014), and specifically associated with the presence of positive relationships with adults on campus (Benbenishty, 2016; Gage, Larson \& Chafouleas, 2016). Similarly, positive relationships were closely related to decreased bully behaviors (Konishi, Hymel, Zumbo, \& Li, 2010).

The fourth common outcome studied in the literature were academic outcomes. Positive relationships with adults on campus were also positively related to academic achievement in both math and English Language Arts (ELA) (McMahon, Wernsman, \& Rose, 2009; Wang \& Degol, 2016). Perceived safety was another school climate factor that was related to academic achievement in math and ELA (Kraft, Marinell, \& Yee, 2016). Relatedly, schools that exhibited a low tolerance for harassment were associated with positively supporting the mental health and academic engagement of LGBTQ students (Benbenishty et al., 2016; Coulter et al., 2016; Hatzenbuehler, Birkett, Van Wagenen \& Meyer, 2014). Lastly, school climates that were perceived as academically engaging, with high expectations for all learners, were positively associated with academic outcomes (Wang \& Degol, 2016). Figure 1 presents an overview of the research visually depicting the relationship between school climate and student outcomes. 


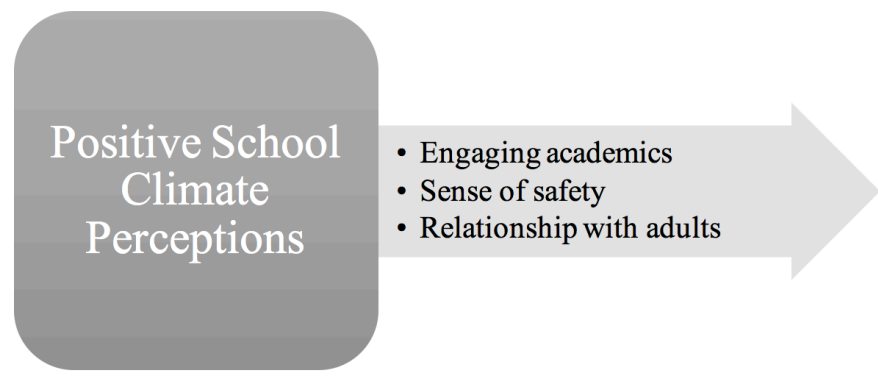

Positive academic outcomes (Wang \& Degol)

Lower rates of violence (Benbenishty; Espelage; Hopson \& Lee; Low)

- Decrease bully behavior (Konoshi)

- Increase achievement in math and ELA (McMahon \& Wang)

- Increase positive mental health and academic engagement (Burton)

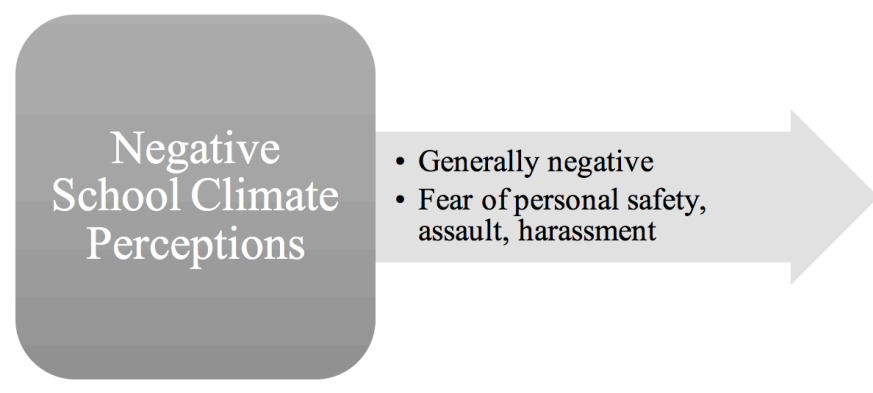

- Decreased physical activity (Doumas; Gase; Richmond)

- Increased substance use/abuse (Doumas; Gase; Richmond)

- Increased absenteeism (VanEck)

- Decreased academic achievement exacerbated by race (Voight)

Figure 1. Overview of school climate research.

Throughout the literature reviewed, the underlying beliefs were that school climate is malleable, it can be observed, and it is important. It was suggested that school climate is important for all students, but particularly important for marginalized students.

Researchers have suggested that student sub-populations, including Black and Hispanic students (Jain, Cohen, Huang, Hanson, \& Austin, 2015; Voight, Hanson, O’Malley, \& Adekanye, 2015) and those who are at risk for victimization, such as girls (Espelage et al., 2014) and LGBTQ students (Burton, 2014; Coulter et al., 2016) more frequently report negative school climates.

In a recent study, Fan, Williams, \& Corkin (2011) explored risks to academic completion and school climate and their findings suggested that students of color perceived climate more negatively than their white peers. Using data from a national sample of 16,168 tenth graders who participated in the Education Longitudinal Study of 
2002, researchers found that black males perceived less connectedness at school and unfair enforcement of rules; Hispanic and Asian students were critical of safety and discipline; and native American students had a less favorable perception of their relationships with teachers (Fan et al., 2011).

In another study, researchers utilized student data from the California Healthy Kids Survey (CHKS) and teacher data from the California School Climate Survey (CSCS) between 2008 and 2010 to explore racial differences in school climate and the achievement gap (Voight et al., 2015). The findings from this study suggested that when there was a wide variation in school climate perceptions by race, there was a similar trend in academic variation by race. Furthermore, schools with a positive perception of climate had higher rates of academic achievement and fewer suspensions and expulsions. These schools were culturally inclusive, they had school norms that promoted diversity, and they implemented fair discipline policies. The authors proposed that improving school climate could have a positive impact on reducing the achievement gap between black and white students (Voight et al., 2015).

The literature on school climate was robust and compelling, however, there were concerns that necessitated additional attention, including how school climate was being studied. First, student perspectives and student outcome measures dominated the research, but school climate undeniably has an influence on many people who are involved in the schools. For example, while studies were limited, school climate was associated with teacher outcomes and behaviors, including turnover, job satisfaction, 
interpersonal relationships, professional collaboration, and expectations of students (Kraft, Marinell, \& Yee, 2016; Thapa, Cohen, Guffey, \& Higgins-D’Alessandro, 2013).

Another concern was that study findings were at times inconclusive and inconsistent. For example, some researchers were unable to determine directionality in relationships (Benbenishty et al., 2016; Wang \& Degol, 2016). In other studies, the strength of the relationship was called into question, with some showing strong relationships between climate variables and outcomes and others showed a weak relationship. The relationship between low socioeconomic status and school climate, which was not resolved in the literature, is an example. One study suggested a relationship between school climate and SES (Jain et al., 2015), but presented no conclusive evidence that school climate was perceived more negatively among students from low SES households. A final concern called into question the processes and approaches to data collection including instruments available and in use for school climate assessment. The following section presents a summary of the literature on school climate assessment.

\section{Assessing School Climate}

As previously noted, school climate has a long history of research in public health and education scholarship. In the published literature reviews that have spanned the topic of school climate and the subdomains, a commonality was the admission of a lack of cohesiveness in fundamentally important terminology, agreement on variables to measure, and the psychometric rigor of instruments (Berkowitz, 2017; Konold et al., 2014; Lee et al., 2017; Thapa et al., 2013; Wang \& Degol, 2016; Zullig et al., 2015). 
Despite decades of attention, there was no formal agreement on a definition of school climate, domains, and the variables that can (and should) be measured.

Figure 2 provides a comparison of the definitions of school climate that were

identified in the literature. The most common definition was Cohen et al. (2009) from the

National School Climate Center. Of ten studies reviewed, $70 \%$ used some part of the

Cohen et al. (2009) definition, (50\% used the definition in full and 20\% used it partially).

As a result, the majority of the definitions were very similar. When analyzing all of the

definitions, two commonalities were noted: first, school climate was associated with

shared beliefs, and second, it intended to capture social or interpersonal school

experiences.

"Shared beliefs, values, and attitudes that shape interactions between students, teachers, and administrators and set the parameters of acceptable behavior and norms for the school (Cohen et al., 2009 p. 192)."

"The quality and character of school life which is based on patterns of peoples' experiences of school life and reflects norms, goals, values, interpersonal relationships, teaching and learning practices, and organizational structures (Bradshaw, 2014, p.594).”

"Social aspects of the learning environment including school members' interactions and relationships, shared values and norms, and the personal development and growth of the members (Lee et al., 2017, p. 91)."

"The atmosphere of the school as represented in the foundational beliefs and values of members of the school community as well as the wider community in regard to education, beliefs and values of members of the school community as well as the wider community in regard to education, beliefs that drive the focus of the school, and the perception of how to foster sustainable change (McGuffey, 2016, p.98)."

"School climate is based on patterns of people's experiences of school life and reflect norms, goals, values, interpersonal relationships, teaching and learning practices, and organizational structures (Thapa et al., 2013, p.2).”

Figure 2. Common definitions citied in school climate research.

The domains that were measured in the different instruments reviewed are listed in

Table 1. There does not appear to be any domains that were shared across all instruments. 
There were domains that appeared frequently, such as: engagement and safety. However, other domains, such as leadership, only appeared in one instrument. As a whole, the available research on ten different instruments included the following domains in the assessment of school climate: interpersonal relationships, safety, discipline practices and perceptions, satisfaction, leadership, connectedness, engagement, and student behaviors.

\section{Table 1}

Domains Measured in the School Climate Research

\begin{tabular}{|c|c|c|}
\hline Domains & Author, Year & Instrument \\
\hline Relationships, fairness, safety, satisfaction & Bear et al. (2011) & DSCS-S \\
\hline Safety, engagement, environment & Bradshaw et al, (2014) & MDS3 \\
\hline $\begin{array}{l}\text { Safety, teaching and learning, interpersonal relationships, } \\
\text { Institutional environment, Social media }\end{array}$ & Durham et al. (2014) & Multimethod \\
\hline $\begin{array}{l}\text { Safety, home-school connectedness, adult support, academic } \\
\text { support at home, peer support, aggressiveness }\end{array}$ & Gage et al. (2016) & Meridian \\
\hline $\begin{array}{l}\text { Belonging/connectedness and social identity, achievement } \\
\text { (standardized test scores), absences, aggression scale, } \\
\text { depression scale, parental education level, SES at school level } \\
\text { (Australian index). }\end{array}$ & Lee et al. (2017) & SCASIM-St \\
\hline $\begin{array}{l}\text { Collaborative leadership, personalizing school environment, } \\
\text { curriculum instruction and assessment }\end{array}$ & McGuffey (2016) & CASE \\
\hline Engagement, Safety, Environment & NCES (2015) & EDSCLS \\
\hline $\begin{array}{l}\text { Safety, teaching and learning, interpersonal relationships, } \\
\text { Institutional environment, Social media }\end{array}$ & Schueler et al. (2014) & $\begin{array}{l}\text { Parent } \\
\text { survey }\end{array}$ \\
\hline $\begin{array}{l}\text { Safe learning environments, norms and standards that } \\
\text { encourage academic success, positive staff-student and intra- } \\
\text { staff relationships, student behaviors and conditions that } \\
\text { facilitate learning, and services and programs that address } \\
\text { student nonacademic barriers to learning. }\end{array}$ & You et al. (2014) & $\begin{array}{l}\text { Brief-CA } \\
\text { School } \\
\text { Climate } \\
\text { Survey }\end{array}$ \\
\hline $\begin{array}{l}\text { Parent involvement and engagement, positive student-teacher } \\
\text { relationships, school connectedness, academic support, order } \\
\text { and discipline, school physical and social environment, } \\
\text { perceived exclusion/privilege, academic satisfaction. }\end{array}$ & Zullig et al. (2015) & $\mathrm{SCM}$ \\
\hline
\end{tabular}


Many instruments that have been developed for use in school climate research have been studied in terms of their psychometric properties. Researchers regularly included evidence of validity and reliability in their publications. The most commonly reported were confirmatory factor analysis, content validity, and Cronbach's alpha. For many instruments, the evidence was gathered during the instrument development and early testing phases but, there was no indication of ongoing efforts to collect or publish validity and reliability evidence. Drawing from industry standards and recommendations for educational assessment, one useful resource for analyzing school climate is the National Research Council's (NRC) assessment triangle (2001). The assessment triangle provides a set of recommendations for instrument developers and simultaneously presents a compelling framework for evaluating assessment tools. The triangle includes three dimensions for assessment consideration. The first is cognition, which represents the construct (e.g. skill, knowledge, or belief) that is being measured. The second is observation, which is the instrument (or tool) that will be used to measure the construct. The third dimension is interpretation and includes the scoring options and interpretation strategies (NRC, 2001).

A side by side comparison of important instrument considerations including available evidence of validity and reliability, identification of a theoretical framework, the type of respondent, the type of publication, and the author is presented in Table 2. What is notable in these comparisons is that researchers consistently reported some level of evidence of validity and reliability, students were the predominant responder, and only two identified a theoretical foundation guiding the measure of the construct. Some type of 
evidence to support the validity and reliability of the instrument was included in all of the published documents that were reviewed, except for one. It is important to note the intended respondent for the survey so the instrument is appropriately used with the appropriate population/school stakeholder group.

Table 2

\section{Comparison of Instrument Characteristics}

\begin{tabular}{lccccc}
\hline \multicolumn{1}{c}{$\begin{array}{c}\text { Evidence of } \\
\text { Validity / } \\
\text { Reliability }\end{array}$} & $\begin{array}{c}\text { Theoretical } \\
\text { Framework }\end{array}$ & Perspective & \multicolumn{1}{c}{ Author } & $\begin{array}{c}\text { Peer } \\
\text { reviewed }\end{array}$ \\
$\begin{array}{l}\text { CHKS - Youth } \\
\text { Resilience }\end{array}$ & Yes & Yes & Student & Hanson \& Kim, 2007 & N \\
DSCS-S & Yes & Yes & Student & $\begin{array}{l}\text { Bear et al., 2011 } \\
\text { Bradshaw et al., }\end{array}$ & Y \\
MDS3 & Yes & No & Student & 2014 \\
Multimethod & None & No & $\begin{array}{c}\text { Student, staff, } \\
\text { teacher }\end{array}$ & Durham et al., 2014 & N \\
Meriden & Yes & No & Student & Gage et al., 2016 & Y \\
SCASIM-St & Yes & No & $\begin{array}{c}\text { Student } \\
\text { Lee et al., 2017 }\end{array}$ & Y \\
CASE & Partial & No & $\begin{array}{c}\text { Student, parent, } \\
\text { staff }\end{array}$ & McGuffey, 2016 & N \\
EDSCLS & Yes & No & $\begin{array}{c}\text { Student, } \\
\text { teacher/staff }\end{array}$ & NCES, 2015 & N \\
Parent survey & Yes & No & Parents & Schueler et al., 2014 & Y \\
Brief-CSCS & Yes & Yes & $\begin{array}{c}\text { Teachers, } \\
\text { administrators, } \\
\text { staff }\end{array}$ & You et al., 2014 & Y \\
SCM & Yes & No & Student & Zullig et al., 2015 & Y \\
\hline
\end{tabular}

A commonality, which can be observed in Table 2 was the lack of a theoretical framework guiding instrument development and interpretation. According to the assessment recommendations offered by the NRC, theory is important because it acts as a "cognitive model" and can explain the variation in what is expected in beliefs (or 
experiences or behaviors) that interact with school climate (2012). To meet the guidelines for educational assessment, a theory of action needs to inform the assessment process and this appeared to be greatly overlooked in these tools. Adequately capturing the variation in responses and understanding the variation possible in responses will influence how data are collected, interpreted, and potentially used for continuous improvement. In entirety, these three tables help identify shortfalls and support the recommendations of many researchers who have advocated for improved consistency and rigor in school climate assessment processes and instruments. Noted areas of improvement were particularly important to address (if and) when data collected will be used for accountability or decision making.

\section{Considerations For School Climate Assessment}

Addressing critical considerations of school climate research and the practical application of assessing and improving school climate is important to the premise of the previously articulated beliefs that school climate is observable and important. First, the meaning of school climate needs to be consistent in conceptualization. It is difficult to consider a consistent, or comparable, body of research without agreement on what school climate is or is not. The variation in definitions used by researchers has led to a sweeping landscape made of relatable, but unique approaches. Among the definitions there were some consistencies. Across multiple instruments and studies, ideas of safety, norms, values, and relationships were consistently included or identified as important.

Defining school climate is important for assessment because the definition will inform what will be measured, whose perspective will be included, and how data will 
inform practice. A result of varying definitions of school climate has been that a wide range of domains have been measured; including perceptions of safety, engagement, belonging, discipline and fairness, satisfaction, parent involvement, leadership, programs and services, physical environment, learning and instruction, and student behaviors. Increasingly, social and emotional learning (SEL), has drawn the attention of school climate advocates and researchers, raising important questions about what can (and should) be measured.

School climate advocates posit the need for school environments to foster emotional growth and development. As a result, SEL has emerged as a potential domain of school climate, yet research remains inconsistent in terms of how to measure SEL and which factors are most important to support for student growth and development. In recent years, there has been considerable attention and criticism in terms of whether or not SEL can be adequately (and ethically) measured at all. There is a growing body of critical research and perspective exploring the assessment of what are termed non-academic factors and SEL. For example, there has been significant attention to concepts such as grit, mindset, motivation, and self-efficacy in the literature (Duckworth \& Seligman, 2017; Dweck, Walton, Cohen, 2014; Zhou, 2016). Simultaneously, there has been mounting criticism in terms of how these characteristics and skills are being measured, a questionable adherence to best practices in assessment, and the appropriateness of including these concepts as part of any accountability framework (Duckor, 2017; Duckworth \& Yeager, 2015; West et al., 2016). 
In terms of informing practice, the majority of the literature documenting school climate assessment instruments were for correlational research studies. The aim of these tools was to inform and build a body of knowledge to better understand school climate and the influence it has in the nation's schools. What still needs to be studied are adequacy of tools for practice-oriented uses, including school accountability. School climate assessment instruments need to be developed for practical application; thus, a consistent purpose guided by a theory of change, and an adherence to standards and expectations for assessment, including ongoing collection of evidence of validity and reliability (Berkowitz, 2017; Konold et al., 2014; Lee et al., 2017; Thapa et al., 2013; Wang \& Degol, 2016; Zullig et al., 2015).

Clearly defining what will be measured, and then developing tools that are rigorous in psychometric properties and consistent with the standards for educational testing and assessment (NRC, 2014, p.44) are important considerations for research, but fundamental to the use of these tools to inform policy and practice. Instruments that are well designed have a greater chance of leading to data that are accurate reflections of school experiences, thus more positively informing leaders and potentially guiding change. Currently, instruments are believed to be adequate for use in research, but their evidence of validity and reliability has been called into question if their use is expected to inform school based practices, procedures, or policies.

School climate definitions and measureable domains will also inform the perspectives that are captured in the data collection. The majority of school climate assessment tools included personal and individual perceptions, but some also espoused the value of 
objectively observable climate measures. For example, Wang and Degol (2016)

suggested observation and walking tours of school environments to measure characteristics of the physical environment. Other researchers have, however, focused entirely on measuring perceptions (Rudasill, Snyder, Levinson, \& Adelson, 2017).

Overall, the literature on school climate reveals an increasing interest in environmental influences on wellbeing, teaching and learning, and academic proficiency. Despite the critical considerations that were raised in this review of the extant research on school climate assessment, the attention on climate as an indicator of school health that impacts teaching and learning continues to steadily increase. The interest is shared by many, including researchers, education leaders, advocacy groups, and politicians.

Academics are actively shaping the landscape through research to explain the impact of climate on personal and academic growth and development. Education leaders are implementing programs at their sites to improve school climate. Advocacy groups are highlighting the voices of marginalized sub-populations, exposing discrimination and inequities, and demanding changes to better protect and serve the most vulnerable students. Policy makers are proposing changes to accountability expectations and processes to include school climate assessment.

Over the past decade there has been considerable expansion in the data points used in evaluating public school success. This evolving trend has continued ever since the focus on data became the cornerstone of the NCLB Act of 2001. However, in the past decade, there has been an increased interest in metrics beyond the academic test, including school climate. In a recent nationwide comparison of state education policy, it was reported that 
four states have now included school climate as a component of state-level school accountability measures (Batel, Sargrad, \& Jimenez, 2016). Understanding the reforms that have led to school climate as an accountability measure requires a brief historical overview.

\section{Education Policy Reform}

Arguably, one significant reform movement in contemporary US education policy was the federal government assuming centralized authority over guiding education policy and practice. This swing to centralization paved the way for the 2001 passage of NCLB and was heightened, as leaders continued to interpret the Nation at Risk to equate to failing schools. With NCLB, both state and local processes were superseded by national standards in content for teaching and learning and accountability measures (Kirst \& Wirt, 2009). NCLB forced the adoption of standardized achievement and allowed the federal government unprecedented control over schools that were labeled as "failing." Schools, teachers, and leaders were penalized and students suffered as the resources and supports necessary for learning were not equitably distributed to all learners.

In just over a decade, the widely criticized centralized, punitive focus of the NCLB Act was rejected by California, when the state shifted to local control with the sweeping financing and accountability reform law, LCFF. California's decentralization of education leadership and authority was a monumental shift from NCLB in procedures and expectations of schools, but also in a change of perspective.

Educator Michael Fullan described this reform as a mind shift that moved from the "wrong" drivers of change (e.g. punitive accountability, individualistic solutions) to the 
"right" drivers of change (e.g. capacity development and collaboration) (Fullan, 2014; Fullan \& Rincón-Gallardo, 2017). Central to California's new law, which is now colloquially referred to as the California Way, were the concepts of LftM and continuous improvement. LftM is focused on the capacity of leaders at the county and district level to use the policy in ways that will support continuous local improvements to teaching and learning (Fullan, 2014). Continuous improvement is a measure that is represented by evidence that shows how schools are getting better at developing capacities in relationships, pedagogy for diversity, assessment, and leadership (Fullan, Hill, RincónGallardo, 2017).

Transitioning to the right drivers of a required a shift in accountability so schools could authentically work towards continuous improvement. As part of the shift, the state moved from a single measure (standardized achievement test) to multiple measures defining school performance. Included in these multiple measures, the importance of the school environment was emphasized and the LCFF became the first comprehensive education policy in the nation to include the public reporting of a local school climate assessment.

School climate, Priority 6 of the LCFF, expects local districts to collect primary data on school climate (at minimum, the domains of safety and connectedness), and submit a summary of findings. The report is made public along with district suspension and expulsion rates on the state Dashboard (CDE, 2017). The state has specified this expectation through the law, but the $\mathrm{CDE}$ has yet to provide specific expectations and 
additional resources for schools and districts on how to successfully meet and use this expectation for actual site-based improvement.

School conditions and climate work group. To support schools through meaningful implementation of the state's school climate accountability expectations, the California Department of Education (CDE) appointed a dozen diverse stakeholders to serve on a work group. The School Conditions and Climate Work Group (SCCWG) members represented the voices of parents, students, teachers, administrators, and researchers. The SCCWG was tasked with making recommendations to the CDE and Superintendent of Public Instruction (SPI) regarding statewide implementation of Priority 6 of the LCFF. The work group set out to develop a definition of school climate, identify essential domains to measure, and offer recommendations for implementation (SCCWG, 2017). In November 2017, the SCCWG presented their recommendations to the SPI and SBE. The definition that was proposed was

School Conditions and Climate refers to the character and quality of school life. This includes the values, expectations, interpersonal relationships, materials and resources, supports, physical environment, and practices that foster a welcoming, inclusive, and academically challenging environment. Positive school conditions and climate ensure people in the school community (students, staff, family, and community) feel socially, emotionally, and physically safe, supported, connected to the school, and engaged in learning and teaching.

Coinciding with the definition, the work group suggested that at a minimum, the domains of safety, relationships, conditions for teaching and learning, and empowerment should be measured through the school climate assessment process. In addition to the suggested definition and domains to measure, the work group presented state and local recommendations. The recommendations that were made to the state were focused on 
strengthening support systems and building capacity so local districts could use data for continuous improvement. The recommendations that were made to local education agencies were practically oriented around instrument selection and data collection. A summary of these recommendations is provided in Figure 3.

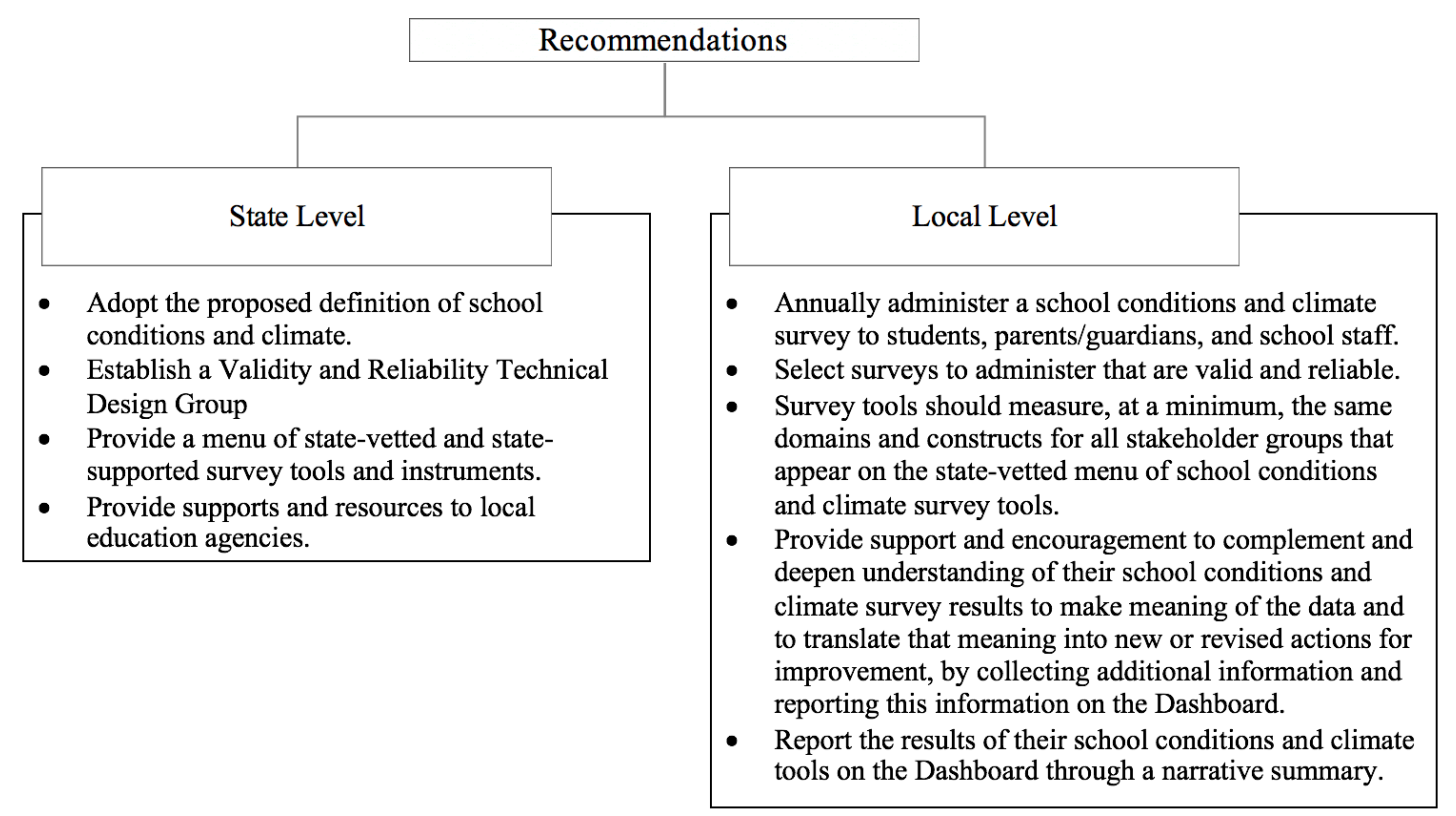

Figure 3. California SCCWG recommendations to the state and local education agencies for implementation of the LCFF requirement to assess school climate and conditions.

LCFF made school climate another data point and for the data to actually guide local efforts in continuous improvement, as expected by the new law, it was important to explore how data have been used for decision making in public schools and by education leaders. Understanding this realm required a review of the literature on data driven decision making, noting best practices and key challenges that affected the collection and use of data to drive change efforts in public schools. 
Data driven decision making in K-12 education. The use of data in schools is not a new phenomenon. As previously noted, the expectation to use data to guide decisions in schools has been increasing since the early 2000's. Some of the contemporary challenges include ensuring the accuracy of data obtained and managing the volume of information that was collected. As a result, researchers have explored this landscape through studies seeking to understand data driven decision making in schools and among school leaders. A review of research revealed a significant focus on the processes associated with using data for decision making, such as interpretation and action planning (Marsh, 2012; Park \& Datnow, 2009; Wohlstetter, Datnow, \& Park, 2008). Many of these studies were site and classroom specific, exploring the influence of leadership, capacities, perceptions, and time related to the way principals and teachers interact with data to inform teaching (Henig, 2012; Marsh, 2012; Park \& Datnow, 2009; Weiss, 2012; Wohlstetter, Datnow, \& Park, 2008).

In addition to studies documenting perceptions and challenges, researchers have developed models that suggest theories of action related to data use. One model proposed a data use process that began with the raw data, followed by interpretation and understanding (Marsh, 2012). Once data were understood, changes could be developed, implemented, and evaluated. The model also included feedback, which resulted in a continuous process of data interpretation (2012). This model emphasized the interpretation of data, which is clearly important, but a more comprehensive framework, presented by Coburn \& Turner (2011), offered a relevant lens for exploring school 
climate assessment acknowledging the complexities in data collection, handling, interpretation, and action.

This framework captured the relationship between four key variables influencing data use in school systems. First, researchers acknowledged the importance of the interventions that increased data use, such as state accountability policy or the accessibility of data collection tools and packages. Second, organizational and political contexts that shaped the way data were handled were identified in the model. These contexts included routines for data handling, organizational norms and expectations, and leadership beliefs and capacities. Processes for data handling were captured in the third component of the framework. This was where the researchers posed the importance of cognitive interpretation of data, including the complexities associated with how specific data points were noticed, how meaning was derived, and how interpretation could guide change or lead to problem solving solutions. The final component of this model was the outcome, the decisions and the actions that were ultimately informed by the data. Importantly, the framework highlights the role of administrative leaders in all aspects of data use. For example, the influence of leadership on the interpretation of policy; the selection of data gathering tools and packages; the organizational structures (such as beliefs, access to data, routines, and norms); and the cognitive processes and potential influences guiding data use (Coburn \& Turner, 2011).

While still evolving, the literature on data driven decision making in schools accurately and appropriately identified the important role of interpretation (Roderick, 2012; Spillane, 2012); the effect of perceptions and beliefs (Coburn \& Turner, 2011; 
Henig, 2012); and the influence of practical considerations including time, capacity, respondent safety, and leadership support (Marsh, 2012; Park \& Datnow, 2009; Park \& Datnow, 2016; Weiss, 2012; Wohlstetter, Datnow \& Park, 2008). With the exception of the framework presented by Coburn \& Turner (2011), few expressed the purpose and process for data collection. Those that did (Henig, 2012; Coburn \& Turner 2011) acknowledged that what was motivating the use of data directly impacted what was measured, how data were obtained, and used.

These key factors impacting data handling methods undoubtedly influence the accuracy and applicability of data that are obtained. As an official indicator of school success, it is important that California schools have the ability to accurately assess school climate, thus calling into question the quality of measurement practices including leader capacity, knowledge, and beliefs towards the policy, the data, and the potential use for continuous improvement.

\section{Implications for Superintendents as Decision Makers}

The extent to which local leaders understand these assessment considerations will influence how they interact with data handling processes. As the mid-level leaders in the state education system, superintendents are responsible for implementing the state mandated local accountability assessment of school climate. According to the scholarship of Michael Fullan, the importance of directing attention to mid-level leaders is that "when it is focused and well led, [the middle] can come up with insightful ideas, generate widespread buy-in, and create stronger accountability with transparent data and better results (Kirtman \& Fullan, 2016)." If the LCFF is going to guide significant changes to 
educational experiences and outcomes, local leaders need to believe in school climate assessment as an important indicator for continuous improvement (Gannon-Slater et al., 2017); have the capacity to use data (Bosworth, 2018); and trust the data that they obtain (Bertino, 2014). Therefore, better understanding this group of leaders throughout the state is important.

The superintendent position is a one-hundred-year young profession that continues to evolve in scope and purpose. At inception, this professional role emerged from a need to enhance teaching. Early leaders were selected for their teaching expertise. Over the years, the desire for teacher expert leaders has waxed and waned as other perspectives and skills were needed, including the democratic negotiator, the evidence-based practitioner, the business expert, and the master communicator (Kowalski, 2005; Kowalski \& Brunner, 2011; Moody, 2011; Sharp, Malone, Walter, \& Supley, 2004).

In the current leadership landscape, there appears to be a split between leaders who lead for organizational transformation and those who lead to manage. According to education leadership scholars, the communication expertise that is required for the modern superintendent demands an ability to communicate openly, learn from the community, think about schools from a complex systems perspective, and facilitate the transformation of schools to improve education outcomes (Kowalski, 2005; Kowalski \& Brunner, 2011; Sharp, Malone, Walter, \& Supley, 2004).

These transformational leaders, who are master communicators, echo organizational development scholarship, namely the work of Edward Schein. For decades Schein has been a leading advocate for organizational leaders to develop and hone the practice of 
humble inquiry, which focuses on learning through observation, active listening, rejecting judgement, and collaboration (2013). At the heart of the practice of humble inquiry is the ability of leaders to both help and to be helped (Schein, 2013). Open communication is endorsed in educational leadership as a belief that leaders are always learning.

Comparatively, the business-centered leader is largely represented through a national movement of neoliberal reform arguing that school leadership should follow principles and practices of corporate business management. One influential champion of this perspective is billionaire Eli Broad. Broad developed and personally sustains the Broad Academy, an exclusive administrator leadership program that has trained an estimated $35 \%$ of superintendents nationwide (Miller, 2012).

The ethos championed by the Broad Academy espouses that education leaders need capacities in business management, rather than knowledge and experience in teaching and learning. The Broad Academy has emphasized competition and school choice, the weakening of teacher unions, and a shift in the professionalization of superintendents from education leaders to business managers (Kowalski, 2005; Miller, 2012). The foundation for this argument was both the failure of US public schools to curb social ills (Labaree, 2012; Miller, 2012) and the notion that school improvements can be actualized through an improved management of funds and increased competition.

The neoliberal perspective is influential and arguably in stark contrast to the perspectives that are offered from the disciplines of educational and organizational leadership. Most notably, Edward Schein's recent work emphasizing humility and the necessity of leaders to ask for help (2013), Kowalski's view of superintendents as master 
communicators and transformational leaders (Kowalski \& Brunner, 2011), and Fullan's emphasis on mid-level leaders focused on learning, capacity building, and collaboration (2011, 2014, \& 2015).

These differing approaches are fundamentally important to school climate assessment because they shape the ways in which data processes are implemented and decisions are made. As was previously articulated, the cognitive processes that guide interpretation and sense making of data are crucial to how data are used.

The cognitive perspective is important because how leaders perceive the purpose and potential of school climate data will guide their assessment processes and use for data for continuous improvement. For example, it has been noted, through other research, that district leaders who espouse a mindset of compliance superficially engage with data, thus limiting the potential for continuous improvement (Earl \& Fullan, 2003). Additionally, the superintendency remains a predominantly white male profession. In fact, about $85 \%$ of superintendents in the nation are white males (Kowalski, 2005; Kowalski \& Brunner, 2011; Sharp, Malone, Walter, \& Supley, 2004). Cognitive processes and perspectives are undeniably influenced by life experiences and white males in the US are arguably interacting with the world differently than women and people of color. If the ways in which policies are interpreted are subject to the cognitive processes of the leader, which are rooted in one's experiences and perspectives, then it would be expected that leaders from different life experiences would interpret policies and data differently. While clearly important to California, district leaders are increasingly expected to use data to inform (and guide) change. Researchers have noted that data are being used by district leaders to 
shape funding, personnel, interventions, and professional development (Coburn \& Turner, 2009).

To summarize, the school superintendent is an important figure that directly and indirectly influences how local districts respond to accountability policies. The intent of the LCFF was to decentralize decision making and shift the accountability mindset from what education scholar, Michael Fullan said are the wrong drivers (e.g. punitive accountability, individualistic solutions) to the right drivers (e.g. capacity development and collaboration) for continuous improvement (2011). Understanding the perspectives and beliefs of these influential leaders is important because these elements will indeed influence how Priority 6 of the LCFF is implemented in local districts.

\section{Research Gaps and Opportunities}

This literature review documented the overlap between four apparently distinct areas of research. In entirety, this review explored the impact of school climate on health and education outcomes, while simultaneously highlighting contemporary relevance of school climate assessment in education policy and practice. What emerged from this analysis was an acknowledgement of extensive research on school climate and related outcomes; a significant body of research on education policy; and a need for additional research on district level practices and decision making, specifically related to school climate assessment. For a visual depiction of the pathway through the literature, which identifies the extensive research on education policy reform and school climate outcomes and the significant gaps in the assessment practices and data driven decision making, including education leader beliefs, see Appendix A. 
These gaps in the literature point to a pressing need as school climate assessment transitions to a place of higher prominence and expectation in education accountability systems. First, the implementation and use of school climate assessment tools to guide practice-oriented decision making and state accountability expectations need to be further developed and studied. Assessment instruments need to be designed with practiceoriented uses in mind, as opposed to research tools used for correlational studies. Second, as California embarks on setting a national trend in school climate assessment accountability, there is a need to better understand the current practices in implementing Priority 6 of LCFF in local districts throughout the state.

Intersecting these research and application-oriented gaps is the role of district leadership, guided by the Superintendent, who is a fundamental player in operationalizing the right drivers of continuous improvement (Fullan, 2005; Fullan 2011; Fullan, 2014; Fullan, 2015). Fullan, who has studied effective education systems, including leaders and leadership, on a global scale offers a robust set of recommendations for effective leadership and district offices (Fullan, 2005; Fullan, 2014). He proposes that effective district leaders need the ability to communicate, build capacity, and a focus on learning and effective districts need to focus on instruction, assessment, and continuous improvement (Fullan, Rincón-Gallardo, Hargreaves \& Ainscow, 2015). The extent to which districts and leaders are prepared for continuous improvement in terms of school climate assessment remains unknown. Subsequently, the third area of research that is needed is related to data driven decision making at the district level, which was less studied than principal and site level experiences. There is a need for research that 
explores the role of district level leadership in decision making, including important underlying beliefs that inform practices. Specifically, it is necessary to better understand superintendent beliefs regarding the importance of school climate assessment, their capacity to use school climate assessment data, and their belief in the trustworthiness of the data that are obtained.

There are few studies that document the influence on beliefs related to importance. These belief orientations inform the value that a leader may place on school climate assessment. Researchers have noted the importance of attitudes informing belief structures, data use, and adherence to policy (or procedural) expectations (Buske \& Zlatkin-Troitschanskaia, 2018; Gannon-Slater et al., 2017). One study explored characteristics of leaders who orient towards accountability versus continuous improvement. In the former, leaders tend to hold others accountable for improvement, monitor systems, and implement top-down decision-making strategies. Alternatively, leaders who orient towards continuous improvement focus on multiple measures, contextual understanding, collaboration, and horizontal decision-making (Gannon-Slater et al., 2017).

As previously articulated, it is important that leaders are data literate and can facilitate assessment processes (Coburn \& Turner, 2011). Included in leadership capacity are skills such as communicating a clear vision, managing a change process, devoting resources, and supporting others (e.g. principals and teachers) to develop capacities to manage, interpret and use data (Bosworth, 2018; Datnow \& Park, 2014). Augmenting the role of attitudes was a study with principal leaders that suggested that leaders used data 
differently based on their resistance, skepticism, acceptance, or enthusiasm towards the data (Buske \& Zlatkin-Troitschanskaia, 2018).

In order to use data to guide decision making, there is a need for trusting the data. Specifically, it has been suggested that leaders need to know how to discern quality, credible, trustworthy data. This skill set is increasingly important as the expectation for leaders to use data in increasingly expected (Bertino, 2014). An underlying problem with using school climate assessment data is that poorly designed tools can misinform or misguide decisions. The implication for local leaders is that decisions will be impacted by the data that are collected through the instruments available. If data are not accurate or credible, decisions may be misguided, inappropriate, or unnecessary.

As previously noted, leadership is important in data handling processes, but as California sets out towards continuous improvement, it becomes important to ask if data obtained are useful to education leaders and school communities for informing and guiding change. This study aims to better understand the beliefs of education leaders who are engaging in the practice of assessing and improving school climate. 


\section{Chapter Three: Methodology and Research Design}

As previously articulated, academic outcomes and health outcomes are interconnected and reciprocal at both individual and population levels (Basch, 2011). School climate which is a contributing factor in both education and health outcomes has been elevated by the state of California with the inclusion of school climate assessment in the LCFF.

The LCFF, and structures to integrate school climate specifically into school plans, now invites discussion and understanding of school health in new ways. School environments that foster, condone, ignore, or perpetuate behaviors that pose risks to healthy development are deeply in need of greater understanding, just as the environments that foster positive health and quality of life are in demand. School climate, if adequately understood and assessed, can influence innovation and changes to improve or sustain healthy school systems. If school climate is not well understood or is poorly assessed, it cannot adequately guide change and may not accurately represent the dynamic complexity of the factors that influence healthy school environments.

The extant literature clearly indicates the importance of school climate on academic and health outcomes, and furthermore, the state of California is committed to ensuring that schools work to continuously improve school climate and conditions. A current challenge is that school climate is not consistently defined and/or measured, thus impacting the use and applicability of assessment tools and the potential for change in local and state education policy and practice (Duckor, 2017; Maul, 2017). While school climate is now a state priority, it remains unclear how districts and schools are collecting 
and using data and whether or not school climate assessment is practically useful in informing local changes to improve academic outcomes for all learners.

As the mid-level leaders in the California education system, superintendents are in a key position to interpret and implement the LCFF. The purpose of this study was to explore superintendent beliefs and local district practices in school climate assessment throughout the state of California. Knowing what schools are doing and superintendent beliefs towards the importance of school climate assessment, their trust in the data, and their capacity to use data to facilitate continuous improvement efforts will help statewide leaders, policy makers, researchers, and school personnel improve their efforts to support local school improvement plans.

There were three research questions guiding this study. First, what instruments and practices are currently being used by California public schools to assess and use school climate data for continuous improvement? Second, what are superintendent beliefs regarding the importance of school climate assessment, their perceived ability to use school climate data for decision making, and their trust in the data? Third, what is the relationship (if any) between superintendent beliefs towards school climate data and other personal factors or school contexts?

\section{Research Methodology and Study Design}

In this study, the researcher explored variations in beliefs and practices of school climate assessment. This study was grounded in a pragmatic mixed methods approach that was systemic and deliberate, but with modest flexibility to explore variations in 
perceptions and practices (Creswell \& Plano Clark, 2011; Creswell \& Creswell, 2018; DeCuir-Gunby \& Schutz, 2017).

The study design was an explanatory sequential mixed methods approach involving two phases of data collection, quantitative followed by qualitative (QUAN $\rightarrow$ Qual). In this strategy, the qualitative process supported potential explanations of the quantitative data results and provided an opportunity to check the researcher's initial interpretation of findings. This study collected data sequentially and analyzed data both sequentially and concurrently to elicit a deeper meaning and understanding of the current practices and beliefs of local leaders as they implement Priority 6 of the LCFF.

The quantitative data were designed to be collected using an online survey because of the potential to capture many responses simultaneously and the overall ease of use and accessibility to the study population. The qualitative research methods provided a rational framework for gathering, analyzing, and reporting on data to uncover, explain, and contextualize meanings derived from the survey (Merriam \& Tisdell, 2016). While remaining iterative and flexible, qualitative methods can (and should) adhere to a set of principles that are recognized in the field for maintaining high standards in ethics and rigorous study design. There are elements of good research that are shared by both qualitative and quantitative methods including research pursuits that are worthy; rooted in a problem; clearly connected to relevant questions; and, ethical in purpose, methods, and implications (Kilbourn, 2006; Tracy, 2010). This study adhered to each of these standards and expectations for research. Figure 4 illustrates the research progression of the research stages from initial data collection through the final analysis and interpretation of data. 




Figure 4. Explanatory sequential mixed methods design visual.

Research methods. The study began with quantitative data collected from an online survey distributed statewide to all superintendents who were included in the publicly available database. Initial data analysis began immediately to allow for preliminary findings, themes, and areas in need of clarity to be further explored in the qualitative data collection phase. Qualitative data were collected via semi-structured interviews and analyzed for cross cutting themes along the same dimensions that were explored in the 
survey. The final step in data analysis was to look at the quantitative and qualitative data side by side and examine similarities, differences, and key insights. Of particular interest in this step was how the qualitative data could help interpret the meaning of the quantitative results.

Study population. The LCFF decentralized decision making, giving local leaders more control, while simultaneously changing state accountability expectations. As a result, mid-level leaders play a key role in interpreting and implementing the policy for local benefit. Furthermore, as a district level measure, school climate assessment expectations invite district leaders to establish the contexts for practices including data collection, analysis, and use of data to guide continuous improvement.

Sampling. To understand district level practices and beliefs, the study participants were all county and district superintendents in the state of California. In total, 1,055 (997 district and 58 county) superintendents were invited to participate in an online, confidential survey prior to the start of the 2018/2019 academic year. The researcher's request was augmented with an endorsement from the CDE. Email addresses were obtained from a public database on the website for the CDE. The entire sample population was the focus of this study and the sampling strategy was a direct invitation for participation from the researcher.

The sample population for the qualitative data collection was also district and county superintendents. Following the quantitative data collection phase, a purposive sample of 25 potential participants was generated through recommendations made by experts and key informants known by the researcher. The final sample was also informed by regional 
and district demographics and included leaders from different regions and communities who represented districts with diversity in student enrollment.

Instrumentation. Two instruments were used to collect data for this study: an online survey and semi-structured interview protocol. The instruments that were developed to support these data collection methods were strategically designed to capture demographic and descriptive data to identify instruments and practices in use and to explore three different concepts related to superintendent beliefs towards school climate assessment.

Survey design. The survey design, informed by best practices in educational measurement and assessment, used the NRC Assessment Triangle and Mark Wilson's Four Building Blocks of instrument development (NRC, 2001; Wilson, 2004). Wilson's Four Building Blocks encompass the same elements of the Assessment Triangle, with the exception of the third vertex of the triangle, interpretation, which is broken into two distinct interpretation strategies, in Wilson's Building Blocks.

Construct maps. The first building block is the construct map (the Assessment Triangle's cognition dimension). The construct map is the mental model for the construct that is being measured (Wilson, 2004). In this study, three construct maps were developed, one for each belief that was going to be measured. The goal of the construct maps was to visually depict the potential range in beliefs and corresponding survey items to maximize the variation. The construct maps were developed based on a pilot study conducted in the prior year with members of the SCCWG and the extant literature on school climate, data, and data driven decision making. See Appendix B for all three construct maps developed for this study. 
Items design. The second building block is "item design" (observation in the NRC Assessment Triangle). This building block encompasses the structure and the format of instrument development (Wilson, 2004). An important consideration for survey development is to mindfully connect the item stems and the response choices to the construct maps. The four-part survey that was used in this study was designed to gather necessary data for all three research questions. The first part of the survey explored superintendent beliefs across the three constructs: importance, capacity, and trust (RQ2). Item stems for part one of the survey were informed by the construct maps and written to capture a range of participant beliefs related to school climate assessment. Survey drafts were reviewed by experts who were accessible to the researcher, followed by a review by one current and one past superintendent, both of whom were known by the researcher. A total of 38 items were included in this section of the final survey, (14 items for importance, and 12 for both capacity and trustworthiness). See Appendix C to view the item stems in the final survey that was used in this study.

The second part of the survey was intended to capture the current practices related to school climate assessment (RQ1). These items were developed to gain a sense of actual practices being used in districts throughout the state. Respondents were asked about instruments they were using to assess school climate, who participates, methods used, and disaggregation practices used during data analysis. A total of six items were included in this category.

The third part of the survey included the demographic questions. These items were necessary to analyze the potential relationships between beliefs and professional 
demographics or school contexts (RQ3). A total of 12 items were included in this section, eight personal and professional characteristics and five items to capture the district level contexts.

The final component was the exit survey. These optional questions were included to improve the validity of the instrument and offer an open-ended feedback mechanism for respondents. Participants were asked if questions were confusing, if they had enough time, and if they had recommendations for the researcher. See Appendix $\mathrm{C}$ for a complete copy of the survey instrument that was used in this study.

The final survey was formatted online using Qualtrics. The consent notification was embedded directly into the survey and voluntary consent was required in order to begin the survey. Questions were formatted to display three at a time and a progress bar was included to help respondents estimate the amount of time remaining. A back button was not included, thus preventing respondents from changing previous responses. Electronic formatting was piloted by the researcher the researcher's advisors on a Macintosh computer, PC, and an iPhone. Adjustments were made based on recommendations to improve usability and user appeal.

Semi-structured interview protocol. Qualitative data were derived from semistructured interviews. The interview protocol was initially drafted to align with the construct map. However, following preliminary quantitative data analysis, the protocol was revised to also reflect concerns and questions that emerged in the quantitative data. The final questions were reviewed by experts who were known and accessible to the researcher. Feedback and recommendations guided changes to the protocol prior to 
initiating the interviews. All interviews were audio recorded and were immediately backed up on a password encrypted computer accessible solely by the researcher.

The protocol used in the qualitative phase of this study covered the same key constructs that were included in the survey, but with follow up questions designed to elicit narrative explanations and contextual examples drawn from respondent experiences. For each construct, an overarching general question was asked and then follow up questions were posed to further engage the participant in sharing and explaining their perspectives and experiences. See Appendix D for the full interview protocol.

Data collection procedures. The sample population was pre-notified via email during the summer of 2018. The pre-notification letter included a copy of the consent notification and the endorsement letter from the SPI at the CDE. The invitation to participate in the study was emailed with an embedded link, three days following the prenotification. Over two months, the entire sample population was emailed four additional times with survey link reminders. One month into the study, low response rates were identified for urban areas and a targeted email was sent directly to this demographic. Additionally, the final reminder coincided with a second endorsement letter that was emailed directly by the CDE. In total, 298 superintendents initiated the survey and 198 completed the survey for a response rate of $28 \%$ and $18 \%$, respectively.

Twelve superintendents were initially invited to an in-depth interview via email. After one week, the researcher phoned all of the potential participants who had not responded. Phone calls resulted in a voice mail message that was immediately followed up with a 
reminder email invitation. This approach successfully secured additional interviews from potential participants who had not previously responded to the email invitations. To maintain adequate diversity in the sample, the remaining superintendents on the original sample list were invited to participate as needed. In total, 20 of the 25 superintendents on the purposive sampling plan were contacted and eight participated in the study. See Appendix E for both the qualitative and qualitative recruitment emails.

Semi-structured interviews were expected to last between 30 and 40 minutes and were conducted over the phone, with the interviewee on the researcher's speaker phone. The researcher conducted all interviews alone, in a private office that was accessible to only the researcher and was free from interruptions. The researcher used a Sony UX Series Digital Voice Recorder for audio recording of all interviews. Additionally, the researcher used the Recorder Pro iPad application for a backup recording of the interview. Upon completion, interviews were immediately backed up and saved on a password protected laptop accessible only to the researcher.

Data analysis. This mixed methods study incorporated several data analysis strategies. Table 3 presents a summary of the data analysis strategies that were used.

Table 3

Data Analysis Summary

\begin{tabular}{llll} 
Research Question & Analysis & Model/Method & Software \\
\hline RQ1 Instruments and & $\begin{array}{l}\text { Quantitative analysis of } \\
\text { Processes }\end{array}$ & $\begin{array}{l}\text { Descriptive } \\
\text { determine commonses to } \\
\text { practice }\end{array}$ & SPSS 25 \\
& & & \\
& &
\end{tabular}


Table 3 (continued).

\begin{tabular}{|c|c|c|c|}
\hline Research Question & Analysis & Model/Method & Software \\
\hline $\begin{array}{l}\text { RQ2 Importance, } \\
\text { Capacity, } \\
\text { Trustworthiness } \\
\text { constructs }\end{array}$ & $\begin{array}{l}\text { Quantitative and } \\
\text { qualitative analysis for } \\
\text { frequency and description } \\
\text { of responses to determine } \\
\text { trends }\end{array}$ & $\begin{array}{l}\text { Descriptive } \\
\text { statistics }\end{array}$ & $\begin{array}{l}\text { SPSS 25, } \\
\text { Stata15, } \\
\text { MS Excel }\end{array}$ \\
\hline $\begin{array}{l}\text { RQ3 Relationships } \\
\text { between beliefs and } \\
\text { personal and/or school } \\
\text { contexts }\end{array}$ & $\begin{array}{l}\text { Quantitative analysis of } \\
\text { variables related to } \\
\text { superintendent beliefs }\end{array}$ & $\begin{array}{l}\text { Regression } \\
\text { analysis }\end{array}$ & $\begin{array}{l}\text { ConQuest, } \\
\text { Stata15 }\end{array}$ \\
\hline
\end{tabular}

Quantitative data analysis. The quantitative data analysis began while data collection was still underway with descriptive statistics to observe representativeness of the responses to tailor follow up invitations for regions that were underrepresented. Upon completion of data collection, descriptive statistical analysis was initiated for each of the items included in the survey, followed by regression analyses to explore relationships in beliefs and respondent demographics. Wilson's third and fourth building blocks of instrument design provide a framework (and rationale) for the researcher's quantitative data analysis (2004). The first two building blocks were discussed previously in the survey design section and the remaining two building blocks are discussed in what follows.

Outcome space. The third building block, called outcome space, is how the instrument is scored. In this study, the instrument scoring was aligned with the construct maps to represent greater or less endorsability of a belief in the importance, capacity, and trust in using school climate data for continuous improvement. The final dataset was 
cleaned and each respondent was given a unique identifier. All responses were coded according to a codebook that included a detailed account of all of the researcher's coding decisions. Missing responses were included in the data analysis and recoded as 9.

Mathematical modeling. The fourth building block, mathematical modeling, is Wilson's second focus of the interpretation vertex of the NRC assessment triangle. This building block is designed to test the stability of the instrument. In this study, the mathematical modelling helped the researcher understand how well the construct maps captured the variation in beliefs and the extent to which the constructs that the researcher intended to measure were actually measured.

A Partial Credit Rasch Model, within the item response approach was employed and fit the data adequately in the capacity and the trustworthiness constructs. Two items were dropped from the importance construct due to poor item fit. The item response model fitted by ConQuest (Adams, Wilson \& Wu, 2012) was a unidimensional random coefficients multinomial logit (URCML) model. A Wright Map was developed using ConQuest, thus illustrating the visual distribution of both the items and the respondents for the three constructs that were being measured in the survey instrument.

The Rasch Partial Credit Model (Adams, Wang, Wilson \& 1997; Masters, 1982) is an item response approach to mathematical modeling for measurement. While there are many benefits of using an item response approach for instrument development, (Embretson, 1996), one benefit that was important in this study was that both the item and the respondent were captured in the output. The Wright Map provided this visual by showing the item difficulty and the person responses side-by-side on the map. When the 
different items match a person response on the same line of the Wright Map, it tells the researcher (or instrument developer) that the probability of endorsing that specific item response is $50 \%$. The value of this approach is that it acknowledges that not all items are the same level of difficulty, in other words, not all items in this study were as easy to endorse for all respondents. Additionally, the Wright Map can be analyzed alongside the construct maps to see how well the items and item responses fit with the hypothesized theory of change that facilitated item design (Wilson, 2004). See Appendix F for the Wright Maps associated with this study.

The quantitative data analysis began immediately after commencing data collection. Using Excel, response data was monitored and used to tailor follow up and reminder messages throughout data collection. A table describing regional and participant response processes was used to document communication and follow up. Descriptive statistics were calculated, using SPSS, for all survey items. A demographic profile table was created to capture the range of respondent and district characteristics. To explore potential patterns and relationships between the dependent and explanatory variables, a standard regression using SPSS was used. A multiple linear regression model was fit to the data to explore the relationship (if any) between the dependent response variable (superintendent beliefs) and the independent explanatory variables (age, gender, experience, education, urbanicity, FRPM, EL, SPED). Linear regression requires variables to be numeric. To meet this expectation, three variables used reference groups and the remaining five variables were continuous. The reference group for highest degree earned was master's degree. The reference group for gender was female; and the 
reference group for community was rural. The five continuous variables were age, years served as a superintendent, and the estimated percentages of student enrollment by English learners, eligibility for free and reduced price meals, and special education. Two items included "prefer not to state" and these responses, with counts fewer than 7 in both categories, were removed for the regression analysis.

The third research question in this study explored the relationship (if any) between the belief score for each construct (dependent variable) and four personal characteristic variables and four school contexts (independent variables). For the personal characteristics, it was hypothesized that women would have stronger beliefs endorsing the usefulness of school climate assessment for continuous improvement due to a prevalent association with care and justice leadership orientations. Education was also hypothesized to be related to strong beliefs endorsing school climate assessment because more education was presupposed to relate to greater approval, skill, or commitment to data driven decision making. Conversely, both older age and length of time as a superintendent were hypothesized to relate to lower strength in beliefs endorsing school climate assessment. This was projected because leaders who are older, or have been in the position for a longer period of time, may have experienced or observed previous failed attempts thus increasing their cynicism and skepticism for substantial change.

The school context variables were contextualized in relationship to the nation's achievement gap. It was hypothesized that the more urban the area, the more diversity there would be in school demographics, and thus the greater the strength in beliefs endorsing school climate assessment. The rationale was that there would be an increased 
level of attention on equity in these districts. The school context variables that were used as measures for diversity included poverty (measured by the eligibility for FRPM), frequency of English language learners, and students eligible for special education.

This study examined the potential relationship between superintendent beliefs and personal characteristics and school contexts. A simple linear regression was calculated to predict superintendent beliefs (dependent variable) based on explanatory demographic variables (independent variable). Each regression was guided by a distinct hypothesis. For example, what is the relationship (if any) between superintendents' strength of belief in the importance of school climate assessment data for continuous improvement and gender? See Appendix G for a list of the questions that were posed for the regression analyses. Interpretation of the regression, with respect to predicting the response variable for a specific value of the explanatory variable, was included in the analysis.

Qualitative data analysis. The qualitative data analysis process for this study was continuous. Analysis began with the first interview and continued throughout data collection. The goal was to derive meaning from both individual and formally developed group perspectives. This process is best characterized as constant comparative for the purpose of generating findings (Merriam, S. \& Tisdell, E., 2016).

The process for this study, while iterative and ongoing, was also strategic. Central to data analysis was the organization of all potential participants in a Data Accounting Log. This matrix included the names, contact information and a record of all communication efforts with each potential participant. Each semi-structured interview followed the same basic protocol, with variation only in the follow up questions. Completed interviews were 
transcribed verbatim, by the researcher, and then each transcript was read in full a minimum of two times.

Following transcription, the qualitative data analysis began. The coding process was deductive, beginning with a provisional start list of codes that were identified from the research question and extant literature (Miles, Huberman, \& Saldaña, 2014). The same constructs that were explored quantitatively were included in the initial qualitative coding structure: importance, capacity, and trustworthiness. Further in vivo coding continued throughout qualitative data analysis and included a process of memoing in the margins of interview transcripts, analytic summaries for each case, and construct tables to support cross-case analysis and construct analysis. This concurrent analysis process allowed the researcher to document and subsequently revise initial interpretations. A codebook was developed to support and record the researcher's decisions, coding definitions, and rationale. After all data were collected, quantitative and qualitative data were analyzed together to further reveal connections, patterns, themes, differences, and variations across all of the data that were obtained.

Two formal matrices were developed and used to facilitate qualitative data analysis. A case summary table was created to summarize each case across the variables and to explore coding schemes and identify emerging themes, similarities, and differences across all cases. Second, a construct table was created to analyze participant responses by each of the three constructs being measured (RQ2) as well as the instruments and processes currently being used in practice by districts to assess school climate (RQ1). The 
construct table was particularly helpful in revealing the variation in responses and led to additional sub-themes within the primary constructs included in this study.

\section{Evidence for Validity and Reliability}

Ensuring the validity and reliability of data was important to this study so there would be confidence that the constructs that were intended to be measured were actually being measured, consistently across many different respondents. According to the preeminent set of guidelines co-authored by expert representatives from American Educational Research Association (AERA), American Psychological Association (APA), \& National Council for Measurement in Education (NCME), Standards in Educational Testing, evidence for validity and reliability is important to collect and analyze because adequate evidence suggesting accuracy and consistency of data will increase the researcher's ability to "draw appropriate inferences" (2014, p.154). In this section, the approaches and considerations that were employed in this study to collect evidence for validity and reliability and to decrease threats to validity and reliability are explained for both quantitative and qualitative data.

Evidence for validity. Validity refers to the evidence that supports the interpretation of analysis, thus, validity asks if the instrument measured what was intended and to what extent the scoring of responses aligned with the theory that informed the instrument design. "Validity is, therefore, the most fundamental consideration" for instrument developers (AERA, APA, \& NCME, 2014). There are five types of validity evidence: content validity, response process validity, internal structure validity, relations to external 
variables validity, and consequences (AERA, APA \& NCME, 2014). In the current study, evidence for three of these five types of validity were collected.

Content validity. According to Standards for Education and Psychological Testing (AERA, APA, \& NCME, 2014), it is important to ensure a relationship between content of the instrument and the construct that is being measured. The content validity for this study helped determine the extent to which the survey measured the three intended constructs: importance, capacity, and trustworthiness. The survey instrument was developed with guidance from Wilson's Four Building Blocks (as previously discussed). Content validity was addressed through four key methodological strategies. The development and use of construct maps provided the basis for a theoretical foundation for each construct being measured. In this study, construct maps were informed by the literature and a pilot study conducted by the researcher one year prior to the current study. Item design was aligned to the construct maps and reviewed by an assessment expert, a school climate expert, and key informants with superintendent experiences. Lastly, response scoring was aligned to the construct maps with the goal of capturing the potential variation in responses.

Response process validity. Evidence that helps researchers (and users) understand how participants interpreted the survey items is called response process validity. Response process evidence typically comes from individual respondents, for example, progressive written responses to show progression of learning, asking respondents about their performance strategies, observing response times or interferences, or querying students about their experience (AERA, APA \& NCME, 2014). For this study, the 
explanatory sequential mixed methods approach allowed the researcher an opportunity to confirm or dispute initial interpretations with the study population directly, thus enhancing the response process validity. Additionally, evidence for the response process was collected in the survey through the optional exit survey questions. These questions were included to provide participants with a qualitative prompt to explain items that were confusing and to offer feedback to improve the instrument. The exit survey offered insight into possible sources of distraction or "noise" in the survey that could potentially interfere with the data that were obtained.

Internal structure validity. The validity of the internal structure of the survey considers the relationships among the items and the construct, looking at the patterns in responses. According to Standards for Education and Psychological Testing, "analyses of the internal structure of a test can indicate the degree to which the relationships among the test items and test components conform to the construct on which the proposed test score interpretations are based (AERA, APA, \& NCME, 2014, p.16).” The fourth building block, as previously discussed, provided data on the internal structure, which was quantitatively examined using Rasch item response model and Wright maps to determine if the evidence supported the construct map and the item design (see Appendix F for the Wright Maps generated for this study).

Relations to external variables and consequences. The two types of evidence that were not collected were relations to external variables and consequences. Validity evidence derived from external variables is when the instrument is compared to another instrument that measures the same (or similar) constructs. Understanding relationships 
within and among variables provides evidence of consistency across instruments when the constructs that are being measured are the same. This type of evidence was not collected in this study, but comparing the belief constructs measured in this study to other belief-related instruments would be helpful in refining and improving the effectiveness of the instrument developed for this study. Second, exploring consequences refers to the collection of evidence to explore the interpretation and use of test scores or results derived from the instrument. According to Standards in Educational Testing, "the validation process involves gathering evidence to evaluate the soundness of their proposed interpretations for their intended use (AERA, APA \& NCME, 2014, p.19).” The goal of these data is to understand and investigate unintended consequences and to confirm that the consequences are not a result of the instrument's inability to measure what was intended. Follow up revisions based on other evidence may lead to a greater need to collect evidence exploring relationships to other variables as well as unintended consequences, particularly if the instrument is to be used in future research studies or for decision making processes.

Evidence for reliability. Reliability refers to the extent to which there are consistencies in the assessment across multiple respondents, and with repeated use (AERA, APA \& NCME, 2014, p.33). Reliability impacts the interpretation and use of data to guide decision making, therefore, reliability is important, but the importance increases as the expectations and the use of the instrument increases (2014). There are four types of reliability evidence: internal consistency, alternative forms, test retest, and rater reliability. In addition to the relevance and application of each of these types of 
reliability evidence, the influence of random errors will also be discussed in the following section.

Internal consistency. Data exploring the internal consistency were collected and analyzed to understand the reliability of the instrument. Using mathematical modeling, in line with item response theory, a reliability coefficient was generated for each of the three scales to ensure that the instrument was measuring just one thing. Person separation and Cronbach's alpha are the internal consistency coefficients applied in this study. Each is "based on the relationships/interactions among scores derived from individual items or subsets of the items within a test" (AERA, APA \& NCME, 2014 p.37). Reliability coefficients derived from item response theory such as person separation are useful because they "represent the increasing proportion of correct responses to an item at increasing levels of the ability or trait being measured" (2014 p.38).

Alternate forms, test retest, rater reliability. Three types of reliability evidence were not collected in this study. First, alternate forms refer to assessments that "are designed to have the same general distribution of content and item formats, the same administrative procedures, and at least approximately the same score means and standard deviations in some specified population (AERA, APA, NCME, 2014, p.35). For the current study, there was only one form of the survey developed and used, thus comparing two or more alternative versions of the instrument was not possible. Second, according to Standards for Education and Psychological Testing, "a very basic way to evaluate the consistency of scores involves an analysis of variation in each test taker's scores across replications of the testing procedure" (2014, p.34). However, test-retest was not determined feasible in 
this exploratory study. It was recognized that conditions that influenced participant responses were contextual and therefore, the relevance of comparing response when conditions were not replicable was not prioritized. Third, because "the reliability/precision of scores depends on how much the test scores vary" $(2014$, p.33) if scores are qualitatively rated, the variation in scoring could be a source of error. In this study, the constructs were measured quantitatively in the instrument and therefore, rater consistency was not relevant. Throughout quantitative data analysis, a codebook was created and any recoding decisions were discussed and then clearly documented in the codebook.

Random errors. Random errors in instrument score data are potential threats to the reliability of an instrument and occur when the responses are unpredictable as a result of (internal or external) contexts that influence how respondents engaged with the instrument (AERA, APA, NCME, 2014). Random errors are "unpredictable fluctuations in test scores" $(2014$, p.36). Conditions that potentially influenced random error in this study included time, motivation, access, and distractions. Several strategies were employed to reduce random error, including notification, survey completion time, accessibility of the instrument, and the strategic use of reminders.

The pre-notification process was included in an effort to help respondents prepare for the survey and appeal to their intrinsic motivation to participate. The survey was designed to take 20 minutes to complete and was conveniently available online. The format was selected due to accessibility using a range of computer and mobile devices, allowing participants to respond at a time (and in the manner) most amenable to their schedule and 
preferences. Reminders were sent to decrease distractions that may have interfered with initial participation and completion. Reminders were sent in the early morning to alert potential participants at the beginning of the workday. Finally, ensuring a large sample size was emphasized throughout data collection to decrease random errors.

Credibility, consistency, and transferability. It is not appropriate to simply apply quantitative concepts of validity and reliability in qualitative study designs, however, "all research is concerned with producing valid and reliable knowledge" (Merriam \& Tisdell, 2016). In qualitative research, there are many terms that are used to describe the consistency and the accuracy of data, including rigor, credibility, transferability, dependability, confirmability, trustworthiness, authenticity (Creswell \& Creswell, 2018; Merriam \& Tisdell, 2016). As researchers continue to debate the best terms and approaches for ensuring the dependability and accuracy in qualitative research, this study employed steps to enhance the credibility of data and interpretation (internal validity), consistency (reliability) in the processes and interpretation of results, and the transferability (external validity) of the study results (Merriam \& Tisdell, 2016).

Credibility. Ensuring credibility of the qualitative data that were collected and analyzed in this study, the researcher relied on peer debriefing, rich thick description, reflective journaling, and establishing trust. Peer debriefing was utilized throughout data analysis to provide an additional perspective towards the interpretation of the qualitative data. This approach is particularly helpful in improving accuracy of the interpretation of findings (Creswell \& Creswell, 2018; Merriam \& Tisdell, 2016). Rich-thick descriptions refers to the depth provided to ensure that readers can understand the context and the 
findings of the study. This study provided depth and description in the reporting of the results and relied on participant perspectives and quotes throughout the presentation of the findings (Creswell \& Creswell, 2018; Merriam \& Tisdell, 2016). Reflective journaling was also employed to enhance credibility. This approach provided a space to explore the researcher's potential bias towards instruments, processes, or perspectives in education leadership, health, or organizational wellness (Creswell \& Creswell, 2018; Merriam \& Tisdell, 2016). Lastly, establishing trust among participants was an important strategy to support in-depth, honest response processes. To increase the credibility of the study, the researcher collaborated with the CDE and letters of endorsement were sent to all potential participants. Additionally, informed consent and protections of confidentiality were important in establishing trust, both of which are discussed in depth in the forthcoming section on ethical considerations.

Consistency. In qualitative research consistency refers to "whether the results are consistent with the data collected" (Merriam \& Tisdell, 2016). Consistency necessarily encompasses the previously discussed approaches to ensure credibility. In addition, this study used the same interview protocol across all interviewees, employed practices to ensure accuracy in transcription, and a detailed record of the research steps and procedures was maintained (2016). First, the qualitative interview protocol was developed following initial quantitative data analysis and the same core questions were asked in all semi-structured interviews. Second, ensuring the reliability of the raw qualitative data was accomplished by careful review of the transcribed interviews and clear coding strategies. The raw interview data were reviewed no less than twice to 
address potential transcription errors. As data were organized by codes, memoing was used to refine coding decisions. The systematic coding was iterative and responsive to the literature as well as data collected in the study. The a priori codebook, informed by the literature review and pilot study, was revised as needed during data analysis. Furthermore, experts were consulted on an ongoing basis and were used to review protocols and design strategies, confirm data analysis and coding plans, discuss study findings, and provide expert support in developing overall interpretations and implications. Third, the researcher meticulously tracked procedures in an audit trail, which was a detailed record of steps, processes, and decisions that were made throughout the entire study (Creswell \& Creswell, 2018; Merriam \& Tisdell, 2016). The audit trail in this study described the data collection and analysis and included both steps and decision making as data were collected, analyzed, and interpreted.

Transferability. In qualitative research, the generalizability of study findings is not possible and therefore, many researchers discuss the relevance of study findings as potentially transferable to other settings and experiences (Merriam \& Tisdell, 2016). In this study, the potential for findings to transfer to other situations was improved through both maximum variation and thick-rich data. Maximum variation refers to the intent to include a diverse representation of respondents to increase the plurality of the responses and the range of responses (2016). Maximum variation is thus, a sampling strategy and an analysis strategy. In this study, the sampling plan sought to include a diverse representation of superintendents throughout the state. The goal was to capture a range of perspectives and experiences of leaders and districts with demographic diversity. The 
second approach that was employed was to provide substantial detail and description of the study and the findings. This approach, referred to as rich, thick descriptions, was discussed previously in the section on credibility.

Response Bias. Response bias is a construct irrelevant threat that can impact data interpretation (AERA, APA \& NCME, 2014, p. 154). In this study, response bias was a threat given the open invitation to all superintendents throughout the state to participate. The concern was in both ensuring an adequate response rate for the statistical analysis that was desired, but also in ensuring the representativeness of responses. The study proposed a statewide survey inviting all superintendents to participate. With this approach, the researcher acknowledged that the response rate and the subsequent representativeness of responses and non-responses, would greatly impact the results and overall findings. Online survey methods vary significantly and a review of the literature on survey research revealed a number of recommendations that were employed to increase the response rate in this study. These methods included the use of prenotification, organization and language of emails, follow up processes, sponsorships, and the appearance and usability of the survey (Cook, Heath, Thompson, 2000; Madariaga et al., 2017; Sills \& Song, 2002).

Pre-notification was a process by which the study population was notified in advance that they will be invited to participate. Pre-notification emails were sent directly from the researcher prior to the survey launch. The pre-notification included an introduction to the study, topics that were included, consent notification, and an endorsement letter from the State Superintendent of Instruction. 
The organization and language of all correspondence was crucial, and to maximize the potential for a response, the researcher drew from best practices in survey research. The strategies that were adopted are described below and presented visually in Figure 5. Personalized emails appear to positively influence response rates (Cook, Heath, Thompson, 2000) and therefore, individual messages were moderately tailored to the invited participants for this study. The language of the messages was concise, but in depth and with particular attention to a tone that would appeal to both the value of participation and a plea for assistance (Kaplowitz, Lupi, Couper \& Thorp, 2012).

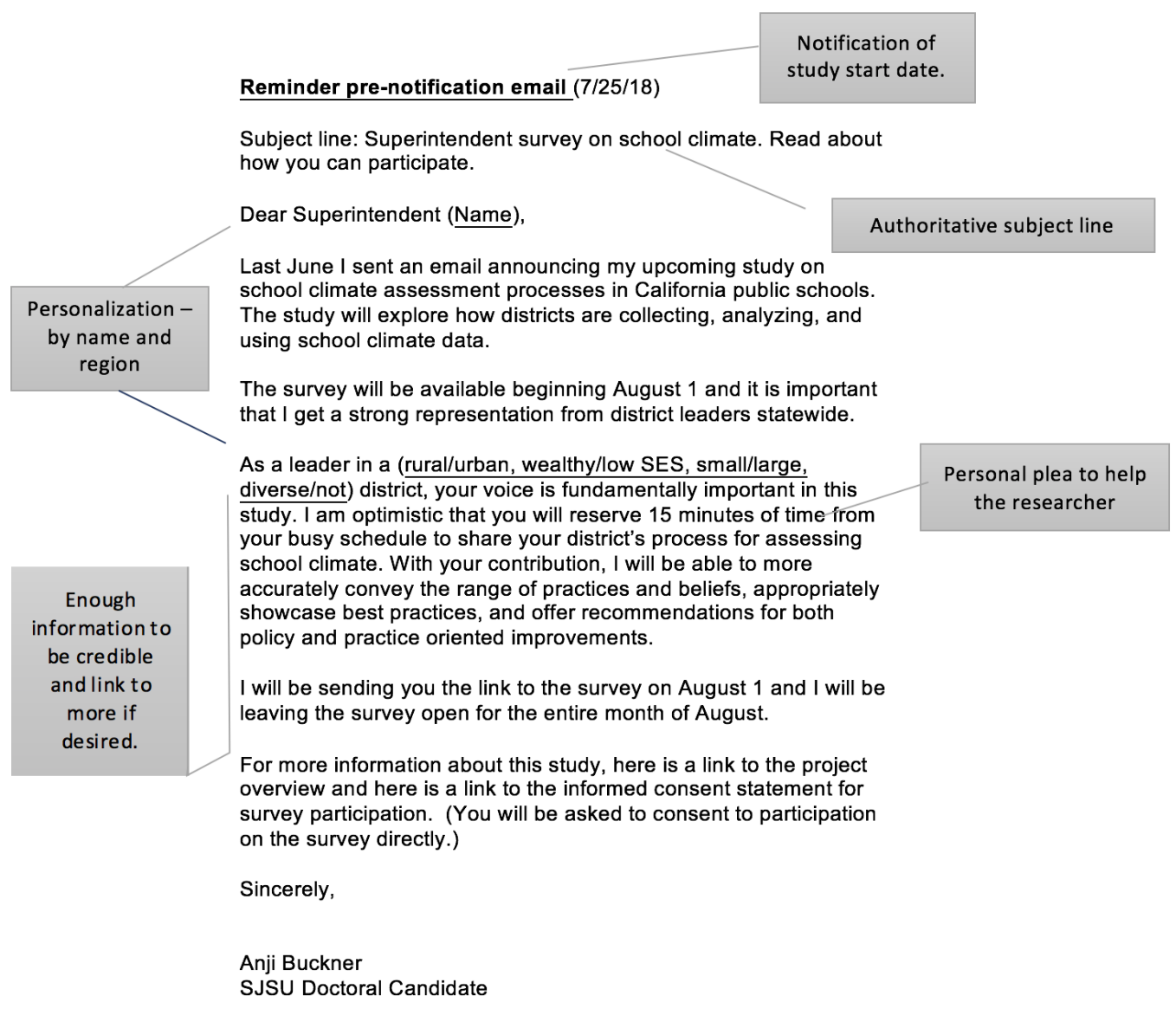

Figure 5. Visualization of email components used to increase response rate. 
Authoritative subject lines have been associated with higher response rates (2011) and this strategy was employed in all email correspondence. For example, "Take a survey on district experiences with school climate assessment" was one subject line that was used in the study. A final suggestion incorporated in this study was a sponsorship (Boulianne, Klofstad \& Basson, 2010). The researcher obtained the endorsement of the CDE and the SPI who emailed a letter encouraging state-wide participation in the online survey.

\section{Ethical Considerations}

This study was approved by the San José State University Institutional Review Board (Protocol \#S18101, see Appendix H). Participation in this study was completely voluntary and participants were free to withdraw or stop participating at any time. Participants were informed of their rights to participate and confidentiality protections through a consent process that included a consent notification and agreement to participate. The consent notification was included in the email invitation, email reminders, and embedded in the survey online. The agreement to participate was embedded in the survey as a mandatory first question. Only participants who voluntarily accepted were able to initiate the full survey. (See Appendix I for a copy of the consent notification.) Written consent was obtained on a consent form for all qualitative interviews in addition to verbal consent to the audio recording at the start of the interview. (See Appendix J for a copy of the interview consent form.)

Participant confidentiality was important to the researcher in this study. Anonymity was not entirely possible, given the use of direct email addresses in Qualtrics; therefore, 
participant confidentiality was upheld through the following measures. First, email addresses were automatically stored by Qualtrics when the respondent used a link embedded in the emails that were sent directly from Qualtrics. Email addresses were not stored when respondents used a generic link that was shared in the CDE endorsement letter. When an email address was automatically stored, there was no way to track the address to a specific survey response because the responses were anonymized within Qualtrics. Second, raw survey data were cleaned and any potential identifying characteristics were removed prior to initiating data analysis. All survey and interview participants were assigned a unique numeric identification number. Third, data were only reported in aggregate thus eliminating any possibility of inadvertently exposing a participant's identity. Lastly, during the qualitative phase of the study, unique identifiers were used and the occasional school or community name was redacted in all data analysis matrices. The qualitative data analyzed in the construct analysis matrix did not include any demographic information.

In summary, the most critical components of this chapter are the approaches taken to ensure that data gathered through this study were accurate, relevant, and meaningful in supporting the researcher in answering the three research questions. The quantitative methods utilized a research based approach to instrument design by following the guidelines of the Standards for Education and Psychological Testing, the National Research Council's assessment triangle, and Mark Wilson's four building blocks. The qualitative methods adhered to high standards and expectations for study design by ensuring a clear connection and relevance to a problem and the research questions, and 
the inclusion of strategies to enhance credibility and consistency of data collection and data analysis. Together, the exploratory sequential mixed methods approach was an appropriate design for this study because the qualitative data augmented the potential for the researcher to accurately interpret the quantitative findings and study implications. 


\section{Chapter Four: Findings}

The purpose of this study was to explore superintendent beliefs and local district practices in school climate assessment throughout the state of California. Knowing what schools are doing and how superintendents perceive the importance of school climate, their ability to use data for continuous improvement, and their trust in the data will help statewide leaders, policy makers, researchers, and school personnel improve their efforts to support plans for local school improvement.

The study design was an explanatory sequential mixed methods approach involving two phases of data collection, quantitative followed by qualitative (QUAN $\rightarrow$ Qual). In this strategy, the qualitative process supported a deeper understanding and explanation of the quantitative data results and the researcher's preliminary analysis and interpretation of the findings. This study collected data sequentially and analyzed data both sequentially and concurrently to elicit a deeper meaning and understanding of the current practices and beliefs of local leaders as they implement Priority 6 of the LCFF

This study addressed three questions. First, what instruments and practices are currently being used by schools to assess and use school climate data for continuous improvement? Second, what are superintendent's beliefs in the importance of school climate assessment, their ability to use school climate data for decision making, and their trust in the data? Third, what is the relationship (if any) between superintendent beliefs towards school climate data and other personal factors or school contexts? This chapter begins with a summary profile of the study participants followed by the presentation of the findings for each of the three research questions. 


\section{Profile of the Participants}

Analysis of the quantitative findings. The study sample was comprised of county and district superintendents who voluntarily participated in an online survey. In total, 298 superintendents initiated and 198 completed the survey. Participants in the online survey were predominantly in their forties or fifties and they were highly educated, experienced leaders. Table 4 presents a summary of the personal demographics of the leaders who participated in the online survey.

Table 4

Survey Participant Personal Demographics

\begin{tabular}{cll}
\hline Participant Demographics & Frequency & Percent \\
\hline Gender & & \\
Female & 79 & $39.7 \%$ \\
Male & 116 & $58.3 \%$ \\
Prefer not to state & 4 & $2 \%$ \\
Race/Ethnicity & & \\
Asian & 7 & $3.5 \%$ \\
Black & 7 & $3.5 \%$ \\
Hispanic & 37 & $18.7 \%$ \\
White & 137 & $69.2 \%$ \\
Prefer not to state & 10 & $5.1 \%$ \\
& & \\
Age & 3 & $1.5 \%$ \\
Younger than 40 & 54 & $27.3 \%$ \\
40-49 & 97 & $49 \%$ \\
50-59 & 33 & $16.7 \%$ \\
60-69 & 6 & $3 \%$ \\
70 or older & 5 & $2.5 \%$ \\
Prefer not to state & & \\
degree completed & & $2 \%$ \\
Bachelor's Degree & 4 & $56.8 \%$ \\
Master's Degree & 113 & $7.5 \%$ \\
EdD & 67 & \\
PhD & 15 & \\
Highest & & \\
& &
\end{tabular}


Table 4 (continued).

\begin{tabular}{clc}
\hline Participant Demographics & Frequency & Percent \\
\hline Length of time in Current Position & & \\
Less than 1 year & 11 & $5.6 \%$ \\
1 to less than 3 years & 61 & $31 \%$ \\
3 to less than 5 years & 42 & $21.3 \%$ \\
5 to less than 10 years & 59 & $29.9 \%$ \\
10 years or more & 24 & $12.2 \%$ \\
& & \\
Length of time as Superintendent (total) & 13 & $6.5 \%$ \\
Less than 1 year & 15 & $23.4 \%$ \\
1 to less than 3 years & 37 & $18.8 \%$ \\
3 to less than 5 years & 61 & $31 \%$ \\
5 to less than 10 years & 40 & $20.3 \%$ \\
10 years or more & & \\
\hline
\end{tabular}

As Table 4 shows, the majority of respondents were white males. Thirty nine percent were female and close to $20 \%$ were Hispanic/Latino. Three percent of the respondents indicated they were Black/African American and another 3\% selected Asian.

Respondents almost entirely held advanced professional degrees, with $41 \%$ holding doctorates and $57 \%$ with a master degree. Nearly $80 \%$ of the participants were in their forties and fifties and while the range of experience was less than one year to more than ten years. Forty one percent had been in their current position for more than five years, $50 \%$ had been a superintendent for more than 5 years. In addition to collecting personal demographics, district demographics were also collected. Study participants were representative of districts that ranged in geographic region, size, enrollment demographics, and community types. Table 5 presents a summary of the district demographics that were identified by the respondents who participated in the online survey. 
Table 5

Survey Participant District Demographics

\begin{tabular}{|c|c|c|}
\hline Participant District Demographics & Frequency & Percent \\
\hline \multicolumn{3}{|l|}{ District Enrollment Size } \\
\hline Very Small (499 or less) & 43 & $21.6 \%$ \\
\hline Small (500-999) & 19 & $9.5 \%$ \\
\hline Medium (1000-9999) & 96 & $48.2 \%$ \\
\hline Large $(10,000-19,000)$ & 20 & $10.1 \%$ \\
\hline Extra Large $(20,000$ or more $)$ & 21 & $10.6 \%$ \\
\hline \multicolumn{3}{|l|}{ District Enrollment Demographics } \\
\hline \multicolumn{3}{|l|}{ English Learners } \\
\hline$<9 \%$ & 32 & $17 \%$ \\
\hline $10 \%-25 \%$ & 68 & $36 \%$ \\
\hline $26 \%-50 \%$ & 67 & $35 \%$ \\
\hline $51 \%-75 \%$ & 16 & $8 \%$ \\
\hline $76 \%>$ & 7 & $4 \%$ \\
\hline \multicolumn{3}{|l|}{ Free and Reduced Priced Meals } \\
\hline$<24 \%$ & 19 & $10 \%$ \\
\hline $25 \%-50 \%$ & 55 & $28 \%$ \\
\hline $51 \%-74 \%$ & 51 & $26 \%$ \\
\hline $75 \%>$ & 69 & $36 \%$ \\
\hline \multicolumn{3}{|l|}{ Special Education } \\
\hline$<9 \%$ & 29 & $15 \%$ \\
\hline $10 \%-13 \%$ & 95 & $49 \%$ \\
\hline $14 \%-20 \%$ & 56 & $29 \%$ \\
\hline $21 \%>$ & 14 & $7 \%$ \\
\hline \multicolumn{3}{|l|}{ Community Type } \\
\hline Rural & 96 & $47.8 \%$ \\
\hline Suburban & 68 & $33.8 \%$ \\
\hline Urban & 29 & $14.4 \%$ \\
\hline Other & 8 & $4 \%$ \\
\hline \multicolumn{3}{|l|}{ Regional Representation } \\
\hline Region 1 & 21 & $10.5 \%$ \\
\hline Region 2 & 14 & $7 \%$ \\
\hline Region 3 & 17 & $8.5 \%$ \\
\hline Region 4 & 20 & $10 \%$ \\
\hline Region 5 & 23 & $11.5 \%$ \\
\hline Region 6 & 8 & $4 \%$ \\
\hline Region 7 & 23 & $11 \%$ \\
\hline Region 8 & 19 & $9.5 \%$ \\
\hline Region 9 & 17 & $8.5 \%$ \\
\hline Region 10 & 16 & $8 \%$ \\
\hline Region 11 & 22 & $11 \%$ \\
\hline
\end{tabular}


As Table 5 shows, medium sized districts and rural areas were overrepresented in the final sample, with nearly half of the respondents who described their district as being in a rural area and half (48\%) reported medium sized enrollment. Twenty percent of respondents worked in districts with enrollment greater than 10,000 and $30 \%$ were in districts with fewer than 1000 students. Every region in the state was represented in the final sample, with the greatest response rate for the Bay Area (regions 4 and 5) and the lowest response rate for the San Joaquin Valley (region 6).

Analysis of the qualitative findings. Eight superintendents were interviewed in the qualitative phase. Participants in the qualitative semi-structured interviews included five males and three females who had been in their current position between 1.5 to 8.5 years. Two participants in the semi structured interviews were county superintendents; one was from a large, urban county and, the second was from a small rural county. The remaining six participants were all district superintendents representing different demographic and geographic regions throughout the state.

District demographics were obtained directly from participants during the semistructured interview as well as from databases available on the CDE website. The participants represented districts with a range of diversity in student demographics and socioeconomic status. For example, the range in the percentage of students who were eligible for FRPM was between 31\% and 99\% in this sample; and, the range of English learner student enrollment was as low as $9 \%$ and as high as $64 \%$. In terms of race and ethnicity, enrollment of Hispanic students was as low as $27 \%$ and as high as $98 \%$ among the districts that were represented by the superintendent participants in this study. Other 
races/ethnicities that were represented by more than $20 \%$ of student enrollment included Native American, Hispanic, and Asian. Four of the superintendents who were interviewed worked in districts in urban areas, three were in rural areas, and one was in a self-described suburban area. Participants represented all sizes of districts; three districts were small or extra small, one was medium, and four were large or extra-large.

Analysis of quantitative and qualitative findings. For both the quantitative and the qualitative methods, the study population represented all regions and district types as well as a range of professional characteristics. The final sample was low in Region 2 and Region 6 , representing $7 \%$ and $4 \%$ (respectively) of the total response. The region with the highest response was Region 5 , with $11.5 \%$ of the total response in the quantitative survey, and one quarter of the qualitative responses. Rural districts were oversampled in the quantitative methods and as a result, the researcher oversampled urban district superintendents in the qualitative data to ensure adequate representation in the final study sample.

\section{Research Question One}

The first research question, what instruments and practices are currently being used by California public schools to assess and use school climate data for continuous improvement, explored the range of practices that were being used by districts to assess school climate. Specifically, the researcher inquired about what instruments were being used for school climate assessment and how were the data handled including data collection, data analysis, and decision making. This question was answered through both quantitative and qualitative data collection methods. 
Analysis of quantitative findings: Instruments and practices in use. Survey results indicated that the most frequently used instrument was the California Healthy Kids Survey (CHKS), followed by Positive Behavioral Intervention and Supports (PBIS). The third most frequent response was a locally developed instrument. Figure 6 shows the frequency of the instruments that were identified as being used to assess school climate.

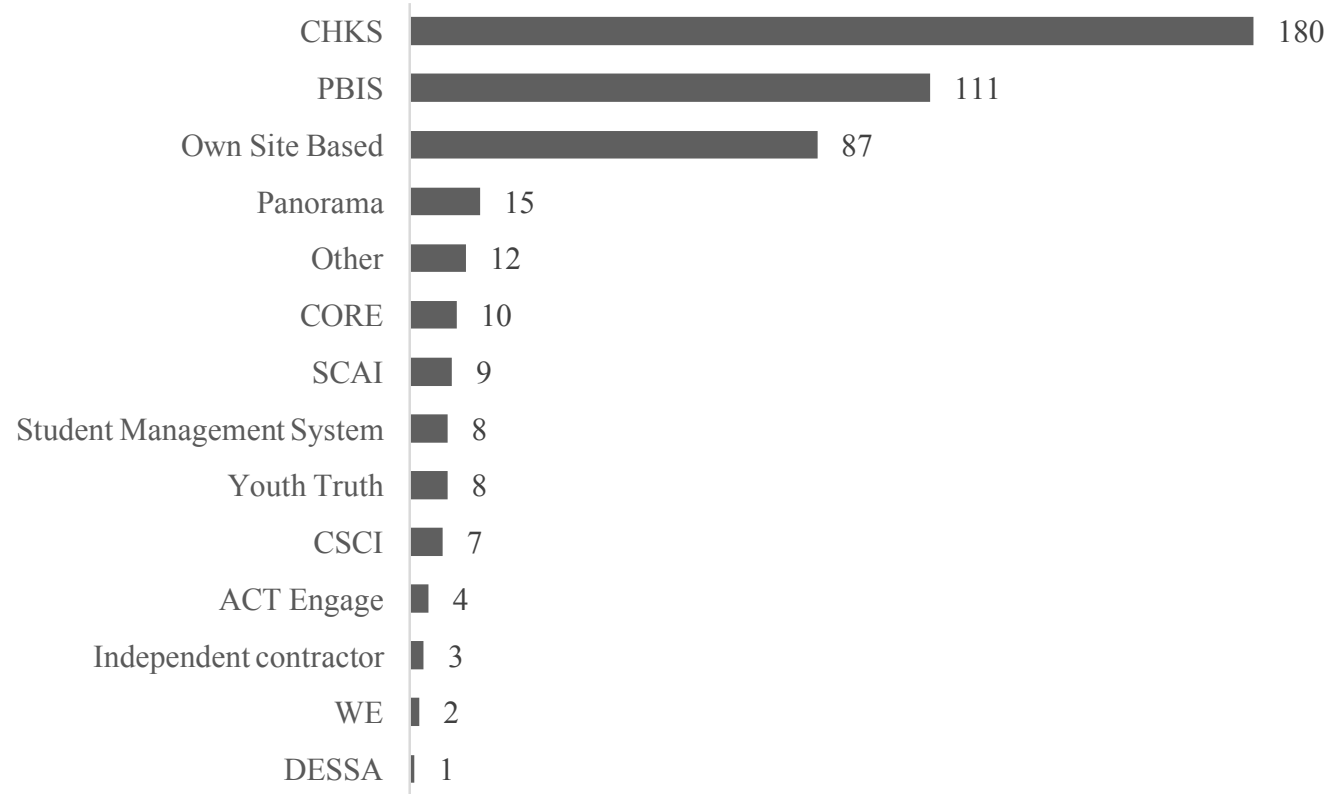

Figure 6. Instruments used by districts for school climate assessment. Values included on the chart represent counts, $\mathrm{n}=205$.

The majority of respondents (75\%) indicated that they used more than one assessment instrument. Of the $25 \%$ who used only one instrument, $70 \%$ used CHKS, $19 \%$ developed their own instrument, and 7\% used PBIS. As Figure 6 illustrates, there are many surveys in use, but CHKS, PBIS, and site based instruments were overwhelmingly the most commonly used to assess school climate. 
To better understand how data were being handled, participants were asked questions about who was involved in data collection, analysis processes, and whether or not data were analyzed by subgroups. For data collection, school districts were asked who participated in school climate surveys. Ninety one percent of the study participants identified students as school climate assessment participants (survey respondents). The second most common group identified was staff (80\%), followed by teachers and parents (74\% and $73 \%$ respectively), and then the community $(29 \%)$. The predominant data collection method was surveys (98\%), but slightly more than a third of district leaders also reported using interviews and observation (36\% and $38 \%$ respectively).

In terms of data analysis, respondents were asked about data disaggregation practices and it was reported that data were disaggregated predominantly by school or student characteristics. Figure 7 shows the frequency of disaggregation practices by student subgroups.

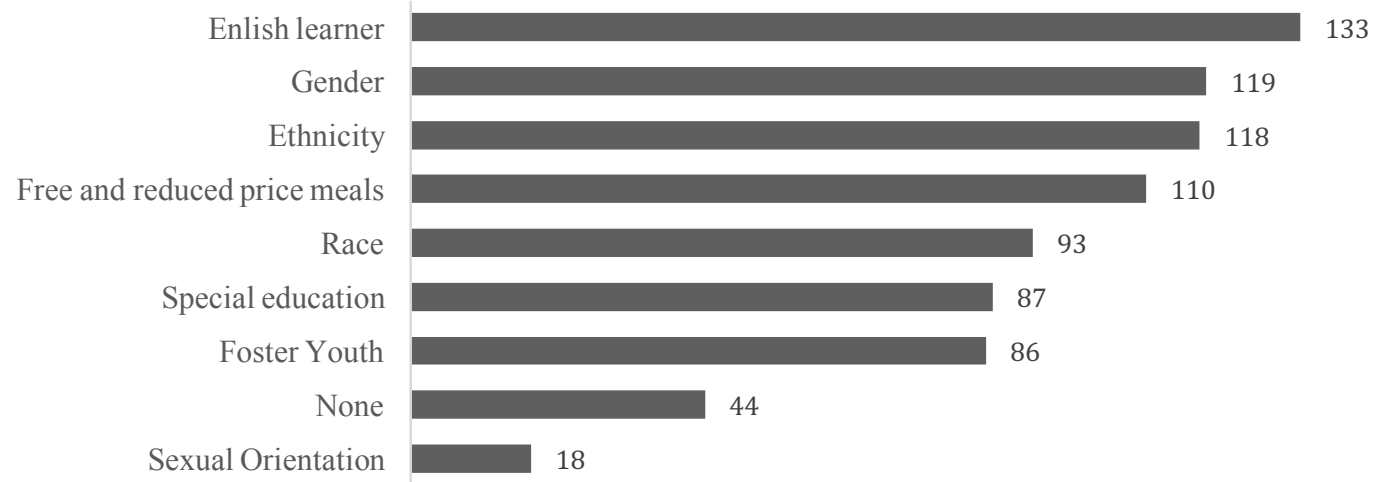

Figure 7. Frequency of data disaggregation by student population, n=198.

As Figure 7 shows, data were disaggregated most frequently by English language learners, gender, ethnicity, and eligibility for free and reduced priced meals. 
Regarding the level of disaggregation, the majority of respondents indicated disaggregation at the school level. Figure 8 , which presents the frequency of responses by the level of data disaggregation, shows that most data were disaggregated at the school level. However, there were 59 respondents who disaggregated at the classroom level and 76 respondents who indicated using disaggregated data at the student level during data analysis.

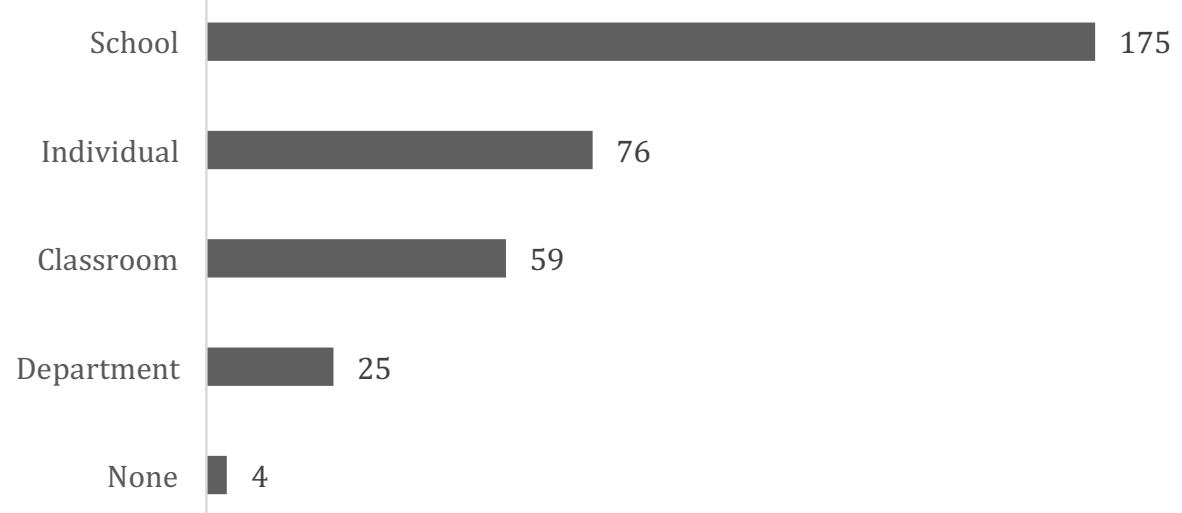

Figure 8. Frequency of data disaggregation by level, $\mathrm{n}=198$.

Survey participants were also asked who participated in decision making to determine how data were used for site based improvements. Respondents identified staff and faculty ( $86 \%$ and $82 \%$ respectively) as the two most frequently involved groups in decision making, followed by parents at $61 \%$. Fewer than half of the study participants indicated that students and the community were included in decision making.

Analysis of qualitative findings: Instruments and practices in use. The results from the interviews have suggested widespread use of the CHKS, which was reportedly in use in all of the districts represented in this study, except one. In the exception, the 
interviewee explained that CHKS had been used previously, but the district had recently contracted with a private company to develop a local school climate survey. The majority of respondents reported using several methods for data collection, including more than one survey instrument. Other surveys that were mentioned during the interviews included WE, MTSS, and Panorama. In addition, many discussed the use of informal observation and inquiry. For example, one participant explained the value of informal assessments in this way:

I think that you've got to walk in and as administrators you've got to build relationships and you've got to understand the landscape and you know, see what is going on within your school walls.... It's a lot of observation and listening.

Relative to data collection, students were consistently identified as survey respondents for school climate assessment and in all but two cases, multiple stakeholders were surveyed. Participants were not specifically asked about data analysis and disaggregation in the semi-structured interviews, but disaggregation of data was articulated by respondents in the interviews as a concern for small rural districts. One superintendent explained the problem in this way,

It is difficult, particularly in my smaller district, where there are only 400 kids. You have to be really careful when you get down to those grade level assessments because you can lose the anonymity factor if you're not careful.

In terms of decision making, respondents described their process as primarily topdown approaches spearheaded by district personnel. Only one case described a comprehensive process of inclusion and shared decision making. This respondent explained their district's process: "Each campus has a leadership team made up of parents, teachers, and the principal." The respondent continued, "At the district level we 
have a district-wide committee that is made of a parent rep, teacher rep from each campus, two principals, and district staff." The respondent went further by describing an inclusive process for the LCAP including representatives from the site, the teacher's union, and an extensive community coalition.

Other interviewees described a less comprehensive group process for decision making. Some spoke about site and district collaborations. One respondent said, "The district and site administration, through a collaborative meeting and agreement" are involved in making decisions about how school climate data are used. Another said, "Me and the principals have a collaborative effort...and we also talk with the counselors." Other interviewees described a centralized process guided by the district. One participant explained,

Decisions on what to do with [data] come through senior leadership, which is my cabinet and then my office. Direction setting at the leadership level and implementation on individual things that might occur from that would be done in consultation with site leadership.... But, direction in general comes from the top end of the leadership in the district.

Others explained a similar process being guided by district personnel, echoing the expression that decision making begins "first with administrators and then with stakeholders" as needed or if relevant to a district identified purpose.

A benefit of the explanatory mixed methods study design was that qualitative findings supported and provided depth to the interpretation of the quantitative results. In this study, the qualitative findings revealed a number of challenges and concerns that did not emerge in the quantitative data. Three key issues that were identified, included concerns 
over the potential misrepresentation of data, the summative nature of school climate assessment, and the possibility of conflict arising from the data collected.

First, data misrepresentation was articulated by participants who expressed concerns over the volume and interpretation of data. One participant simply said that "Sometimes it's just too much data." Others expressed concern regarding sensemaking and interpretation. One concern was overgeneralization and another signaled concern for manipulation. A participant said, "Data can be misinterpreted and used in very different ways." Another respondent implicated data that were not obtained, saying that "the absence of data sometimes leaves people to believe that there is no problem."

A second concern that was revealed was that school climate data are not always immediately relevant. One respondent said, "A lot of these data points come too late. It's too summative." Another said, "It will fluctuate...depending on the unique needs of the students." A third area of concern was that sometimes data can lead to conflict. This was described by a participant who said:

Well, let's just say that you're in a community that really thinks it has its act together and thinks it's all good and positive and the school climate survey results come back to say that it is not. Well, what that means then is that you are going to have to weather some controversy from the results as you seek to make your school or school district better as a result of the findings.

\section{Analysis of quantitative and qualitative findings: Instruments and}

practices in use. Evidence from both quantitative and qualitative data suggest that CHKS is in widespread use in the state of California. The CHKS was the most frequently selected instrument in the quantitative survey and the most frequently identified in the qualitative interviews. Both data sources also lend 
evidence to suggest that top-down decision-making practices were common and did not always include students. The consistencies that were most notable across these two datasets were that beliefs that data that can directly improve or support teaching and learning were the easiest for participants to endorse. The exception was with students who were not frequently included in the data handling and decision-making processes. While students were not consistently involved, both datasets provided evidence to support the claim that districts are using multiple instruments and collecting data from multiple perspectives or stakeholders.

Furthermore, the quantitative dataset suggests widespread practice in disaggregating data to better understand the experiences of student sub-groups during data analysis. Interviewees were not directly asked about disaggregation of data, but it was reported in the qualitative data that there were particular concerns for data disaggregation in smaller districts because anonymity was harder to uphold. The specific challenges facing small districts in analyzing data by subgroups did not emerge in the quantitative findings, but the mixed method findings suggest that this an area where additional inquiry is necessary to better understand the rural and small district needs to establish a clear set of expectations throughout the state while upholding adequate and ethical student privacy.

\section{Research Question Two}

The second research question was, what are superintendent's beliefs regarding the importance of school climate assessment, their perceived ability to use school climate 
data for decision making, and their trust in the data? To answer the second research question, the quantitative and qualitative data were analyzed. Both methods queried superintendents about their beliefs in the importance of school climate assessment, their capacity to use the data for decision making, and their trustworthiness of the data. The following presentation of the study findings includes a summary of the three constructs and findings from both data collection methods.

Analysis of quantitative findings: Importance. The importance construct offers insight into the range of endorsability of beliefs about the importance of school climate assessment for continuous improvement among superintendents. To understand their perceptions of importance, participants were asked questions about school climate in relationship to other accountability indicators, continuous improvement, the importance of having data about particular stakeholders, and the potential uses for school climate data. The results suggested a high perception of overall importance of school climate in public schools, but concerns were also expressed.

Survey participants were asked to rank the 6 state priorities for accountability for all public schools in California. School climate was ranked in one of the top three $83 \%$ of the time. Specifically, it was ranked the highest priority the most frequently, with thirty two percent of respondents who ranked school climate first and roughly a quarter of respondents who ranked school climate as either second (26\%) or third (24\%) in accountability importance. Study participants were also asked if school climate was the most important factor in continuous improvement. Roughly three fourths of all respondents agreed with the statement. Specifically, 31\% strongly agreed and $43 \%$ 
agreed that school climate was the most important factor in continuous improvement.

Table 6 provides a summary of statistics for items across the importance construct. In terms of the subject of the data that were obtained through school climate assessment, results suggested that leaders believed it was important to have data about many different stakeholder groups.

Table 6

Importance Construct Summary Statistics

\begin{tabular}{lccccccc}
\hline Abbreviated item stem & $\begin{array}{c}\text { Un- } \\
\text { important } \\
(1)\end{array}$ & $\begin{array}{c}\text { Somewhat } \\
\text { important } \\
(2)\end{array}$ & $\begin{array}{c}\text { Very } \\
\text { important } \\
(3)\end{array}$ & $\begin{array}{c}\text { Extremely } \\
\text { Important } \\
(4)\end{array}$ & $\begin{array}{c}\text { Missing } \\
\text { Values }\end{array}$ & Mean & SD \\
\hline Importance of data about & 0 & 19 & 134 & 92 & 53 & 3.3 & .61 \\
students & $0 \%$ & $6.38 \%$ & $44.97 \%$ & $30.87 \%$ & $17.79 \%$ & & \\
Importance of data about & 1 & 31 & 131 & 82 & 53 & 3.2 & .67 \\
teachers & $.34 \%$ & $10.40 \%$ & $43.96 \%$ & $27.52 \%$ & $17.79 \%$ & & \\
Importance of data about & 1 & 24 & 139 & 74 & 60 & 3.0 & .68 \\
staff & $.34 \%$ & $8.05 \%$ & $46.64 \%$ & $24.83 \%$ & $20.13 \%$ & & \\
Importance of data about & 0 & 54 & 132 & 58 & 54 & 3.2 & .63 \\
parents & $0 \%$ & $18.12 \%$ & $44.30 \%$ & $19.46 \%$ & $18.12 \%$ & & \\
Importance of & 16 & 123 & 83 & 18 & 58 & 2.42 & .73 \\
community perspectives & $5.37 \%$ & $41.28 \%$ & $27.85 \%$ & $6.04 \%$ & $19.46 \%$ & & \\
& 2 & 48 & 128 & 62 & 58 & 3 & .71 \\
Important to evaluate & $.67 \%$ & $16.11 \%$ & $42.95 \%$ & $20.81 \%$ & $19.46 \%$ & & \\
Important for health and & 1 & 75 & 128 & 29 & 65 & 2.79 & .66 \\
wellness & $.34 \%$ & $25.17 \%$ & $42.95 \%$ & $9.73 \%$ & $21.81 \%$ & & \\
Important for budget & 7 & 83 & 125 & 18 & 65 & 2.65 & .67 \\
priorities & $2.35 \%$ & $27.85 \%$ & $41.95 \%$ & $6.04 \%$ & $21.81 \%$ & 25 \\
Important for & 3 & 73 & 124 & 29 & 69 & 2.78 & .68 \\
collaboration & $1.01 \%$ & $24.50 \%$ & $41.61 \%$ & $9.73 \%$ & $23.15 \%$ & 2.78 \\
Important for teacher PD & 2 & 58 & 135 & 33 & 70 & 2.87 & .65 \\
Important for site based & $.67 \%$ & $19.46 \%$ & $45.30 \%$ & $11.07 \%$ & $23.49 \%$ & & \\
collaboration & 2 & 63 & 127 & 37 & 69 & 2.87 & .68 \\
\hline
\end{tabular}

As Table 6 shows, ninety six percent of respondents indicated that it was important (or very important) to have school climate data about students; $90 \%$ believed it was important to have data about staff; and, $86 \%$ believed it was important to have data about 
teachers. While still important, a lower percentage of respondents indicated a desire for data about parents (77\%) and perspectives of community advocacy groups (42\%).

For data uses, superintendents were asked about six different potential uses of school climate data. Among the options offered, the response with the highest frequency was the belief in the importance of using school climate data to evaluate schools. Seventy eight percent of respondents indicated that evaluation was very or extremely important. The other potential uses included building capacity for health and wellness, determining budget priorities, site collaboration, professional development, and community collaboration. Responses suggested some variation in the beliefs related to importance of these potential uses for school climate data, but teacher PD and site based collaboration were endorsed by $72 \%-74 \%$ of respondents, respectively (not including missing values).

As Table 6 shows, the majority of respondents believed that it was important to have data about students and teachers. Upon analyzing the distribution of responses, the mean was the highest for data about students $(\mathrm{M}=3.2)$ and given the relatively low standard deviation $(\mathrm{SD}=.61)$, the evidence is suggesting that the majority of respondents agreed that it was important to have data about students. Having data about teachers had a mean of greater than three $(\mathrm{M}=3.2)$ and a low standard deviation $(\mathrm{SD}=.67)$, similarly suggesting that data about teachers was also believed to be important.

Comparatively, there was more variation in responses regarding the importance of community perspectives. On average this item was harder for respondents to endorse and there was more variability in the responses. The mean $(M=2.4)$ suggested that there was some difficulty with endorsement of the statement that community perspectives were 
important to their vision of continuous improvement. This difficulty was reflected in the frequencies with one third (34\%) of the respondents agreeing that community perspectives were important to their vision of continuous improvement. This item had the highest percentage of respondents (16\%) who believed that community perspectives were unimportant, thus signaling an additional area of further inquiry into the perceived role of the community in visions for continuous improvement.

Table 6 also shows the range of beliefs among study participants regarding how data should be used. As previously stated, respondents believed in the importance of using school climate data to evaluate schools. The mean response $(\mathrm{M}=3)$, which corresponds to "very important," and the standard deviation $(\mathrm{SD}=.71)$ suggests some variation in the endorsability of the belief. The other items that queried participants about their beliefs in the uses of data suggest a lower level of importance. These findings indicate the need for additional inquiry in terms of how data can be used for continuous improvement because there was a number of respondents who did not believe in the importance of using data to inform budget decisions, health and wellness, or community collaboration. A higher number of participants agreed with the importance of using data to inform professional development and site-based collaboration, as previously noted.

Analysis of qualitative findings: Importance. The importance construct was explored qualitatively by analyzing why school climate assessment is important and important for what types of uses. Results suggested that school climate assessment data were important indicators of organizational health and potentially useful for a number of school improvement initiatives. In addition, the qualitative data offered insight into how 
these participant leaders were conceptualizing school climate. Study participants said that school climate was "making sure that students feel healthy and safe and connected" and that school climate "data informs some of the root causes, when students are not feeling safe, supported." Another participant offered that school climate was a school responsibility to make "sure that we capitalize on how students feel when they come to school. ...They need to be able to come to our schools and feel like they belong."

There was broad agreement in the belief that school climate was important. One lens that accurately captures the importance of school climate as an element of organizational health. Respondents described the importance by saying, for example: "It's kind of the heart and soul of how any local education agency is going to perform." The organizational lens emphasizes the importance of a healthy environment. One study participant explained, "Understanding school climate is a really important thing for administrators and teachers and parents because it is so interconnected to all of the other indicators of health, whole child, and whole community." Another connected the importance of a positive school climate directly to student learning, saying

When you have a good climate and there is mutual trust and respect amongst all of the employees in the organization, it is going to be a more positive atmosphere for students, which will, you know - only help them to perform better.

Another participant explained the importance in terms of productivity in meeting the expectations of a school. The participant said, "You know, if you don't have a good positive school climate you are not going to have kids that want to come to school and you're not going to have teachers that are motivated to come to work and nothing is going to get done." 
This lens also captured the perspectives that school climate data are important as a tool for surveilling the health of the organization. One respondent focused on needing to know what to change. The participant offered, "If you don't have a needs assessment, with data, you don't know where you have a baseline and you don't know where you need to get. You can't have real goals and you can't monitor improvement." Another expressed this perspective more broadly situating schools in context with a community. This participant proposed that "schools are often the places where symptoms and needs and issues of community can be observed."

A second perspective analyzed with the importance construct explored beliefs regarding the potential usefulness of school climate data. A lens of continuous improvement captured the range of viewpoints expressed by the respondents on the importance of using school climate data to guide change. One respondent shared how data were used to signal, or motivate deeper learning. This respondent offered an example of how data revealed that some students "were treated differently based on race or ethnicity." The leader continued, "So, that led us to develop inclusivity task forces; basically, places where we can listen to the thoughts of the community members, student, and also staff, on issues related to inclusivity."

To support site-based improvement initiatives, many respondents spoke about personnel. One reported, "I have been able to hire district social workers," and another said, "We have increased the number of school counselors." Others spoke about how data led to additional training, "We have allocated resources into different layers of training, 
including restorative practices, the mindfulness training which has been really well received."

Respondents also highlighted the importance of using data to support studentinvolved initiatives. One participant shared that

One of the things that we have done - in our K-8's - we provide breakfast in the classroom. Something very simple. Just by feeding our students in the mornings having the teachers spend 15 or 20 minutes with them; having breakfast and talking in small groups about their day. How their morning was going, or how their night went. We have seen a decline in discipline. Going to the office. And, the attendance has actually improved dramatically.

Another offered examples of using data to inform site-based initiatives to help students feel included. The participant said,

We have buddy benches at all of our elementary schools at our middle schools, [and] we have implemented an orientation for new students. So, any new student gets to shadow a student for a day and the second day, a student ambassador shadows them to make sure that they have people to eat with at least for the first few days.

Another perspective explained that data were used to facilitate collaboration. This participant said, "The data is informing better collaboration both inside the school system but also between non-profit partners and businesses that are coming in through mentorships and internships."

The lens of continuous improvement also captured the beliefs towards accountability. To better understand what school climate accountability included, this study asked participants about using school climate data to evaluate schools. The qualitative data suggested that using school climate data to evaluate schools is a complex issue and findings from this study revealed a range of perspectives and a number of concerns. Results from this study suggested that superintendents believed in accountability and 
school climate assessment, but universally cautioned that the focus must be on continuous improvement. Furthermore, participants affirmed that if data were used for evaluation, then the focus should emphasize the process and not the outcome. One participant articulated this sentiment, saying: "I believe that there should be accountability as long as ... we learn about the journey that districts are on." Another interviewee said, "I think it is more helpful to say that schools should be required to use school climate data in their continuous improvement planning efforts and some of their other activities, but it should not be used to evaluate a school."

A concern related to evaluating schools based on school climate data was if leaders believed that evaluation would lead to punitive responses the data may not inform any genuine continuous improvement efforts. One participant said,

In terms to evaluating, which implies punitive action, if that's where that goes, I don't think helps. Again, what will happen, some will be driven - many will be driven to solving the problems or the things that lead to the pain without actually solving the problem. I guess another way to say it is, accountability is important, I value accountability. What I want to avoid is the unintended consequences of accountability which leads people to solve symptoms and not root causes.

Another concern expressed by many respondents was evaluation evolving into an outcome such as a qualitative label, a ranking, or an unfair comparison. One participant described this by saying, "Sometimes when you have any kind of indices of how schools are doing, it becomes a byline - this school is failing or this school isn't safe and we don't want labels. Those aren't helpful." Similarly, another said, “I would rather be acknowledged, supported, celebrated. Because, when we evaluate, we are - on one side of the fence - you're doing it well or not well at all." Another respondent cautioned the use of data by outsiders to qualitatively label schools. This participant said, 
School climate can go badly if you have people that are trying to go after your school system. They say it's unsafe and some of that language is coded. Whenever someone says unsafe, sometimes yeah, okay - you've got problems with fights, suspensions, whatever. But, often times unsafe is about coded language - 'that there are too many minorities in your school so I want to transfer out because your school is unsafe'. So, the data - you always have to be mindful of who is using it and for what purposes.

Another concern when evaluation was perceived to focus on outcomes, rather than continuous improvement was the ranking of schools. When asked about ranking, one participant said, "I am not sure what the usefulness would be ranking schools. Useful it is, the data, to sort of help us focus in areas that are truly a concern. But I don't know how useful it would be to rank one school against the other, based on that data." Another respondent proposed that an outcome focus, such as ranking could lead to gaming. The participant said,

Ranking, I don't think nets us any kind of real long-term gain because of the gaminess that ranking leads folks to. I'll give you an example, the dashboard has suspension rates. We're doing the hard work of absolutely decreasing suspension rates for the right reasons, in terms of reducing the school to prison pipeline, but other districts, what they did, because they had high suspensions - they were using in school suspensions. So, taking them out of class and then putting them in a kind of an in-school detention all. ... So, school districts, they're showing a reduction in school suspension rates, but they're still doing in school suspension, but they're calling it, like a study hall - and getting away with that. So, on paper, their numbers have come down. You see how the system can be gamed and that's why we've got to be careful what we ask for.

Another area of concern related to evaluation focused on outcomes, rather than the process was in a cautious expression of comparability when definitions and instruments used for school climate assessment were inconsistent. One participant described the concern this way: 
If you have one district doing this self-evaluation on their climate to see how it impacts student engagement and student learning, I think that is fine and that would be appropriate. But, if you take that school district and then compare it to a climate survey of the district down the road who has identified, or defined climate in a different manner, then it is not - it can't be used. It is not valid.

Similarly, another cautioned the idea of ranking by saying, "If there isn't one cogent understood widely accepted definition of what climate is then there is no way you can use it to rank schools."

Relatedly, if school climate was to be used in evaluation, the majority of interviewees endorsed the belief that standardized tools were important. One said: "So, these days everything we do is standardized. We are looking at things through the same lens, whether it is instruction or the results of assessments, it is the same lens." Another directly addressed the comparability concern, saying: "I think it's good for the system as a whole so that whether we're comparing districts or schools that there is some reliability because there is standardization of the data." However, not all participants agreed on the level that tools should be standardized.

Several respondents expressed the need for local context and relevance. One said: "I really think it needs to be locally contextualized." Other respondents emphasized the need for balance. One simply said: "Standardization is important, but context is also important." Another participant said,

If we're going to use a survey or instrument across a large population I think it would have to be standardized. ... [but,] is a one size fits all thing useful? I think it has two edges. I think if there was one that was standard issue ... that might be useful from the perspective that it has been vetted. Flip side to that, it may not be specific enough at my particular level, school, district, county - to be as useful as it might be. 
Conversely, another participant cautioned against local standardized, suggesting: "I think standardizing solely at the local level, may cause more confusion and harm because of individual natural tendency to want to compare or maybe to learn from each other." While a number of concerns were revealed in the qualitative data analysis in the importance construct, one consistency was that there was widespread endorsability in the belief that school climate assessment data were important for continuous improvement.

Analysis of quantitative and qualitative findings: Importance. Results from both quantitative and qualitative data analysis suggest that superintendents believe that assessing school climate is important. A benefit of the mixed methods approach was that the qualitative data helped to contextualize the vision of continuous improvement. A side-by-side comparison of quantitative and qualitative responses regarding the use of school climate for evaluation purposes is presented in Figure 9.
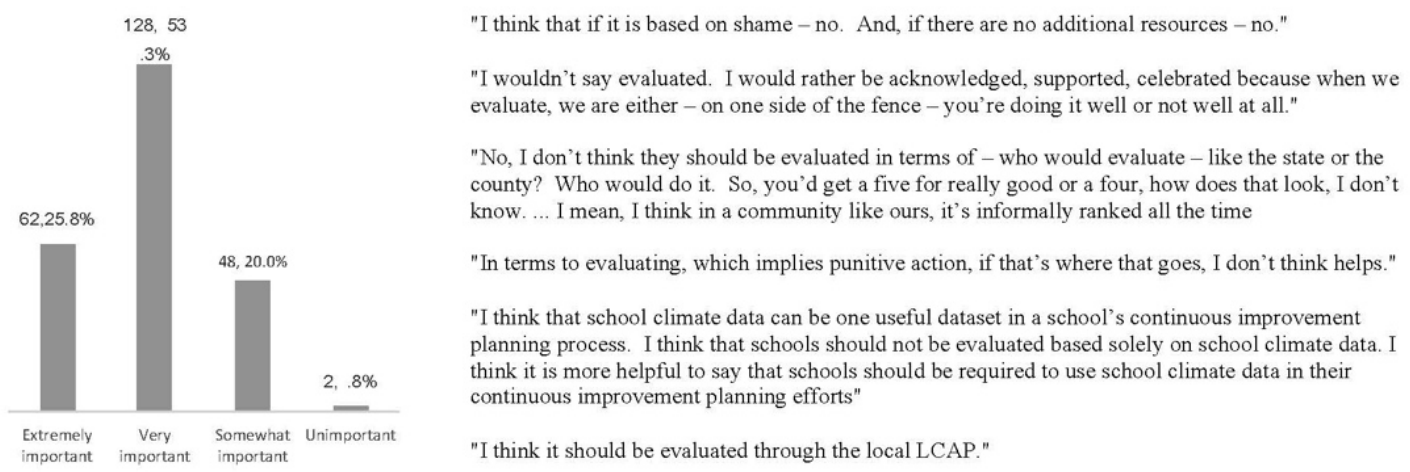

Figure 9. Side-by-side data analysis of importance of evaluation.

For example, the majority of the survey respondents agreed that school climate data should be used for evaluating schools, but slightly more than $20 \%$ indicated uncertainty. The qualitative responses offered potentially relevant considerations for the uncertainty in 
the quantitative responses. As Figure 9 shows, the qualitative responses suggest a wide range of considerations regarding how school climate assessment could be used for evaluation, including whether districts should be evaluated at the local or state level. The qualitative responses also suggest endorsement of the belief in evaluation that is free from labels and punitive consequences, and provided there are resources for the necessary supports for change that are identified by the district.

Another example of qualitative data augmenting the interpretation of the quantitative results was whether or not standardized instruments should be used for school climate assessment and meeting the expectations of the LCFF. Figure 10 presents the variation in participant responses regarding standardization of an instrument.
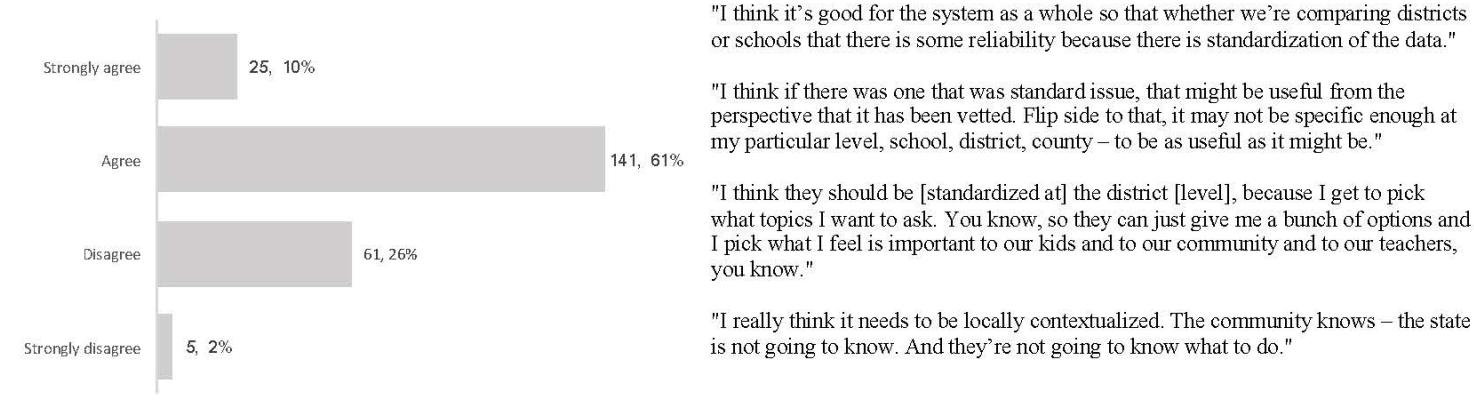

Figure 10. Side-by-side data analysis of importance of standardization.

Figure 10 shows the qualitative responses aligned with the quantitative responses offering a sampling of considerations that were expressed and may influence superintendent perspectives that were reflected in the variation of the quantitative responses. Specifically, the qualitative data suggest that some superintendents have concerns about the relevance of a state wide standardized instrument. 
Analysis of the quantitative findings: Capacity. The capacity construct captured the range of participant endorsability in their beliefs about their own ability to use school climate assessment data for decision making and to lead others in using data for decision making. The following section will report the quantitative, qualitative, and mixed methods findings for this construct. Table 7 provides a summary of the statistics for the items included in the capacity construct.

Table 7

\section{Capacity Construct Summary Statistics}

\begin{tabular}{lccccccc}
\hline Abbreviated item stem & $\begin{array}{c}\text { Strongly } \\
\text { Agree } \\
\text { (1) }\end{array}$ & $\begin{array}{c}\text { Agree } \\
(2)\end{array}$ & $\begin{array}{c}\text { Disagree } \\
(3)\end{array}$ & $\begin{array}{c}\text { Strongly } \\
\text { Disagree } \\
(4)\end{array}$ & $\begin{array}{c}\text { Missing } \\
\text { Values }\end{array}$ & Mean & SD \\
\hline Can make decisions based & 44 & 170 & 9 & 3 & 72 & \multirow{2}{*}{ (1.87 } & .52 \\
on data & $14.77 \%$ & $57.05 \%$ & $3.02 \%$ & $1.01 \%$ & $24.16 \%$ & & \\
Lead others to use data to & 53 & 166 & 3 & 4 & 72 & 1.81 & .52 \\
support students & $17.79 \%$ & $55.70 \%$ & $1.01 \%$ & $1.34 \%$ & $24.16 \%$ & & \\
Lead others to use data to & 50 & 169 & 7 & 2 & 70 & 1.83 & .50 \\
support teachers & $16.78 \%$ & $56.71 \%$ & $2.35 \%$ & $.67 \%$ & $23.49 \%$ & & \\
Lead others to use data to & 43 & 176 & 6 & 2 & 71 & 1.85 & .46 \\
support staff & $14.43 \%$ & $59.06 \%$ & $2.01 \%$ & $.67 \%$ & $23.83 \%$ & & \\
Lead others to use data to & 25 & 169 & 31 & 1 & 72 & 2.03 & .50 \\
support parents & $8.39 \%$ & $56.71 \%$ & $10.40 \%$ & $.34 \%$ & $24.16 \%$ & & \\
Lead others to use data to & 12 & 149 & 56 & 8 & 73 & 2.25 & .60 \\
support community & $4.03 \%$ & $50.00 \%$ & $18.79 \%$ & $2.68 \%$ & $24.50 \%$ & & \\
Make decisions about & 31 & 160 & 25 & 3 & 79 & 2.0 & .56 \\
subgroup needs & $10.40 \%$ & $53.69 \%$ & $8.39 \%$ & $1.01 \%$ & $26.51 \%$ & & \\
Determine budget & 22 & 167 & 27 & 2 & 80 & 2.04 & .51 \\
priorities & $7.38 \%$ & $56.04 \%$ & $9.06 \%$ & $.67 \%$ & $26.85 \%$ & & \\
Build capacity in health & 47 & 157 & 15 & 1 & 78 & 1.86 & .53 \\
and wellness & $15.77 \%$ & $52.68 \%$ & $5.03 \%$ & $.34 \%$ & $26.17 \%$ & & \\
Identify partnerships & 26 & 162 & 23 & 2 & 85 & 2.0 & .52 \\
Identify areas for PD & $8.72 \%$ & $54.36 \%$ & $7.72 \%$ & $.67 \%$ & $28.52 \%$ & & \\
Identify areas for site & 29 & 176 & 9 & 1 & 83 & 1.91 & .43 \\
based collaborations & $9.73 \%$ & $59.06 \%$ & $3.02 \%$ & $.34 \%$ & $27.85 \%$ & & \\
\hline & 28 & 174 & 11 & 2 & 83 & 1.93 & .46 \\
\hline
\end{tabular}


As Table 7 shows, quantitative findings suggested a strong belief in capacity to use data, but the capacity was strongest when directly related to teaching and learning. Overwhelmingly, survey respondents expressed confidence in their own professional abilities to use data for decision making and lead others in using data for decision making. Ninety-five percent of the respondents endorsed the statements that asked about their ability to make decisions based on school climate data and their ability to lead others in using school climate to support students, teachers, and staff.

Further analysis revealed some variation in participant responses. One variation suggested a trend that capacities were believed to be greatest when the data were directly relevant to the classroom, or in direct support of teachers and students. For example, respondents believed that they had strong ability to lead others in support of students (98\%), teachers (95\%), and staff (95\%). Similarly, they believed they had the capacity to use data to inform PD (95\%) and site based collaboration (93\%).

When data were less directly relevant to the classroom unit, the variation in the responses widened. When asked about using data to meet the needs of parents and the community slightly more than $14 \%$ of respondents did not believe they had the capacity to use school climate data to meet the needs of parents and more than $28 \%$ indicated that they did not have the ability to meet the needs of community advocacy groups.

The majority of respondents indicated confidence in their ability to make decisions as is evidenced in the mean $(\mathrm{M}=1.87)$ and the standard deviation $(\mathrm{SD}=.52)$. These statistical values suggested a strong belief in agreement, with little variation across the response options, thus indicating consistency among respondents in their beliefs to make decisions 
based on school climate data. There was a similar trend in the level of confidence that was suggested by the items inquiring about respondents' ability to lead others in using data for decision making. For this item, the mean $(\mathrm{M}=1.81)$ and the standard deviation $(\mathrm{SD}=.52)$ show very little variability in responses and a high overall agreement with the statement.

As previously noted, capacities were strongest, when closest to teaching and learning. For example, as shown in Table 7, the mean for using data to identify areas for professional development $(\mathrm{M}=1.91)$ with a standard deviation $(\mathrm{SD}=.43)$, and similarly, the mean for site based collaboration $(\mathrm{M}=1.93)$ and the standard deviation $(\mathrm{SD}=.46)$ suggested widespread endorsement in believing in data use to identify areas for professional development and site based collaborations. However, across all items in this dimension, the means suggested favorable beliefs in superintendent capacities to use data and the standard deviations show very little variance in these favorable beliefs.

Analysis of qualitative findings: Capacity. The qualitative findings also suggested that superintendents believed in their capacities. However, the qualitative findings also revealed beliefs about potential areas for improvement as well. All respondents reported their own and district capacity as a strength. They, unequivocally, believed in their ability to use school climate data to make decisions. In response to the question, "Do you feel that you have the capacity to make decisions based on school climate data?" all respondents affirmed with comments that asserted their confidence. They said, "Definitely so," and "Yes, within my organization I have authority," and "Yes, I do believe that our office and our team have the capacity to make decisions based on data 
available," and "Yeah, I have a good grasp in terms of data, datasets we're using to be able to make decisions."

While these local leaders believed in their capacities, they also acknowledged that there was room for improvement both within their district and in the community. Several respondents expressed the need for capacity development specifically at the site level. "Right now, we are trying to build capacity across the district with teacher leaders, administrators, parents and district office personnel. So, we're not there yet, but we are working on it." This respondent continued to explain how the district was working to build capacity at the teacher level by offering two distinct, but related examples. The respondent shared, "We just sent a team to the national PBIS conference so we could start that. We are in the infancy stages with MTSS." In the second example, the respondent identified a very specific area of capacity development that was needed. The respondent said, "We believe that we need to do a lot of capacity building with our teachers and administrators to know our own biases." For example, it was offered: "At the winter break, not everyone is Christian, but we say 'What did you do over Christmas break?'... There is some bias there."

Other respondents also expressed the need for specific assessment and data analysis skill sets to be developed at the site level. One interviewee said,

Our site leaders have been so focused on looking and analyzing academic data so they're having to learn how to pull together other datasets that they are now less familiar with and how they manifest in terms of climate and culture, such as attendance, and behavior data. Such as, you know even anecdotal data that I gather from students and staff. So, I think they have not been used to looking at data in that way, other than academic. 
Similarly, supporting capacity development in data interpretation was suggested. One cautioned, "To just look at raw data and make judgement calls -without the right supports along the way, it might just be misleading."

Relatedly, an interviewee exposed a challenge with data interpretation being influenced by the mental models that shape peoples' interpretations and understanding of experiences. This participant said:

I think there are challenges in using data, including in schools and with the community and parents. Much of that has to do with mindset and how we contextualize the data. I think it is unique to schools because most everyone has been in a school [and] they apply their experiences. Their lens. The ways they were raised. Their memory of how discipline occurred for example, or the needs that they and their peers had growing up. And, often, that context is not applicable to use today or [with] today's data.

While some participants expressed a desire in improving capacities to engage parents and the community, others acknowledged the challenges. One participant, who spoke about wanting to increase capacities with parents said, generally, "Parental engagement is one area that we are working very hard on. That's an area where we need to build capacity." Another shared that the accessibility of school climate data may be inadequate: "Almost everything we do here is inclusive and we have a lot of really inclusive decision making, but I am not sure if I was a parent and not an educator that it would all make sense to me."

Others acknowledged that there were community and parent related challenges that impacted their capacity to engage and involve stakeholders outside of the school. One respondent explained a practical problem that districts and schools may face with parents. The participant said, 
Our problem in our community is half of the parents can't even take care of themselves sometimes, let alone the kids.... You know. It's hard to get a hold of them, it's hard to talk to them. There is such a substance abuse problem. The parents are a big part of that. They just feel that it is the school's responsibility to deal with everything, you know. And they don't want to deal with anything. Once they send them to school, it's our problem.

Similar to the quantitative data, the qualitative data suggested capacities were strongest when directly related to teaching and learning. One interviewee explained that the purpose of public schools is teaching and learning and the further away from the classroom, the further away from the purpose. The respondent said: "Our focus in the school district is typically on the students who come to school every day. The influence that we have with parents is, I'll be blunt, it's limited because of time and other constraints." The same respondent continued, "Certainly we can help to shape the thinking of the community, but just like with the parents, you're one step farther away from the child, which is the focal point of our work and the point where we have the most access."

Others expressed the problem even more broadly, opining "I think the concept that a school, a school district on its own, can have a great deal of influence is probably ill founded. In isolation.” Similarly, another said:

I think schools are blamed for a lot of social problems. We're not capable of handling a lot of these problems. So, sometimes the data, if you're just looking at school climate - yeah, there are issues there - but,... you need to look at neighborhoods and communities.

A final perspective that emerged from these data suggested that while leaders believed in their capacity to interpret and use data for decision making, they were not 
always able to use the data to solve problems because of availability or inconsistencies in resources. One participant said,

It's not equitable, there are some schools that have parent liaisons and counselors and family resource centers, but there are most who do not. I believe that some of those resources should be universal and should be accessible at every school district and ideally every school site. But California schools are not funded to have that resource.

Another described this as a tension in terms of the purpose of school climate assessment as a mandate or for continuous improvement. The participant said:

There is so much training that I wish our professionals could go through. But we can only pull out of class and at the same time we are going through a revamp of standards and instructional materials and we're still in a climate of almost needing to provide information to the state because it's a mandate, but not necessarily that it is the best information that we need to provide to help us make decisions.

The quantitative and qualitative findings related to superintendent's beliefs about their capacity to use school climate data for continuous improvement were consistently strong in district capacity and in areas directly related to teaching and learning. There was greater variation in beliefs towards capacities to engage, support, meet the needs of parents and community advocacy groups.

Analysis of quantitative and qualitative findings: Capacity. While there were consistencies across both datasets, there was also variation in some of the responses. Specifically, the qualitative data offer some potential insight into the variation in responses to those items that inquired about capacities in dimensions that were further from direct teaching and learning. In the quantitative findings, 39 respondents disagreed in their capacity to meet parent needs, and 58 respondents disagreed with the statement that they used data to help meet the needs of community advocacy groups. A smaller 
number (23), indicated that they were not able to use data to identify areas for partnerships. Relative to these items, which all represented some distance from direct teaching and learning, the qualitative data offered some considerations that may explain some of the contextual factors that influence parent and community relations with schools and districts. Figure 11 presents a side-by-side view of the quantitative results for two items, meeting the needs of parents and community advocacy groups, next to a sampling of qualitative responses that may offer relevant context for some of the variation in the quantitative results related to parent and community engagement.

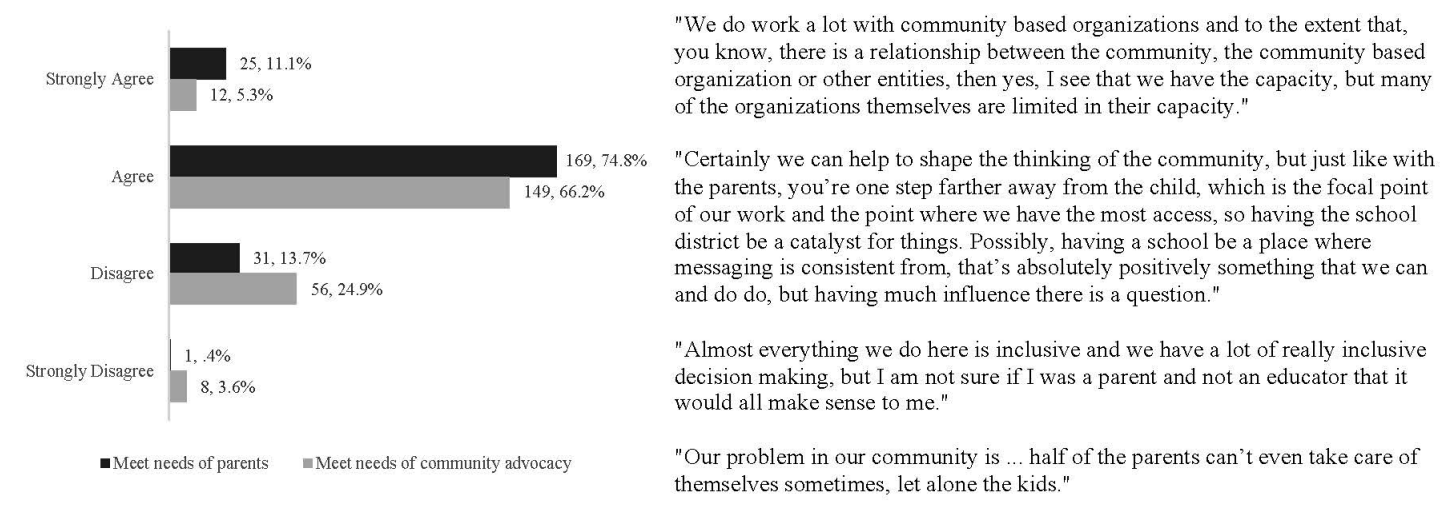

Figure 11. Side-by-side quantitative and qualitative data showing capacity to meet the needs of parent and/or community advocacy groups.

As shown in Figure 11, there were participants who disagreed with the statement about their capacity to meet the needs of parent (Disagree $=31$, Strongly Disagree $=1$ ) and advocacy groups (Disagree $=56$, Strongly Disagree $=8$ ). The qualitative data suggested that there were a number of considerations influencing the relationships that schools have with their communities, including accessibility of information and community-level 
problems that affect family wellbeing. It is possible that community dynamics, influenced the variability in the quantitative responses to this item.

Analysis of quantitative findings: Trustworthiness. The trustworthiness construct captured the endorsability of superintendent beliefs in trusting school climate assessment data. The results suggested that there may be a range of beliefs that exist and understanding the trustworthiness of school climate data is complex and multidimensional.

The majority of superintendents endorsed the idea that it is important to adopt a school climate survey that has strong technical evidence $(88 \%)$ and that instruments in use must be technically sound, particularly when capturing the experiences of vulnerable populations $(87 \%)$. However, the results of this study suggest a degree of uncertainty when it comes to trusting the data that are obtained from the school climate surveys. A summary of statistics for items in the trustworthiness construct is presented in Table 8 .

Table 8

Trustworthiness Construct Summary Statistics

\begin{tabular}{|c|c|c|c|c|c|c|c|c|}
\hline Abbreviated item stem & $\begin{array}{c}\text { Strongly } \\
\text { Agree } \\
(1) \\
\end{array}$ & $\begin{array}{l}\text { Agree } \\
\text { (2) }\end{array}$ & $\begin{array}{l}\text { Not Sure } \\
\text { (3) }\end{array}$ & $\begin{array}{c}\text { Disagree } \\
(4)\end{array}$ & $\begin{array}{c}\text { Strongly } \\
\text { Disagree } \\
\text { (5) } \\
\end{array}$ & $\begin{array}{c}\text { Missing } \\
\text { Values } \\
\end{array}$ & Mean & SD \\
\hline $\begin{array}{l}\text { All the useful } \\
\text { information we need }\end{array}$ & $\begin{array}{c}18 \\
6.04 \%\end{array}$ & $\begin{array}{c}98 \\
32.89 \%\end{array}$ & $\begin{array}{c}34 \\
11.41 \%\end{array}$ & $\begin{array}{c}52 \\
17.45 \%\end{array}$ & $\begin{array}{c}9 \\
3.02 \%\end{array}$ & $\begin{array}{c}87 \\
29.19 \%\end{array}$ & 2.70 & 1.066 \\
\hline Fair and unbiased & $\begin{array}{c}4 \\
1.34 \%\end{array}$ & $\begin{array}{c}67 \\
22.48 \%\end{array}$ & $\begin{array}{c}96 \\
32.21 \%\end{array}$ & $\begin{array}{c}42 \\
14.09 \%\end{array}$ & $\begin{array}{c}3 \\
1.01 \%\end{array}$ & $\begin{array}{c}86 \\
28.86 \%\end{array}$ & 2.87 & .796 \\
\hline $\begin{array}{l}\text { Important to have } \\
\text { technical evidence }\end{array}$ & $\begin{array}{c}55 \\
18.46 \%\end{array}$ & $\begin{array}{c}134 \\
44.97 \%\end{array}$ & $\begin{array}{c}15 \\
5.03 \%\end{array}$ & $\begin{array}{c}8 \\
2.68 \%\end{array}$ & $\begin{array}{c}0 \\
0 \%\end{array}$ & $\begin{array}{c}86 \\
28.86 \%\end{array}$ & 1.88 & .686 \\
\hline $\begin{array}{l}\text { Depicts needs of } \\
\text { subgroups }\end{array}$ & $\begin{array}{c}6 \\
2.01 \%\end{array}$ & $\begin{array}{c}93 \\
31.21 \%\end{array}$ & $\begin{array}{c}64 \\
21.48 \%\end{array}$ & $\begin{array}{c}43 \\
14.43 \%\end{array}$ & $\begin{array}{c}4 \\
1.34 \%\end{array}$ & $\begin{array}{c}88 \\
29.53 \%\end{array}$ & 2.74 & .881 \\
\hline $\begin{array}{l}\text { Technically sound } \\
\text { for subgroups }\end{array}$ & $\begin{array}{c}56 \\
18.79 \%\end{array}$ & $\begin{array}{c}129 \\
43.29 \%\end{array}$ & $\begin{array}{c}19 \\
6.38 \%\end{array}$ & $\begin{array}{c}7 \\
2.35 \%\end{array}$ & $\begin{array}{c}0 \\
0 \%\end{array}$ & $\begin{array}{c}87 \\
29.19 \%\end{array}$ & 1.89 & .691 \\
\hline Any data useful & $\begin{array}{c}44 \\
14.77 \%\end{array}$ & $\begin{array}{c}136 \\
45.64 \%\end{array}$ & $\begin{array}{c}21 \\
7.05 \%\end{array}$ & $\begin{array}{c}8 \\
2.68 \%\end{array}$ & $\begin{array}{c}1 \\
.34 \%\end{array}$ & $\begin{array}{c}88 \\
29.53 \%\end{array}$ & 1.98 & .712 \\
\hline
\end{tabular}


Table 8 (continued).

\begin{tabular}{lcccccccc}
\hline Abbreviated item stem & $\begin{array}{c}\text { Strongly } \\
\text { Agree }\end{array}$ & $\begin{array}{c}\text { Agree } \\
(1)\end{array}$ & $\begin{array}{c}\text { Not Sure } \\
(3)\end{array}$ & $\begin{array}{c}\text { Disagree } \\
(4)\end{array}$ & $\begin{array}{c}\text { Strongly } \\
\text { Disagree } \\
(5)\end{array}$ & $\begin{array}{c}\text { Missing } \\
\text { Values }\end{array}$ & Mean & SD \\
\hline Data do not allow & 0 & 15 & 21 & 155 & 20 & 87 & 3.85 & .678 \\
decision making & $0 \%$ & $5.03 \%$ & $7.05 \%$ & $52.01 \%$ & $6.71 \%$ & $29.19 \%$ & & \\
Trust data for & 6 & 137 & 56 & 10 & 1 & 88 & 2.35 & .640 \\
interventions & $2.01 \%$ & $45.97 \%$ & $18.79 \%$ & $3.36 \%$ & $.34 \%$ & $29.53 \%$ & & \\
Trust data to inform & 6 & 142 & 48 & 13 & 1 & 88 & 2.33 & .659 \\
teacher PD & $2.01 \%$ & $47.65 \%$ & $16.11 \%$ & $4.36 \%$ & $.34 \%$ & $29.53 \%$ & & \\
Trust for site based & 5 & 123 & 60 & 16 & 1 & 93 & 2.44 & .694 \\
collaborations & $1.68 \%$ & $41.28 \%$ & $20.13 \%$ & $5.37 \%$ & $.34 \%$ & $31.21 \%$ & & \\
& 11 & 105 & 74 & 17 & 0 & 91 & 2.47 & .722 \\
Our surveys valid & $3.69 \%$ & $35.23 \%$ & $24.83 \%$ & $5.70 \%$ & $0 \%$ & $30.54 \%$ & & \\
& 9 & 97 & 81 & 19 & 1 & 91 & 2.55 & .742 \\
Our surveys reliable & $3.02 \%$ & $32.55 \%$ & $27.18 \%$ & $6.38 \%$ & $.34 \%$ & $30.54 \%$ & & \\
& & & & & & & & \\
\end{tabular}

As Table 8 shows, there was more variance in this construct than the other two, suggesting the need for further exploration and research. There were three survey items in this construct where more than $15 \%$ of the respondents disagreed with the statements: a) school climate data give all the useful information necessary; b) surveys are fair and unbiased; and c) surveys accurately depict the needs of subgroups. The means for the three items all showed a slightly favorable average, but the variance was high and both the mean and standard deviations for all three are greater than any of the other items included in this construct. For all three items, between 15\%-20\% did not agree and 11\%$30 \%$ were not sure. The means were all falling in between agree and not sure $(M=2.70$, $\mathrm{M}=2.87, \mathrm{M}=24)$ and the standard deviations $(\mathrm{SD}=1.1, \mathrm{SD}=.80, \mathrm{SD}=.88)$ suggested substantial variation in these beliefs among the respondents.

This construct also explored trust in data uses. Respondents were asked about using data specifically for decision making and informing interventions, professional development, and site-based collaborations. The majority of survey respondents endorsed 
the belief that school climate data was trusted enough to invest in interventions, professional development, and site-based collaborations. However, a significant number of respondents were unsure. Table 9 shows the responses for four items with a lot of variance in the response options regarding trusting school climate data for use in continuous improvement efforts.

Table 9

Trust in Using Data for Continuous Improvement

\begin{tabular}{lccc}
\hline Item & Agree* & Disagree** & $\begin{array}{c}\text { Not } \\
\text { Sure }\end{array}$ \\
\hline $\begin{array}{l}\text { School climate survey data give us all the useful } \\
\text { information we need to make good decisions for } \\
\text { continuous improvement. }\end{array}$ & $54 \%$ & $30 \%$ & $16 \%$ \\
$\begin{array}{l}\text { We can trust the school climate survey data to invest in } \\
\text { particular interventions to improve school climate. }\end{array}$ & $68 \%$ & $5 \%$ & $27 \%$ \\
$\begin{array}{l}\text { We can trust the school climate survey data to inform the } \\
\text { choice of teacher professional development to improve } \\
\text { school climate. }\end{array}$ & $70.5 \%$ & $6.5 \%$ & $23 \%$ \\
$\begin{array}{l}\text { We can trust the school climate survey data to target } \\
\text { specific site based collaborations to improve school } \\
\text { climate. }\end{array}$ & $63 \%$ & $8 \%$ & $29 \%$ \\
\hline
\end{tabular}

Note. *Agree column includes both "agree" and "strongly agree" responses.

**Disagree column includes both "disagree" and "strongly disagree" responses.

As shown in Table 9, the majority of respondents indicated that they believed that school climate data would give all the necessary data for continuous improvement, but there were $30 \%$ who did not agree. The findings from this study suggested that data were not unequivocally trusted by school district leaders. On the contrary, survey respondents indicated uncertainty related to the quality and credibility of data that were obtained 
through the school climate surveys that were being used. Table 10 presents a summary of this uncertainty for the items with the highest frequency of "not sure" responses.

Table 10

High Uncertainty in Trustworthiness of Data

Item

"Not Sure"

School climate surveys, for the most part, are unbiased and fair. $45.3 \%$

The school climate data we use accurately depicts the needs of all $30.5 \%$ our student subgroups.

The school climate surveys we use are valid. $35.7 \%$

The school climate surveys we use are reliable.

$39.1 \%$

Many respondents (between 30\% and 45\%) were not sure if school climate surveys were able to accurately depict the needs and experiences of student subgroups, or if surveys were fair, unbiased, valid, or reliable. As Table 10 shows, a significant percentage of superintendents were not able to endorse their trust in the data regarding the instrument properties and relevance to all students.

Analysis of qualitative findings: Trustworthiness. It is important to understand the degree to which leaders' trust school climate data because the same leaders are being asked to use these data to inform (or guide) their continuous improvement efforts in creating and sustaining a positive school climate. The extent to which leaders trust that data are accurately representing their school/district populations and stakeholders will impact how data are used. The qualitative data analysis also captured a belief in the importance of quality instruments as well as variation in their trust in the data. 
Interviewees were asked about their beliefs in the importance of using tools with psychometric evidence of effectiveness. All but one participant said "It is so important." The one respondent who was cautious first expressed the importance of quality tools, but then added, "Those are coded words. You can call anything unfair and biased. So, I am very skeptical.... What are the metrics and what are you looking at? Do the metrics include qualitative data not just quantitative data?" While respondents agreed that tools to assess school climate needed to be rigorously developed, there was variation in responses when asked about their level of trust in the data they acquired and used.

Four different perspectives emerged from these interviews. First, data were trusted because the responses were believable because the data were consistent, or data confirmed their beliefs, or they trusted the honesty of the survey respondents. Some interviewees felt that the data were trustworthy because they were aligned with their own beliefs, experiences, or observations. "It validates what we hear from parents. It validates what we see." Another felt they were trustworthy because they were consistent. The respondent said, “They're pretty consistent from year to year and from what we hear when we meet with parents, student, and staff." Another trusted the results because they believed the responses were honest, "The results come back and they are pretty honest statements. I trust that the kids are taking it and they're being pretty honest about it.”

Second, data were believed to be trustworthy because of the conviction that all data are useful. One participant said, "We have a growth mindset. ... Even when the data is negative, it is still good because it is telling us something." Another respondent said, "I think it's all good. I think - you know - there is something valuable." 
Third, data were trusted because they were developed by experts. This perspective focused on schools as the end-user and their responsibility was to ensure that data collection procedures were followed, but it was the responsibility of the survey developer to ensure the quality of the instrument. Several respondents who represented this perspective trusted the instrument because of its familiarity. "They have a reputation. They have been around for a while." Another said: "I feel comfortable with the survey because it's been around for a while and I've used it before." Two respondents spoke specifically about a responsibility to ensure that the procedures were followed. This was explained by one participant who reassured that the surveys were "Administered in appropriate ways; procedures are followed."

Others indicated their trust in the survey developer, saying, "I would assume that if the tool is created that it would be reliable and valid." Another said, "The instrument was developed in consultation with a company that has experience building these surveys and also some experience in interpreting the data." Finally, another offered that because "the tools that we use are not locally developed we kind of feel like the tools that we are implementing are valid and reliable."

The final perspective offered concern or skepticism when it came to trusting the data. Some respondents expressed uncertainty related to some qualities of the instruments, one simply retorted. "I hope they are unbiased." Others expressed concern for data analysis that over simplifies the complexity of people's experiences in our schools. The participant said, "When there is a reliance on numbers or trying to oversimplify a very complex set of data and information - it is harmful." Others expressed a concern for data 
misrepresenting experiences because the data are not dynamic, but static. One participant said, "I think that instruments that are point in time and in and of itself are thereby not as holistic and really can't assess school climate." Similarly, another said, "We believe all data is point in time and it cannot be trusted in and of itself - by itself." Another participant offered a suggested solution, proposing that "A lot of the data that we are using are perceptions at a time. I think the better way is [to] see patterns."

Analysis of quantitative and qualitative findings: Trustworthiness. Analysis of both quantitative and qualitative data suggest a range of beliefs that may exist among superintendents and their trust in the data. There was more variation in the quantitative results, although uncertainty emerged in the results from both datasets. Evidence suggested that there was more complexity in this construct than the other two and further inquiry is needed. Some of the uncertainty is presented in Figure 12, which shows sideby-side responses related to superintendent trust in the data being fair and unbiased.

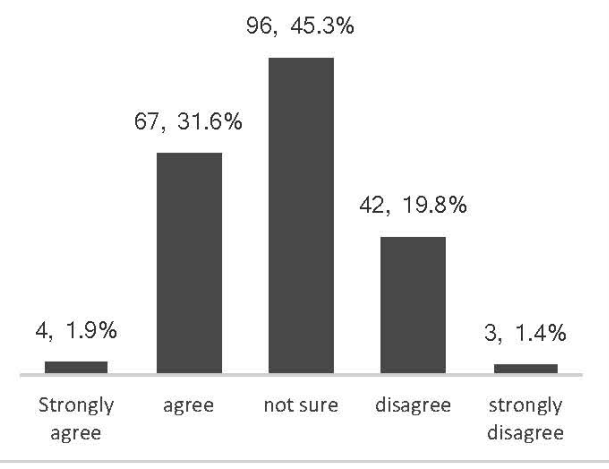

"I think there - the risk, always, that we have implicit or unknown bias and so even the developers of the instrument, seeing the world through their lens and an inability to perhpaps, recognize their own bais."

"I don't know. A lot of times when we are looking at something, we typically ask, 'What did you put into place to make sure it was it vetted, how was it vetted?' but at the end of the day, um, I'm not sure. To be honest with you. I don't know."

"Those are coded words. You can call anything unfair and biased. So, I am very skeptical. What are the metrics and what are you looking at? Do the metrics include qualitative data not just quantitative data?"

Figure 12. Side-by-side quantitative and qualitative data visualizing trustworthiness construct fair and unbiased surveys. 
As Figure 12 illustrates, there was uncertainty in both the quantitative and the qualitative findings. Just under half of the respondents were not sure if the surveys used for school climate assessment were fair and unbiased. The qualitative results suggest that the uncertainty was in both the development of instruments and in the data, that were obtained.

\section{Research Question Three}

This section presents the findings of the relationship between superintendent beliefs and selected variables collected in the demographic data from the survey. It was expected that school climate would be more enthusiastically endorsed by some superintendents than others. It was hypothesized that urban, diverse, high poverty district leaders would endorse school climate as an indicator of equity; that women would endorse school climate more because they are more commonly associated with caring approaches to leadership; that the higher the education the more likely to strongly endorse school climate assessment because of a commitment to data driven/informed decision making; and that the longer a superintendent was in their position the less likely they would be to enthusiastically endorse school climate assessment because they may harbor more skepticism towards changing political priorities and educational reform efforts.

To analyze response patterns, a Rasch Partial Credit Model within the item response approach was employed and fit the data adequately in the capacity and trustworthiness constructs. Two items were dropped from the importance construct due to poor item fit. The item response model fitted by ConQuest (Adams, Wu, \& Wilson, 2012) was a unidimensional random coefficients multinomial logit (URCML) model. A Wright Map 
was developed using ConQuest to visually illustrate the distribution of respondents and items for each of the three constructs that were explored in this study. Each of the three Wright Maps are included as Appendix F.

The unidimensional Rasch Partial Credit Model gave an estimate of person ability (or in this study, belief) on the logit scale (which is the mathematical unit that is used in Rasch measurement). The EAP (Expected A Posterior) estimate of person belief was used for the multiple regression to explore potential relationships between belief scores and eight explanatory variables: English learner enrollment, FRPM eligibility, SPED enrollment, age, experience, urbanicity, education, and gender. EL enrollment, FRPM eligibility, SPED enrollment, age, and experience were treated as continuous variables, as described in chapter three. A reference group was used to analyze urbanicity, education, and gender. The reference groups were rural, master degree, and female. The results from this study show that there were four explanatory variables that were statistically significant at the .05 level, which means that there was a $95 \%$ probability that the results were not due to random chance.

Importance construct. For the importance construct, the mean belief on the logit scale was 0.0012 with a standard deviation of 1.4846 and a range of -4.3204 to 4.3618 . These results suggest that there was more variability from the mean estimated person belief on the logit scale than the results for the trustworthiness scale. The estimate of person belief for importance was used to perform the multiple regression exploring each of the eight different explanatory variables. 
There was a statistically significant difference at the .05 level ( $\mathrm{t}=1.99$, CI [.0047-

1.2121]) between rural and suburban superintendents in the importance construct.

Compared to superintendents who worked for districts in rural areas, superintendents who worked for districts in suburban areas had an average estimated logit score of .6084

higher. The results suggest that superintendents for districts in suburban areas were more likely to endorse the statements that were included in the importance construct compared to superintendents in rural areas. Table 11 presents the regression results for the importance construct.

Table 11

Regression Summary for Importance Construct

\begin{tabular}{lrrrrr} 
& & & & \multicolumn{2}{c}{ CI 95\% } \\
Variable & Coef. & $\mathrm{t}$ & $\mathrm{SE}$ & $\mathrm{LL}$ & $\mathrm{UL}$ \\
\hline EL & 0.0057 & 0.76 & 0.0075 & -0.0092 & 0.0206 \\
FRPM & 0.0036 & 0.57 & 0.0064 & -0.009 & 0.0163 \\
SPED & 0.0027 & 0.12 & 0.0216 & -0.04 & 0.0454 \\
Age & -0.1802 & -1.02 & 0.1762 & -0.5281 & 0.1677 \\
Experience & -0.0784 & -0.69 & 0.1132 & -0.302 & 0.1451 \\
Urban & 0.4073 & 1.08 & 0.3764 & -0.3357 & 1.1504 \\
Suburban* & 0.6084 & 1.99 & 0.3058 & 0.0047 & 1.2121 \\
BA & -0.4885 & -0.49 & 1.001 & -2.4642 & 1.4871 \\
EdD & -0.2295 & -0.81 & 0.2818 & -0.7859 & 0.3269 \\
PhD & -0.1225 & -0.25 & 0.4895 & -1.089 & 0.844 \\
Female & 0.0708 & 0.27 & 0.2637 & -0.4498 & 0.5915 \\
Intercept & 0.3014 & 0.37 & 0.8051 & -1.288 & 1.8908 \\
\hline
\end{tabular}

Note. $\mathrm{N}=298$, Coef.=regression coefficient, $\mathrm{SE}=$ standard error, $\mathrm{CI}=$ confidence interval, $\mathrm{LL}=$ lower limit, $\mathrm{UL}=$ upper limit, $*=$ significant at the $\mathrm{p}<.05$ level.

These data do not show any additional statistically significant (at the .05 level) relationships between the independent explanatory variables and the dependent (estimated personal belief score for the importance scale) variable. As Table 11 shows, at the .05 significance level, there were no statistically significant differences between 
superintendents by student demographics, as analyzed by English learners, Free and Reduced Price Meal eligibility, and special education, or by personal characteristics.

Capacity construct. For the capacity construct, the mean belief estimate on the logit scale was 0.0122 with a standard deviation of 1.4443 and a range of -5.4933 to 4.8679 . These results suggested that there was more variability from the mean estimated person belief on the logit scale than the results for the trustworthiness scale. The estimate of person belief for capacity was used to perform the multiple regression exploring the eight different explanatory variables. Table 12 presents the regression results for the capacity construct.

Table 12

Regression Summary for Capacity Construct

\begin{tabular}{lrrcrc} 
& & & & \multicolumn{2}{c}{ CI 95\% } \\
Variable & Coef. & $\mathrm{t}$ & $\mathrm{SE}$ & $\mathrm{LL}$ & $\mathrm{UL}$ \\
\hline EL & -0.0108 & -1.64 & 0.0066 & -0.0238 & 0.0022 \\
FRPM & -0.0019 & -0.34 & 0.0056 & -0.0129 & 0.0091 \\
SPED & 0.0118 & 0.63 & 0.0189 & -0.0255 & 0.0491 \\
Age & 0.183 & 1.19 & 0.1538 & -0.1206 & 0.4866 \\
Experience & -0.1226 & -1.24 & 0.0988 & -0.3177 & 0.0725 \\
Urban* & 0.6826 & 2.08 & 0.3284 & 0.0342 & 1.3311 \\
Suburban & 0.0317 & 0.12 & 0.2669 & -0.4951 & 0.5585 \\
BA & -0.0158 & -0.02 & 0.8733 & -1.7399 & 1.7083 \\
EdD* & -0.6013 & -2.44 & 0.2459 & -1.0868 & -0.1157 \\
PhD* & -1.047 & -2.45 & 0.4272 & -1.8909 & -0.2039 \\
Female & 0.3422 & 1.49 & 0.2301 & -0.1121 & 0.7966 \\
Intercept & -0.0084 & -0.01 & 0.7026 & -1.3955 & 1.3787 \\
\hline Nore & . & &
\end{tabular}

Note. $\mathrm{N}=298$, Coef.=regression coefficient, $\mathrm{SE}=$ standard error, $\mathrm{CI}=$ confidence interval, $\mathrm{LL}=$ lower limit, $\mathrm{UL}=$ upper limit, $*=$ significant at the $\mathrm{p}<.05$ level.

As Table 12 shows, there was a statistically significant difference at the .05 level when comparing superintendents who work for districts in rural areas to superintendents 
who work for districts in urban areas $(\mathrm{t}=2.08$, CI [0.0342-1.3311]). The superintendents who worked in districts in urban areas had an average estimated logit score of .6826 higher than superintendents who work for districts in rural areas, which means that suburban superintendents were more likely to endorse the statements in the capacity construct when compared to rural superintendents.

The results, as shown in Table 12, also revealed a relationship between education and the capacity construct. When compared to superintendents with a master degree, superintendents with a Doctorate in Education (EdD) had an estimated logit score that was -.6013 lower, which means that they were less likely to endorse the statements that were included in this construct when compared to superintendents with a master degree. This result was statistically significant at the .05 level ( $\mathrm{t}=-2.44, \mathrm{CI}:[-1.0868$ to -0.1157$])$. There was also a statistically significant difference at the.05 level $(\mathrm{t}=-2.45$, CI [-1.8989 to-0.2039]) when comparing superintendents with a master degree to superintendents with a Doctorate in Philosophy $(\mathrm{PhD})$. The superintendents with a PhD had an estimated logit score of -1.047 lower, which means that they were significantly less likely to endorse the statements that were included in the capacity construct when compared to superintendents with a master degree.

Trustworthiness construct. For the trustworthiness construct, the mean belief estimate on the logit scale was -0.001 with a standard deviation of .5803 and a logit range of -1.7258 to 2.0382 . These results suggested that there was not as much variability from the mean estimated person belief on the logit scale when compared to the other two constructs that were measured in this study. The estimate of person belief for 
trustworthiness was used to perform the multiple regression exploring the eight different explanatory variables. Table 13 presents the regression results for the trustworthiness construct.

Table 13

Regression Summary for Trustworthiness Construct

\begin{tabular}{lrrrrr} 
& & & & \multicolumn{2}{c}{ CI 95\% } \\
Variable & Coef. & $\mathrm{t}$ & $\mathrm{SE}$ & \multicolumn{1}{c}{ LL } & \multicolumn{1}{c}{$\mathrm{UL}$} \\
\hline EL & 0.0021 & 0.66 & 0.0032 & -0.0042 & 0.0083 \\
FRPM & 0.0012 & 0.47 & 0.0027 & -0.004 & 0.0065 \\
SPED & -0.0033 & -0.36 & 0.0091 & -0.0212 & 0.0146 \\
Age & -0.049 & -0.66 & 0.0738 & -0.1948 & 0.0969 \\
Experience & 0.0588 & 1.24 & 0.0475 & -0.0349 & 0.1525 \\
Urban & 0.0883 & 0.56 & 0.1578 & -0.2232 & 0.3998 \\
Suburban & 0.1048 & 0.82 & 0.1282 & -0.1483 & 0.3579 \\
BA & 0.3486 & 0.83 & 0.4195 & -0.4796 & 1.1768 \\
EdD & -0.0453 & -0.38 & 0.1181 & -0.2785 & 0.188 \\
PhD & -0.0043 & -0.02 & 0.2052 & -0.4095 & 0.4008 \\
Female & 0.1174 & 1.06 & 0.1105 & -0.1009 & 0.3356 \\
Intercept & -0.163 & -0.48 & 0.3375 & -0.82293 & 0.5033 \\
\hline Note. N & &
\end{tabular}

Note. $\mathrm{N}=298$, Coef.=regression coefficient, $\mathrm{SE}=$ standard error, $\mathrm{CI}=$ confidence interval, $\mathrm{LL}=$ lower limit, $\mathrm{UL}=$ upper limit.

As Table 13 shows, there were no statistically significant differences at the .05 level in the estimated person belief score and the eight explanatory variables. For example, the EL enrollment regression coefficient of 0.0021 and the confidence interval with a lower limit of -.0042 and an upper limit of 0.0083 means that the belief scores could be negative, thus as EL enrollment increases, belief in the trustworthiness of data decreases; belief scores could be zero, which means that there was no difference between the belief score and EL enrollment; or, belief scores could be positive, which means that as EL enrollment increases, belief in the trustworthiness of data also increases. In this case, 
since there was not a statistically significant difference at the .05 level this construct and any potential relationships between superintendent beliefs and personal characteristics or school context requires further study.

In conclusion, this chapter presented the findings for this mixed methods study that explored the district practices and superintendent beliefs towards school climate assessment. The findings revealed that school climate assessment is believed to be important for visions of continuous improvement; superintendents believe they have capacities to use school climate assessment data for continuous improvement; and, they believe it is important to have quality tools to use for assessment. The variability across these overarching themes and the implications of this study are discussed in the next chapter. 


\section{Chapter Five: Discussion}

\section{Summary of the Study}

As previously articulated, academic outcomes and health outcomes are interconnected and reciprocal at both individual and population levels (Basch, 2011) and contextual factors make a difference in both (Basch, 2011; Berliner, 2014; Durlak et al., 2011; Farrington et al., 2012). As a result, there has been an increasing trend to incorporate some of these out of school factors in measures of school success. In California, this trend is evident in the implementation of the state's revised public school finance system, LCFF, which identified school climate as a required statewide measure of accountability.

Integrating school climate into school plans can invite discussion and understanding about school experiences in new ways. School environments that pose risks to healthy development are deeply in need of greater understanding, just as the environments that foster positive health are in demand. School climate, if adequately understood and assessed, can influence changes to improve the health of the school. If school climate is not well understood or is poorly assessed, it cannot adequately guide change and may not accurately represent the dynamic complexity of the factors that influence healthy school environments.

The extant literature clearly indicated the importance of school climate on academic and health outcomes, and furthermore, the state of California is committed to ensuring that schools work to continuously improve school climate and conditions that support teaching and learning. A current challenge is that there are inconsistencies in how school 
climate is defined, thus impacting how it is measured and subsequently influencing how well data can be used to facilitate continuous improvement efforts.

The purpose of this study was to explore superintendent beliefs and local practices in school climate assessment throughout California. Knowing what schools are doing and the beliefs of superintendents regarding the importance of school climate assessment, their capacity to use data, and their trust in the data will help statewide leaders, policy makers, researchers, and school personnel improve their efforts to support local school improvement plans. This chapter explains the implications for each of the three research questions and presents relevant conclusions and recommendations.

\section{Summary of RQ1: Implications}

The first research question was what instruments and practices are currently being used by California public schools to assess and use school climate data for continuous improvement. This question was designed to identify the instruments that districts were using to assess school climate and explore some of the practices that were employed by districts to collect, analyze, and use school climate data for continuous improvement. The evidence from this study showed widespread use of two instruments, the CHKS and PBIS. Site developed instruments were the third most commonly used assessment tools. This study presented evidence that many districts were using multiple methods to assess school climate, including more than one survey, observations, and focus groups. Findings also suggested that, while multiple stakeholders commonly participated, leaders highly endorsed having data about students, teachers, and staff and they prioritized staff involvement when using data to make decisions. 
Based on the results of this study, it can be concluded that CHKS is widely used but a new trend may be emerging. CHKS was historically required of schools receiving "Tobacco-Use Prevention Education Funding" and therefore, the staggered year survey may have been informally institutionalized. Results showing the range of tools in use could signal an increasing trend in adopting other instruments, particularly as the assessment industry continues to evolve in response to the changing state needs.

\section{Summary of RQ2: Implications}

The second research question was designed to capture superintendent beliefs along three constructs: the importance of school climate assessment, the capacity to use data for decision making, and trustworthiness in the data. The study findings supported the mandate for school climate assessment for continuous improvement and confirmed what has been supported in the literature: school climate is important and it makes a difference. Both quantitative and qualitative data revealed a strong endorsement of the importance of school climate and high capacities among district leadership to use data to improve conditions of teaching and learning. Leaders also believed it was important to have quality instruments so data obtained were relevant and meaningful.

While the importance of school climate was largely supported, these results highlighted how local education agencies can maximize the opportunities presented in the LCFF through additional supports and resources. Based on study results, it can be concluded that there is a need to improve leader capacities in interpreting data and using data to productively guide continuous improvement efforts and there is a state level need 
in providing more avenues to assist local districts and counties implement changes that are identified in their assessments.

\section{Summary of RQ3: Implications}

The third research question was designed to explore potential relationships in beliefs towards school climate assessment and personal characteristics or school contexts. The

findings from the regression analyses found that there were differences in the beliefs of superintendents who worked for rural districts compared to those in either suburban or urban districts. There was a statistically significant difference, at the .05 level, between rural superintendents and suburban superintendents in the importance construct and between rural superintendents and urban superintendents in the capacity construct. Therefore, the results of this study propose that there is more to learn about the nuances of assessing school climate in rural areas.

There was also a statistically significant difference, at the .05 level, in the capacity construct between superintendents with a master degree and superintendents with an EdD or a PhD. From these findings, it can be inferred that there are differences in the way that education levels and degree pathways influence beliefs towards school climate assessment. Interestingly, these findings suggested that with more education, superintendents were less likely to endorse statements about their capacity to use school climate assessment data for continuous improvement efforts. It is possible that with increased education, superintendents become more critical of reform strategies or assessment approaches, or that they believe that the more they know, the more they know they do not know. An alternative consideration is that there may be relationships that 
were not discernable in this dataset because the scale is still in development and the reliability of the three scale needs to be improved.

While only a few explanatory variables were found to be statistically significant, at the .05 level, in influencing the belief scores for each of the three constructs, the fact that there were no other relationships is an interesting finding. It is feasible to propose that the greater the differences between and among superintendents the more we would expect inconsistencies and variability in interpretation and approach to implementation of school climate assessment processes. If beliefs are congruent, the policy recommendations may be easier to implement and sustain. It is possible that an improved instrument would capture more relationships, but currently, a meaningful starting point is to explore the experiences of rural superintendents to better understand the rural contexts that influence school climate assessment. Another inquiry could explore the role of education in assessment literacy for educators and education leaders.

From the results of this study, regardless of superintendent education level and rural nuances, it can be concluded that local leaders bring a range of perspectives and expectations and commitments to their interpretation and implementation of the law and local education agencies will, sometimes, need more help and resources to implement the changes identified through their school climate assessment data.

\section{Discussion}

In 2017 the SCCWG, which was the state appointed work group established to provide guidelines and recommendations to the SBE regarding the implementation of the 
school climate assessment accountability expectation, proposed the adoption of the following definition (SCCWG, 2017):

School conditions and climate refers to the character and quality of school life. This includes the values, expectations, interpersonal relationships, materials and resources, supports, physical environment, and practices that foster a welcoming, inclusive, and academically challenging environment. Positive school conditions and climate ensure people in the school community (students, staff, family, and community) feel socially, emotionally, and physically safe, supported, and connected to the school, and engaged in learning and teaching.

This panel of experts reviewed the literature and engaged in discourse for more than a year before proposing the above definition of school climate to the SBE and the SPI. A definition of school climate is important to ground policy makers, state officials, and local leaders in a consistent understanding of what school climate is and is not. As both the literature and this study suggest, there is a need to have an agreed upon understanding of school climate, including a definition, that can guide assessment practices. This is particularly important in California where school climate assessment is included in the state accountability expectations.

As was previously discussed, the LCFF signaled a significant change in California education policy by decentralizing decision making and shifting accountability from a single measure of success to multiple measures of success. The reform rests on the theoretical concepts of continuous improvement and LftM. Both of these concepts, codified through the policy have been supported by education leaders, practitioners, and scholars. Leading scholar Michael Fullan has written extensively about the LCFF, continuous improvement, and LftM. Fullan has described the changes championed in this policy as a mindset that is moving from the wrong drivers (e.g. punitive accountability, 
individualistic solutions) to the right drivers (e.g. capacity development and collaboration) for continuous improvement (Fullan \& Rincón-Gallardo, 2017).

In the spirit of the LCFF, continuous improvement means getting better. It is inclusive of many other concepts such as learning, collaboration, relationship building, assessment, leadership, and capacity. With the shift in decision-making, the role of local leaders in guiding a process that can lead to continuous improvement efforts has become increasingly important. It has been suggested that mid-level leaders will be able to capitalize on their local knowledge and networks to leverage district and community strengths to meet the unique needs of local schools (Fullan \& Rincón-Gallardo, 2017).

What is implied in this policy is that mid-level leaders have shared beliefs towards assessment and continuous improvement; that they have the knowledge and capacity to establish assessment practices and collect and use data to inform local decisions; and relative to school climate, that there are shared commitments and beliefs towards school climate assessment. The results from this study suggest that the ability of the LCFF to motivate and sustain change may be compromised because there appears to be a range of beliefs related to the importance of school climate assessment, capacities to use school climate data for continuous improvement, and trust in the data. The range of beliefs that exist will undoubtedly influence how local districts interpret the policy expectations, implement assessment practices, and use data for decision making.

If the underlying concepts of continuous improvement and LftM are going to play an integral role in reshaping the educational experiences in California public schools then we need to establish additional avenues for capacity development in assessment literacy; 
we need to address the power dynamics that influence assessment practices; and we need to ensure that resources are provided to local communities to support their continuous improvement plans. Each of these recommendations are discussed below.

Assessment literacy. The findings from this study suggest a need for professional development related to assessment literacy for education leaders. Respondents readily acknowledged site-level needs related to assessment literacy, but results also suggested inconsistencies among district-level leaders. For example, many survey respondents thought it was important to use high-quality instruments, but they also expressed a belief that all data were helpful, even if they were uncertain in their trust of the data. These inconsistencies suggest the need for greater understanding of the underlying mental models (the way people construct narratives and make sense of experiences) that guide perspectives and understanding of school climate assessment among education leaders. These sense-making narratives are often resistant to change and unless they are part of an individual's area of expertise, they are likely to be underdeveloped or ill-informed (Braun \& Mislevy, 2005). One helpful way of exploring underlying mental models is to apply the concept of p-prims.

In the early 1980s, physicist and education professor Andrea diSessa coined the term phenomenological primitive (p-prim for short) to describe the explanations that nonexperts present for specific phenomena that occur around them. When the term was originally introduced it was used to explain how people made sense of basic physics in everyday life, for example, force and velocity (diSessa, 1993). However, over the years, the term has found relevant applications in other fields, including education and 
educational assessment. Assessment experts have long recognized the complexity associated with theories that guide educational testing, including scientific test theory, and they understand that assessment is not about one test score (Duckor, Draney, Wilson, 2009). Education assessment experts recognize that "assessment is about reasoning from a handful of particular things students say, do, or make, to more broadly cast inferences about what they know, have accomplished, or are apt to do in the future" (Braun \& Mislevy, 2005).

In applying scientific test theory to assessment, the assessment needs to have a clear purpose and a rationale for the tasks that will generate the evidence that is needed. Furthermore, it is believed that the more data available, the more confident one can be about the probability of the outcome. However, not all education leaders are assessment experts and therefore, it is important to acknowledge p-prims that may be contributing to education leader perspectives and approaches towards assessment, including school climate assessment. Three p-prims were identified as potentially influencing the beliefs among participants in this study.

First, a common p-prim in educational testing that was relevant in this study was that "A test measures what it says at the top of the page" (Braun \& Mislevy, 2005). This pprim is relevant to this study and school climate assessment because there are inconsistencies in the instruments that are being used to measure school climate. District leaders report using several different measures to assess school climate, but the variables that are assessed may not be the same, the contextual factors that lead up to the assessment may not be the same, and the way that leaders analyze the results may not be 
the same. As a result, several districts may be using an assessment that clearly identifies it by title as a "School Climate Survey," but for example, one district assessment for school climate may yield data on implicit bias, another on individual social skills, and yet another on health-related behaviors. Furthermore, some districts may be using an instrument with other titles, suggesting that school climate proxies could also be measuring the same (or different) constructs and school dynamics (for example, CHKS).

A second common p-prim in educational testing is "A test is a test is a test." This pprim emerged through the findings of this study as a belief that all data are potentially helpful and useful to leaders for decision making. The belief expressed by study participants was that any assessment can be given and the information obtained could be useful in some way. While the results from this study supported the prevalence of this pprim, there was also evidence that suggested that some superintendents question this $p$ prim. For example, leaders inconclusively endorsed the need for a state-level standardized assessment tool. One reason that this was reportedly difficult to endorse was because local leaders believed that a standardized tool would eliminate the local relevance. This concern suggested that there were some leaders who believed that assessments were not equally meaningful and relevant.

The third p-prim that is common in educational testing and related to this study was that "You can tell if an item is good by looking at it." This p-prim assumes that item design is clear on the surface, ergo, there is no need to identify or understand the underlying theory that is purportedly guiding the change that is being assessed. The prevalence of this p-prim emerged through responses that included picking and choosing 
items from a testing bank, or trusting the assessment because of trust in the developer, or expressing that the items simply looked or sounded "good."

Understanding the mental models and specifically the p-prims that influence the ways in which local leaders are implementing school climate assessment processes and using school climate assessment data are important because they can inform professional development approaches to improve assessment literacy. Professional training and education that can be tailored to address the underlying assumptions and misconceptions could positively influence assessment beliefs and inform local practices. Additionally, educational leaders are susceptible to industry claims and endorsements that suggest an ability to measure growth in non-cognitive factors. Supporting the development of a critical lens, through assessment literacy, could help education leaders determine which services and products to adopt. In summary, this recommendation proposes that it is important to understand the mental models that inform assessment practices and decision making because professional development for assessment literacy can be tailored to address prevalent beliefs, further supporting local leaders with institutionalizing assessment practices that can positively facilitate continuous improvement.

Power dynamics. A second recommendation from this study acknowledges that knowledge, power, and conflict influence assessment practices. From this perspective, there is a recognition that data are important leverages of power and conflict and, as a result, sometimes less able to authentically guide continuous improvement. For example, there has been an ongoing political focus on implementing changes to the educational system that will close the achievement gap. A previous focus was on academics, 
including a significant emphasis in the disciplines of math, science, and engineering. As it became evident that these efforts were not substantially influencing the nation's achievement gap, the focus shifted to equity, including school climate and "noncognitive" factors such as social and emotional learning, resilience, trust, and safety. By moving to include school climate assessment in the state accountabilities framework, the state of California is showing how, through policy and legislation, political and legislative actors have the ability to control the levers, or indicators, of school success.

In addition to a political focus, there may also be emerging contests of power between and among groups for data and information. In terms of school climate and school climate assessment, this includes the question of who has the power to shape the narrative and determine what matters in school climate assessment data collection, analysis, interpretation, and use. This would include whose voices are captured through the assessment and whose voices (or experiences) are emphasized in the analysis and subsequent use of data. School leaders can manipulate or present data in ways that reinforce leader or administrator perspectives, or beliefs, and school climate assessment data could also potentially empower community advocacy and parent groups who may use data to support school leaders or condemn school leaders. If school climate assessment data are going to genuinely lead to an improved understanding of experiences at school so changes can be implemented to improve conditions, it is important to assess school climate without undue political pressures and influences. In summary, this second recommendation proposes increased state discourse regarding the equitable funding of 
public schools and supporting communities in developing capacities to build relationships and collaborate to identify and work towards shared educational goals.

Resources. The final recommendation is to continue to advocate for resources and supports for schools and districts to adequately implement the changes that are identified through their assessment practices. There continues to be a predominant focus on individual student improvements to close the achievement gap, rather than structural and systemic change. If the focus is centered around continuous improvement, then at minimum, the state needs to support local districts with additional resources to implement their improvement plans. However, it should be acknowledged that as long as the exogenous factors remain unchallenged and unchanged, significant and sustained improvements in educational outcomes will continue to be largely inconsequential at the system level. Thus, we can better support schools and education leaders immediately, but we have to work creatively and innovatively across multiple systems, to challenge issues of equity within our communities, and our schools, if we want to see substantial changes in education outcomes for all learners.

\section{Study Limitations}

There were several limitations to this study. First, the reliability of the instrument across the three constructs needs improvement. The reliability coefficients for the importance, capacity, and trustworthiness constructs were .729, 0636, and .577 respectively. The lowest reliability was for the trustworthiness scale, but all of the reliability coefficients signal a need to further explore these constructs. The inconsistencies in response patterns for the trustworthiness construct suggest that the 
construct is multidimensional. It is possible that the items included in the trustworthiness construct were potentially confounding knowledge and belief in the same construct. It is expected that levels of knowledge of assessment literacy would impact beliefs. A further study could tease these two related, but different constructs, apart.

Another limitation was that there was a number of respondents who did not complete the entire survey, thus signaling non-response bias. To reduce this bias, the researcher communicated time, content, and expectation to invited participants, but there remained roughly $10 \%$ of respondents who did complete the survey in full. The exit survey questions suggested that the survey length may have led to some participants not completing the survey and others indicated that the lack of a back button prevented their ability return to previous items that they may have left blank. Another factor impacting the potential for response bias was that urban superintendents were under-represented in the survey, even though the majority of California students are educated in urban districts. However, the needs of rural superintendents are often overshadowed in the state. A key informant policy expert at CDE suggested to the researcher that the oversampling of rural superintendents is not likely a major limitation because their perspectives are not consistently heard with the same magnitude of the urban superintendent perspective. Nonetheless, the researcher made sure that urban superintendents were adequately represented in the final qualitative sample.

The data analysis for the trustworthiness construct posed another limitation. Unlike the other two constructs that were included in the survey, the trustworthiness construct included a neutral category. The qualitative findings suggested that the "not sure" 
responses were more in line with less trust in the data, without follow up inquiry, or a cognitive lab, it is not known why respondents selected this response choice. A final limitation was that there was no specific analysis designed to learn more about the roughly one fifth of the respondents who did not indicate that school climate assessment

was important for continuous improvement. It is speculated that some of the respondents who did not endorse the importance construct may have shared similarities with the perspectives of the qualitative respondents who expressed some degree of skepticism towards school climate assessment, but these perspectives were not captured through the survey and additional follow up is recommended.

\section{Conclusion}

This study explored superintendent practices and beliefs towards school climate assessment because understanding what schools are doing and what local leaders believe will impact the data that are collected and how the data are used for decision making and continuous improvement. Drawing from the results of this study, three recommendations were presented. First, an improved understanding of mental models influencing assessment beliefs and practices can lead to highly tailored, relevant professional development to improve capacities in assessment literacy. Second, researchers, politicians, education leaders, and community stakeholders need to expand their discourse and to support engagement strategies that enhance local capacity development and collaborative efforts to work amongst different viewpoints, increasing the potential for local leaders to impact meaningful change relative to school experiences. Lastly, best practices that can immediately improve conditions of learning should be prioritized 
among state leaders and policy makers to further advance efforts at improving educational equity.

This study was important because it invited discourse around education policy, assessment, data driven decision making, continuous improvement, and school health. The findings suggested that local leaders are indeed in a unique position to interpret and use school climate assessment to facilitate local efforts for change. The findings also suggested that local leaders need additional support and resources, including capacity development in assessment literacy, but also in the areas of managing diverse community and school interests. While the majority of participants responded positively in their beliefs towards the importance of school climate assessment, there were nearly one fifth who did not. A follow up study is necessary to better understand the perspectives of education leaders who do not believe that school climate assessment was important for continuous improvement because this underlying belief will undoubtedly influence district practices and capacities in using school climate data to inform local change efforts. Another follow up study could explore how different stakeholders in public schools perceive, define, and experience school climate. The state has not yet formally adopted a definition of school climate and it would be important to know how closely the SCCWG definition aligns with the perceptions and experiences of key stakeholders such as students, faculty, staff, and parents. Ultimately, continued research on this topic will help further policy and practice recommendations and supports, enabling local communities, with guidance of education leaders, to improve and sustain school environments that enhance conditions of teaching and learning for all students. 


\section{References}

Adams, R.J., Wilson, M., Wu, M. (2012). ConQuest 3.0 [Computer Program]. Hawthorne; Australian Council for Educational Research.

Adams, R.J., Wilson, M., Wang, W. (1997). The multidimensional multinomial logit model. Applied Psychological Measurement, 21(1), 1-23. doi:10.1177/0146621697211001

Adler, N.E., D.M. Cutler, J.E. Jonathan, S. Galea, M. Glymour, H.K. Koh, and D. Satcher. (2016). Addressing Social Determinants of Health and Health Disparities. Discussion Paper, Vital Directions for Health and Health Care Series. National Academy of Medicine, Washington, DC. Retrieved from: https://nam.edu/wpcontent/uploads/2016/09/Addressing-Social-Determinants-of-Health-and-HealthDisparities.pdf

American Educational Research Association (AERA), American Psychological Association (APA), \& National Council for Measurement in Education (NCME). (2014). Standards for educational and psychological testing. Washington D.C.: American Educational Research Association.

American Public Health Association. (2017). What is public health. Retrieved from https://www.apha.org/what-is-public-health

Basch, C. E. (2011). Healthier students are better learners: A missing link in school reforms to close the achievement gap. Journal of School Health, 81(10), 593-598. doi: $10.1111 / \mathrm{j} .1746-1561.201 .00632 . \mathrm{x}$

Batel, S., Sargrad, S., \& Jimenez, L. (2016). Innovation in accountability: Designing systems to support school quality and student success. Center for American Progress. Retrieved from: https://www.americanprogress.org/issues/education-k12/reports/2016/12/08/294325/innovation-in-accountability/

Bear, G. G., Gaskins, C., Blank, J., \& Chen, F. F. (2011). Delaware school climate Survey-Student: Its factor structure, concurrent validity, and reliability. Journal of School Psychology, 49(2), 157-174. doi: 10.1016/j.jsp.2011.01.001

Benbenishty, R., Astor, R. A., Roziner, I., \& Wrabel, S. L. (2016). Testing the causal links between school climate, school violence, and school academic performance A cross-lagged panel autoregressive model. Educational Researcher, 45(3), 197-206. doi: 10.3102/0013189X16644603

Berkowitz, R., Astor, R. A., Pineda, D., DePedro, K. T., Weiss, E. L., \& Benbenishty, R. (2017). Parental involvement and perceptions of school climate in California. Urban Education,1-31 doi: 10.1177/0042085916685764 
Berliner, D. C. (2009). Poverty and potential: Out-of-school factors and school success. Education and Public Interest Center and Policy Research Unit, Retrieved from: https://nepc.colorado.edu/sites/default/files/PB-Berliner-NON-SCHOOL.pdf

Berliner, D. (2013). Effects of inequality and poverty vs. teachers and schooling on America's youth. Teachers College Record, 115(12), 1-26.

Berliner, D.C. (2014). Exogenous variables and value-added assessments: A fatal flaw. Teachers College Record, 116(1), 1-31.

Berliner, D. C., \& Glass, G. V. (Eds.). (2014). 50 myths and lies that threaten America's public schools: The real crisis in education. New York, NY, US: Teachers College Press.

Bertino, E. (2014). Data Trustworthiness - Approaches and Research Challenges. DPM/SETOP/QASA, p.17-25. Springer, Cham. doi:10.1007/978-3-31917016-9 2

Bosworth, K., Garcia, R., Judkins, M. \& Saliba, M. (2018) The impact of leadership involvement in enhancing high school climate and reducing bullying: An exploratory study, Journal of School Violence, 17(3), 354-366, doi:10.1080/15388220.2017.1376208

Boulianne, S., Klofstad, C. \& Basson, D. (2010). Sponsor prominence and response patterns to an online survey. International Journal of Public Opinion Research, 23(1), 79-87. doi: 10.1093/ijpor/edq026

Bradshaw, C. P., Waasdorp, T. E., Debnam, K. J., \& Johnson, S. L. (2014). Measuring school climate in high schools: A focus on safety, engagement, and the environment. Journal of School Health, 84(9), 593-604. doi:10.1111/josh.12186

Braun, H. I., \& Mislevy, R. (2005). Intuitive Test Theory. Phi Delta Kappan, 86(7), 488497. doi:10.1177/003172170508600705

Braveman, P., Kumanyika, S., Fielding, J., LaVeist, T., Borrell, L., \& Manderscheid, R. (2011). Health disparities and health equity: The issue is justice. Environmental Justice, 101(S1), 149. DOI: 10.2105/AJPH.2010.300062

Burton, C. M., Marshal, M. P., \& Chisolm, D. J. (2014). School absenteeism and mental health among sexual minority youth and heterosexual youth. Journal of School Psychology, 52(1), 37-47. doi:10.1016/j.jsp.2013.12.001 
Buske, R., \& Zlatkin-Troitschanskaia, O. (2018). Investigating principals' data use in school: The impact of evidence-oriented attitudes and epistemological beliefs. Educational Management Administration \& Leadership. doi:10.1177/1741143218753192

California Department of Education. (2017). Culture and climate. Retrieved from https://www.cde.ca.gov/qs/cc/

Cimpian, J. R., Lubienski, S. T., Timmer, J. D., Makowski, M. B., \& Miller, E. K. (2016). Have Gender Gaps in Math Closed? Achievement, Teacher Perceptions, and Learning Behaviors Across Two ECLS-K Cohorts. AERA Open, 2(4). doi: $10.1177 / 2332858416673617$

Coburn, C. \& Turner, E. (2011). Research on data use: A framework and analysis. Measurement: Interdisciplinary Research \& Perspective, 9(4), 173-206. doi: 10.1080/15366367.2011.626729

Cohen, J., McCabe, L., Michelli, N. M., \& Pickeral, T. (2009). School climate: Research, policy, practice, and teacher education. Teachers College Record, 111(1), 180-213.

Collaborative for Academic, Social, and Emotional Learning (CASEL). (2017). What is SEL? Retrieved from http://www.casel.org/what-is-sel/

Cook, C., Heath, F., \& Thompson, R. L. (2000). A Meta-Analysis of Response Rates in Web- or Internet-Based Surveys. Educational and Psychological Measurement, 60(6), 821-836. doi:10.1177/00131640021970934

Coulter, R. W., Birkett, M., Corliss, H. L., Hatzenbuehler, M. L., Mustanski, B., \& Stall, R. D. (2016). Associations between LGBTQ-affirmative school climate and adolescent drinking behaviors. Drug and Alcohol Dependence, 161, 340-347. doi:10.1016/j.drugalcdep.2016.02.022

Creswell, J.W. \& Creswell, J.D. (2018). Research design: Qualitative, quantitative, and mixed methods approaches (5th ed). Thousand Oaks, CA: Sage Publications.

Creswell, J. \& Plano Clark, V. (2011). Designing and conducting mixed methods research (2nd ed). Thousand Oaks, CA: Sage Publications.

Datnow, A., \& Park, V. (2014). Data-driven leadership (Vol. 12). John Wiley \& Sons.

DeCuir-Gunby, J.T. \& Schutz, P. (2017). Developing a mixed methods proposal: A practical guide for beginning researchers. Thousand Oaks, CA: Sage Publications. 
DePaoli, J. L., Fox, J. H., Ingram, E. S., Maushard, M., Bridgeland, J. M., \& Balfanz, R. (2015). Building a grad nation: Progress and challenge in ending the high school dropout epidemic. annual update 2015. Civic Enterprises. Retrieved from https://www.americaspromise.org/report/2015-building-grad-nation-report

DePaoli, J., Balfanz, R., Bridgeland, J., Atwell, M., \& Ingram, E. (2017). Building a grad nation: Progress and challenge in raising high school graduation rates, 2017 annual update. America's Promise Alliance. Retrieved from https://gradnation.americaspromise.org/report/2017-building-grad-nation-report

diSessa, A., (1993) Toward an Epistemology of Physics, Cognition and Instruction, 10(23), 105-225, doi: 10.1080/07370008.1985.9649008

Doumas, D. M., Midgett, A., \& Johnston, A. D. (2017). Substance use and bullying victimization among middle and high school students: Is positive school climate a protective factor? Journal of Addictions \& Offender Counseling, 38(1), 2-15. doi:10.1002/jaoc. 12025

Duckor, B. (2017). Got grit? Maybe... Phi Delta Kappan, 98(7), 61-66

Duckor, B., Draney, K., Wilson, M. (2009). Measuring measuring. Toward a theory of proficiency with the constructing measures framework. Journal of Applied Measures, 10(3), 296-319.

Duckworth, A. L., \& Seligman, M. E. P. (2017). The Science and Practice of SelfControl. Perspectives on Psychological Science, 12(5), 715-718. doi:10.1177/1745691617690880

Duckworth, A. L., \& Yeager, D. S. (2015). Measurement Matters: Assessing Personal Qualities Other Than Cognitive Ability for Educational Purposes. Educational Researcher, 44(4), 237-251. doi:10.3102/0013189X15584327

Durham, R. E., Bettencourt, A., \& Connolly, F. (2014). Measuring School Climate: Using Existing Data Tools on Climate and Effectiveness to Inform School Organizational Health. Baltimore Education Research Consortium.

Durlak, J., Weissberg, R., Dymnicki, A., Taylor, R., \& Schellinger, K. (2011). The impact of enhancing students' social and emotional learning: A meta-analysis of school based universal interventions. Child Development, 82(1), 405-432. doi:10.1111/j.1467-8624.2010.01564.x

Dusenbury, L., \& Weissberg, R. (2017). State efforts to promote social and emotional learning in students: A status report. Collaborative for Academic, Social, and Emotional Learning. 
Dweck, C. S., Walton, G. M., \& Cohen, G. L. (2014). Academic Tenacity: Mindsets and Skills that Promote Long-Term Learning. Bill \& Melinda Gates Foundation.

Earl, L. \& Fullan, M. (2003) Using Data in Leadership for Learning, Cambridge Journal of Education, 33:3, 383-394, doi: 10.1080/0305764032000122023

Embretson, S. E. (1996). The new rules of measurement. Psychological assessment, 8(4), 341.

Espelage, D., Polanin, J., \& Low, S. (2014). Teacher and staff perceptions of school environment as predictors of student aggression, victimization, and willingness to intervene in bullying situations. School Psychology Quarterly, 29(3), 287.

Fan, W., Williams, C. M., \& Corkin, D. M. (2011). A multilevel analysis of student perceptions of school climate: The effect of social and academic risk factors. Psychology in the Schools, 48(6), 632-647. doi:10.1002/pits.20579

Farrington, C. A., Roderick, M., Allensworth, E., Nagaoka, J., Keyes, T. S., Johnson, D. W., ... Beechum, N. O. (2012). Teaching adolescents to become learners: The role of noncognitive factors in shaping school performance--A critical literature review. ERIC.

Fullan, 2005. Turnaround Leadership, The Educational Forum, 69(2), 174-181, doi: $10.1080 / 00131720508984681$

Fullan, M. (2011). Choosing the wrong drivers for whole system reform (pp. 3-4). Melbourne: Centre for Strategic Education.

Fullan, 2014. California's golden opportunity: Status note. Motion Leadership. Michaelfullan.ca

Fullan, M. (2015). A golden opportunity: The California collaborative for educational excellence as a force for positive change. C. Forward (Ed.), 10.

Fullan, M., Rincon-Gallardo, S., \& Hargreaves, A. (2015). Professional capital as accountability. Education Policy Analysis Archives, 23(15). doi:10.14507/epaa.v23.1998.

Fullan, M. \& Rincón-Gallardo, S. (2017). California's golden opportunity. Taking stock: Leadership from the middle. Motion Leadership: Michaelfullan.ca

Fullan, M., Hill, P., \& Rincón-Gallardo, S. (2017). Deep Learning: Shaking the Foundation. Ontario, Canada: Fullan, M., Quinn, J., \& McEachen, J. Retrieved from http://npdl.global/wp-content/uploads/2017/03/npdl- case_study_3.pdf 
Gage, N. A., Larson, A., \& Chafouleas, S. M. (2016). The Meriden School Climate Survey-Student Version: Preliminary Evidence of Reliability and Validity. Assessment for Effective Intervention, 41(2), 67-78. doi:10.1177/1534508415596960

Galea, S., Tracy, M., Hoggatt, K. J., DiMaggio, C., \& Karpati, A. (2011). Estimated deaths attributable to social factors in the united states. American Journal of Public Health, 101(8), 1456-1465. doi: 10.2105/AJPH.2010.300086

Gannon-Slater, N., La Londe, P. G., Crenshaw, H. L., Evans, M. E., Greene, J. C., \& Schwandt, T. A. (2017). Advancing equity in accountability and organizational cultures of data use. Journal of Educational Administration, 55(4), 361-375. doi:10.1108/JEA-09-2016-0108

Gase, L.N., DeFosset, A., Perry, R. (2016). Youths' perspectives on the reasons underlying school truancy and opportunities to improve school attendance. The Qualitative Report, 21(2), 299-320.

Glossary of Education Reform. (2014). Student outcomes. Retrieved from http://edglossary.org/student-outcomes/

Hanson, T. L., \& Kim, J. O. (2007). Measuring Resilience and Youth Development: The Psychometric Properties of the Healthy Kids Survey. Issues \& Answers. REL 2007No. 34. Regional Educational Laboratory West.

Hargreaves, A., \& Ainscow, M. (2015). The top and bottom of leadership and change. Phi Delta Kappan, 97(3), 42-48. doi:10.1177/0031721715614828.

Hatzenbuehler, M. L., Birkett, M., Van Wagenen, A., \& Meyer, I. H. (2014). Protective school climates and reduced risk for suicide ideation in sexual minority youths. American Journal of Public Health, 104(2), 279-286.

Hemphill, F. C., \& Vanneman, A. (2011). Achievement Gaps: How Hispanic and White Students in Public Schools Perform in Mathematics and Reading on the National Assessment of Educational Progress. Statistical Analysis Report. NCES 2011459. National Center for Education Statistics.

Henig, J. (2012) The politics of data use. Teachers College Record, 114, 1-32

Hopson, L. M., \& Lee, E. (2011). Mitigating the effect of family poverty on academic and behavioral outcomes: The role of school climate in middle and high school. Children \& Youth Services Review, 33(11), 2221-2229. doi:10.1016/j.childyouth.2011.07.006 
Jackson, C. L., Agénor, M., Johnson, D. A., Austin, S. B., \& Kawachi, I. (2016). Sexual orientation identity disparities in health behaviors, outcomes, and services use among men and women in the united states: A cross-sectional study. BMC Public Health, 16(1), 807. doi:10.1186/s12889-016-3467-1

Jain, S., Cohen, A. K., Huang, K., Hanson, T. L., \& Austin, G. (2015). Inequalities in school climate in California. Journal of Educational Administration, 53(2), 237-261. doi:10.1108/JEA-07-2013-0075

Kaplowitz, M. D., Lupi, F., Couper, M. P., \& Thorp, L. (2012). The Effect of Invitation Design on Web Survey Response Rates. Social Science Computer Review, 30(3), 339-349. doi:10.1177/0894439311419084

Karakos, H. L., Voight, A., Geller, J. D., Nixon, C. T., \& Nation, M. (2016). Student civic participation and school climate: Associations at multiple levels of the school ecology. Journal of Community Psychology, 44(2), 166-181. doi:10.1002/jcop.21748

Kilbourn, B. (2006). The qualitative doctoral dissertation proposal. Teachers College Record, 108(4), 529.

Kirst, M.W., \& Wirt, F.W. (2009). The political dynamics of American education $\left(4^{\text {th }}\right.$ ed.) Richmond, CA: McCutchan Publishing Corporation.

Kirtman, L., \& Fullan, M. (2016). Key competencies for whole-system change. Bloomington, IN: Solution Tree Press.

Konishi, C., Hymel, S., Zumbo, B. D., \& Li, Z. (2010). Do School Bullying and Student-Teacher Relationships Matter for Academic Achievement? A Multilevel Analysis. Canadian Journal of School Psychology, 25(1), 19-39. doi:10.1177/0829573509357550

Konold, T., Cornell, D., Huang, F., Meyer, P., Lacey, A., Nekvasil, E., ... Shukla, K. (2014). Multilevel multi-informant structure of the authoritative school climate survey. School Psychology Quarterly, 29(3), 238.

Kowalski, T.J., (2005) Evolution of the School Superintendent as Communicator, Communication Education, 54:2, 101-117, doi: $10.1080 / 03634520500213322$

Kowalski, T.J,. and Brunner, C. C., (2011). The School Superintendent: Roles, Challenges, and Issues. The Sage Handbook of Educational Leadership (110-134). Thousand Oaks, CA: Sage Publications 
Kraft, M. A., Marinell, W. H., \& Yee, D. (2016). Schools as organizations: Examining school climate, teacher turnover, and student achievement in NYC. brief. Research Alliance for New York City Schools. Retrieved from http://www.hsredesign.org/wpcontent/uploads/2018/07/SchoolsAsOrganizations_PolicyBrief.pdf

Krahn, G. L., Walker, D. K., \& Correa-De-Araujo, R. (2015). Persons with disabilities as an unrecognized health disparity population. American Journal of Ppublic Health, 105(S2), S198-S206. doi: 10.2105/AJPH.2014.302182

Krueger, P. M., Tran, M. K., Hummer, R. A., \& Chang, V. W. (2015). Mortality attributable to low levels of education in the united states. PloS One, 10(7), e0131809.

Labaree, D. (2012). School syndrome: Understanding the USA's magical belief that schooling can somehow improve society, promote access, and preserve advantage. Journal of Curriculum Studies, 44(2), 143-163. doi:10.1080/00220272.2012.675358

Lee, E., Reynolds, K. J., Subasic, E., Bromhead, D., Lin, H., Marinov, V., \& Smithson, M. (2017). Development of a dual school climate and school identification MeasureStudent (SCASIM-st). Contemporary Educational Psychology, 49, 91-106. doi:10.1016/j.cedpsych.2017.01.003

Low, S., \& Van Ryzin, M. (2014). The moderating effects of school climate on bullying prevention efforts. School Psychology Quarterly, 29(3), 306. doi:10.1037/spq0000073

Lu, M. C., Kotelchuck, M., Hogan, V., Jones, L., Wright, K., \& Halfon, N. (2010). Closing the black-white gap in birth outcomes: A life-course approach. Ethnicity \& Disease, 20 (1 Suppl 2), S2-62-76.

Madariaga, L., Nussbaum, M., Burq, I., Maranon, F., Salazar, D., Maldonado, L., ... Naranjo, M.A. (2017). Online survey: A national study with school principals. Computers in Human Behavior, 74, 35-44. doi:10.1016/j.chb.2017.03.067

Marsh, J. (2012). Interventions promoting educators' use of data: Research insights and gaps. Teachers College Record, 114, 1-48.

Martin, C., Sargrad, S., \& Batel, S. (2016). Making the Grade: A 50-State Analysis of School Accountability Systems. Center for American Progress.

Masters, G.N. (1982). A rasch model for partial credit scoring. Psychometrika,47(2), 149-174. doi:10.1007/BF02296272 
Maul, A. (2017). Rethinking traditional methods of survey validation. Measurement: Interdisciplinary Research and Perspectives, 15(2), 51-69. doi:10.1080/15366367.2017.1348108

McGuffey, A. R. (2016). A national study of the validity and utility of the comprehensive assessment of school environment (CASE) survey. NASSP Bulletin, 100(2), 97-116.

McMahon, S. D., Wernsman, J., \& Rose, D. S. (2009). The relation of classroom environment and school belonging to academic self-efficacy among urban fourth-and fifth-grade students. The Elementary School Journal, 109(3), 267-281.

Merriam, S.B. and Tisdell, E.J. (2016). Qualitative research: A guide to design and implementation, 4th Edition. San Francisco, CA: Jossey-Bass.

Miles, M.B., Huberman, A. M., and Saldaña, J. (2014). Qualitative data analysis: A methods sourcebook, 3rd Edition. Thousand Oaks, CA: Sage Publications.

Miller, V. (2012). The Broad challenge to democratic leadership: The other crisis in education. Democracy \& Education, 20(2), Article 1.

Moody, M. (2011). Superintendent-Board Relations: Understanding the Past to Promote the Future. Educational Leadership and Administration: Teaching and Program Development, 23, 75-84.

National Center for Education Statistics (NCES). (2015). ED school climate surveys (EDSCLS) national benchmark study. Appendix D. EDSCLS Pilot Test 2015 Report.

National Commission on Excellence in Education. (1983). A nation at risk: The imperative for educational reform. The Elementary School Journal, 84(2), 113-130.

National Research Council. (2001). Knowing what students know: The science and design of educational assessment. Committee on the Foundations of Assessment. J.W. Pellegrino,N. Chudowsky, \& R. Glaser (Eds.). Board on Testing and Assessment, Center for Education, Division of Behavior and Social Sciences and Education. Washington D.C.: National Academy Press.

National School Climate Council. (2017). School climate. Retrieved from http://www.schoolclimate.org/climate/

O'Brennan, L. M., Bradshaw, C. P., \& Furlong, M. J. (2014). Influence of classroom and school climate on teacher perceptions of student problem behavior. School Mental Health, 6(2), 125-136. doi:10.1007/s12310-014-9118-8 
O'Malley, M., Voight, A., Renshaw, T. L., \& Eklund, K. (2015). School climate, family structure, and academic achievement: A study of moderation effects. School Psychology Quarterly, 30(1), 142.

Office of Disease Prevention and Health Promotion (ODPHP). (2017). Disparities. Retrieved from https://www.healthypeople.gov/2020/about/foundation-healthmeasures/Disparities

Olshansky, et al (2012). Differences In Life Expectancy Due To Race And Educational Differences Are Widening, And Many May Not Catch Up. Health Affairs 2012, 31(8), 1803-1813. doi:10.1377/hlthaff.2011.0746

Park, V., \& Datnow, A. (2009). Co-constructing distributed leadership: District and school connections in data-driven decision-making. School leadership and Management, 29(5), 477-494. doi:10.1080/13632430903162541

Park, V. \& Datnow, A. (2016). Ability grouping and differentiated instruction in an era of data-driven decision making. American Journal of Education, 123, 281-306. doi:10.1086/689930

Perry, A. (1908). The management of a city school. New York: The Macmillan company.

Pomeranz, J. L., \& Chang, V. W. (2017). Severe deprivations of education should be considered states of emergency. Journal of Public Health Management and Practice (JPHMP), 23(4), 336-338. doi:10.1097/PHH.0000000000000490

Quality of life research unit, University of Toronto. (2017). Quality of life model. Retrieved from http://sites.utoronto.ca/qol/qol_model.htm

Richmond, T. K., Milliren, C., Walls, C. E., \& Kawachi, I. (2014). School social capital and body mass index in the national longitudinal study of adolescent health. Journal of School Health, 84(12), 759-768. doi:10.1111/josh.12213

Rudasill, K. M., Snyder, K. E., Levinson, H., \& Adelson, J. L. (2017). Systems view of school climate: A theoretical framework for research. Educational Psychology Review, 30(1), 35-60.

Roderick, M. (2012). Drowning in Data but Thirsty for Analysis. Teachers College Record, 114(11), 11.

Schein, E. H. (2013). Humble inquiry: The gentle art of asking instead of telling. BerrettKoehler Publishers. 
Schueler, B. E., Capotosto, L., Bahena, S., McIntyre, J., \& Gehlbach, H. (2014). Measuring parent perceptions of school climate. Psychological Assessment, 26(1), 314.

School Conditions and Climate Work Group (SCCWG). (2017). School conditions and climate work group recommendation framework. Report prepared for Superintendent of Public Instruction, California Department of Education. Sacramento, CA

Sharp, W. L., Malone, B. G., Walter, J. K., \& Supley, M. L. (2004). A Three-State Study of Female Superintendents. Educational Research Quarterly, 27(3), 22-37.

Sheldon, S. B., Epstein, J. L., \& Galindo, C. L. (2010). Not just numbers: Creating a partnership climate to improve math proficiency in schools. Leadership \& Policy in Schools, 9(1), 27-48. doi:10.1080/15700760802702548

Sills, S. J., \& Song, C. (2002). Innovations in Survey Research: An Application of WebBased Surveys. Social Science Computer Review, 20(1), 22-30. doi:10.1177/089443930202000103

Spillane, J. (2012). Data in practice: Conceptualizing the data-based decision-making phenomena. American Journal of Education, 118, 113-141. doi:10.1086/663283

Telfair, J., \& Shelton, T. L. (2012). Educational attainment as a social determinant of health. NC Med J, 73(5), 358-365.

Thapa, A., Cohen, J., Guffey, S., \& Higgins-D'Alessandro, A. (2013). A Review of School Climate Research. Review of Educational Research, 83(3), 357-385. doi:10.3102/0034654313483907

Tracy, S. J. (2010). Qualitative Quality: Eight “Big-Tent” Criteria for Excellent Qualitative Research. Qualitative Inquiry, 16(10), 837-851. doi:10.1177/1077800410383121

Van Eck, K., Johnson, S.R., Bettencourt, A., Johnson, S.L. (2017). How school climate relates to chronic absence: A multi-latent profile analysis. Journal of School Psychology, 61, 89-102. doi:10.1016/j.jsp.2016.10.001

Voight, A., Hanson, T., O’Malley, M. \& Adekanye, L. (2015). The racial school climate gap: Within-school disparities in students' experiences of safety, support, and connectedness. American Journal of Community Psychology, 56(3-4), 252-267. doi: 10.1007/s10464-015-9751-x.

Venkataramani, A. S., Chatterjee, P., Kawachi, I., \& Tsai, A. C. (2016). Economic opportunity, health behaviors, and mortality in the United States. American Journal of Public Health, 106(3), 478-484. 
Wang, M., \& Degol, J. (2016). School climate: A review of the construct, measurement, and impact on student outcomes. Educational Psychology Review, 28(2), 315. doi:10.1007/s10648-015-9319-1

Weiss, J. (2012). Data for improvement, data for accountability. Teachers College Record, 114, 1-7.

West, M. R., Kraft, M. A., Finn, A. S., Martin, R. E., Duckworth, A. L., Gabrieli, C. F. O., \& Gabrieli, J. D. E. (2016). Promise and Paradox: Measuring Students' NonCognitive Skills and the Impact of Schooling. Educational Evaluation and Policy Analysis, 38(1), 148-170. doi:10.3102/0162373715597298

Wilson, M. (2004). Constructing measures: An item response modeling approach. Mahwah, New Jersey: Lawrence Erlbaum Associates.

Wohlstetter, P., Datnow, A., \& Park, V. (2008). Creating a system for data-driven decision-making: applying the principal-agent framework. School Effectiveness and School Improvement, 19(3), 239-259. doi:10.1080/09243450802246376

World Health Organization. (2017). Social determinants of health. Retrieved from https://www.who.int/social_determinants/en/

You, S., O'Malley, M. D., \& Furlong, M. J. (2014). Preliminary development of the Brief-California school climate survey: Dimensionality and measurement invariance across teachers and administrators. School Effectiveness and School Improvement, 25(1), 153-173. doi:10.1080/09243453.2013.784199

Zhou, K. (2016). Education for people and planet: Creating sustainable futures for all. (No. Global Education Monitoring Report 2016). UNESCO.

Zullig, K. J., Collins, R., Ghani, N., Hunter, A. A., Patton, J. M., Huebner, E. S., \& Zhang, J. (2015). Preliminary development of a revised version of the school climate measure. Psychological Assessment, 27(3), 1072. 
Appendices

\section{Appendix A: Visual Depiction of the Gaps in the Research}

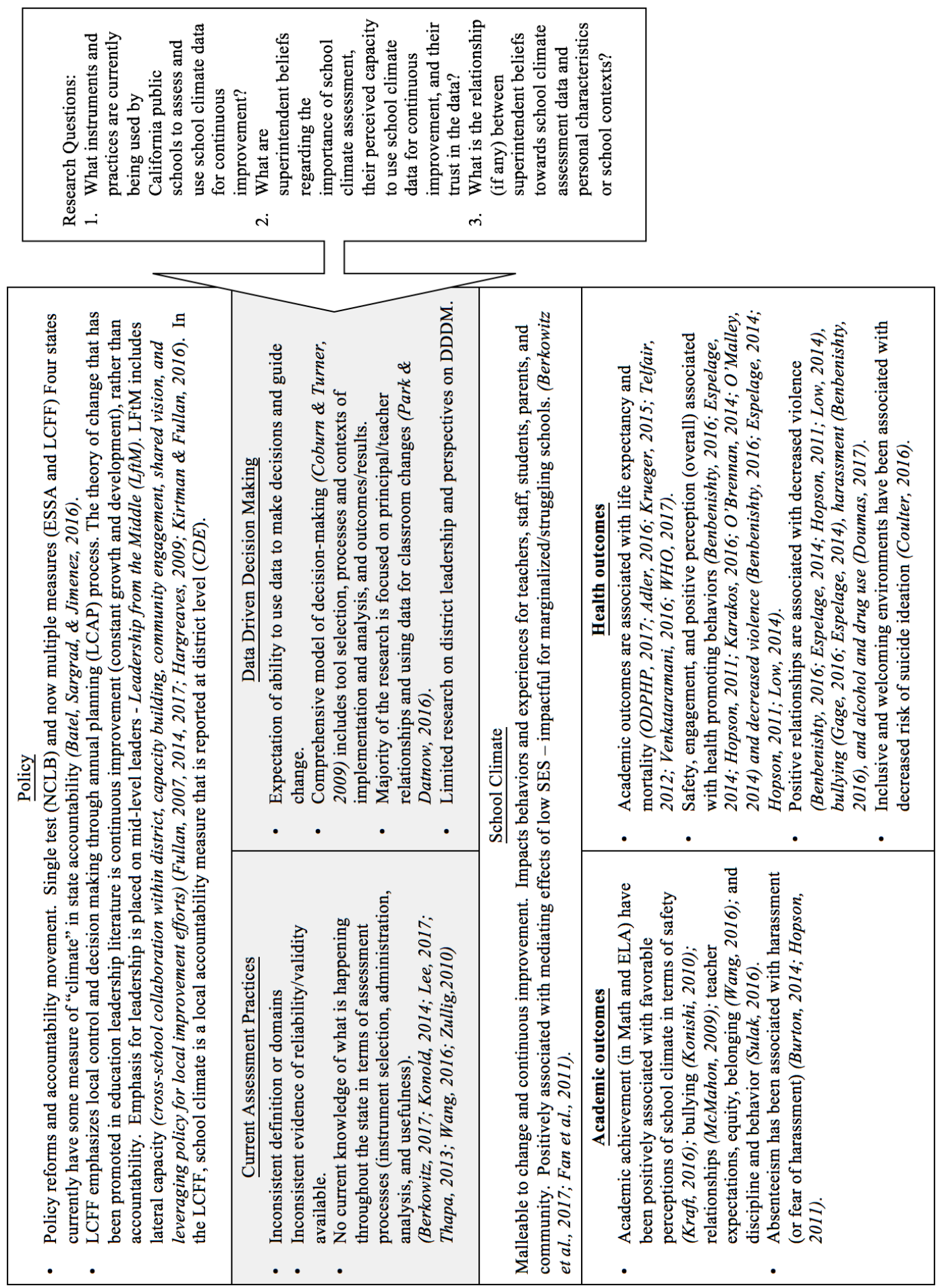




\section{Appendix B: Construct Maps}

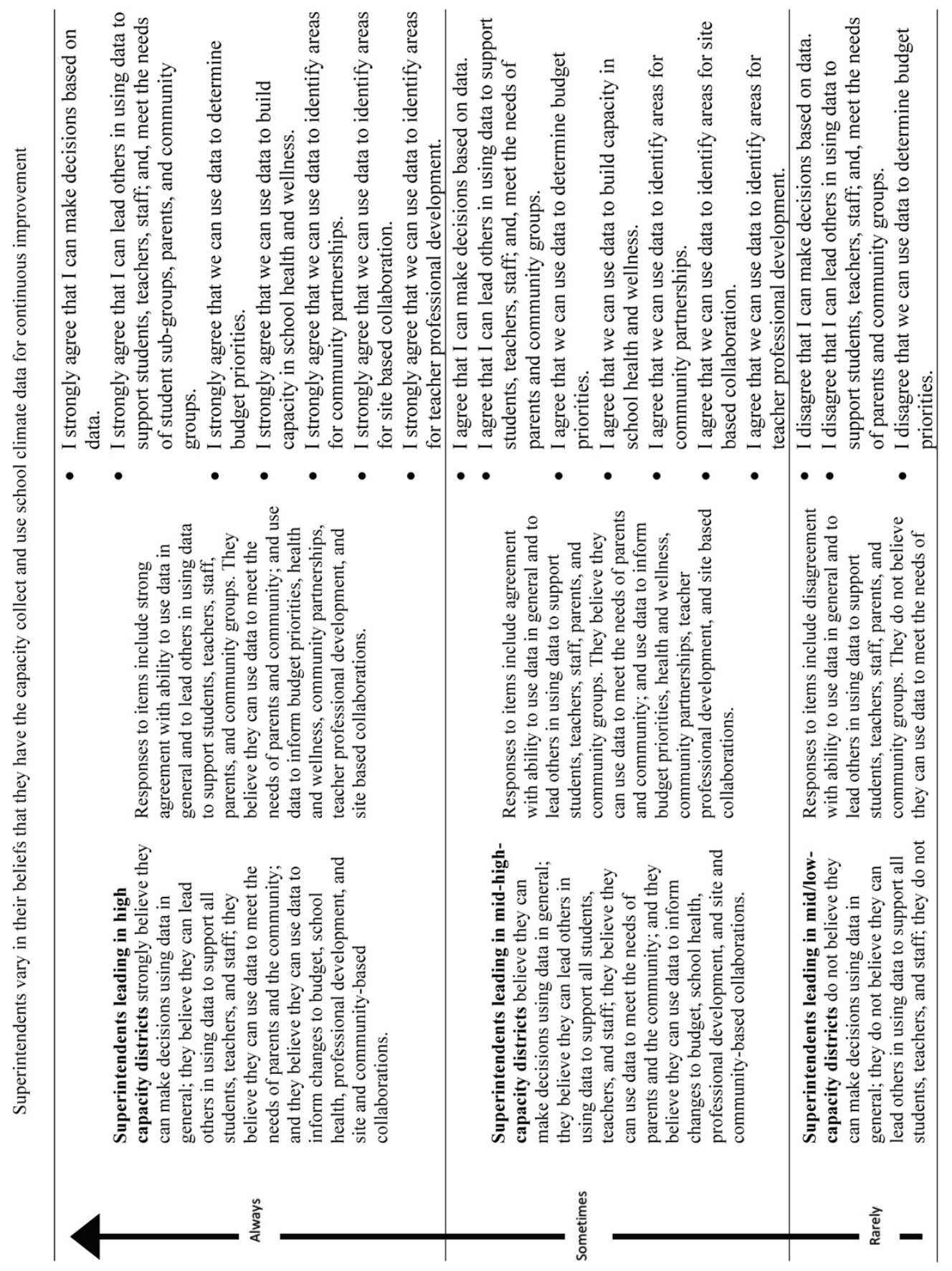




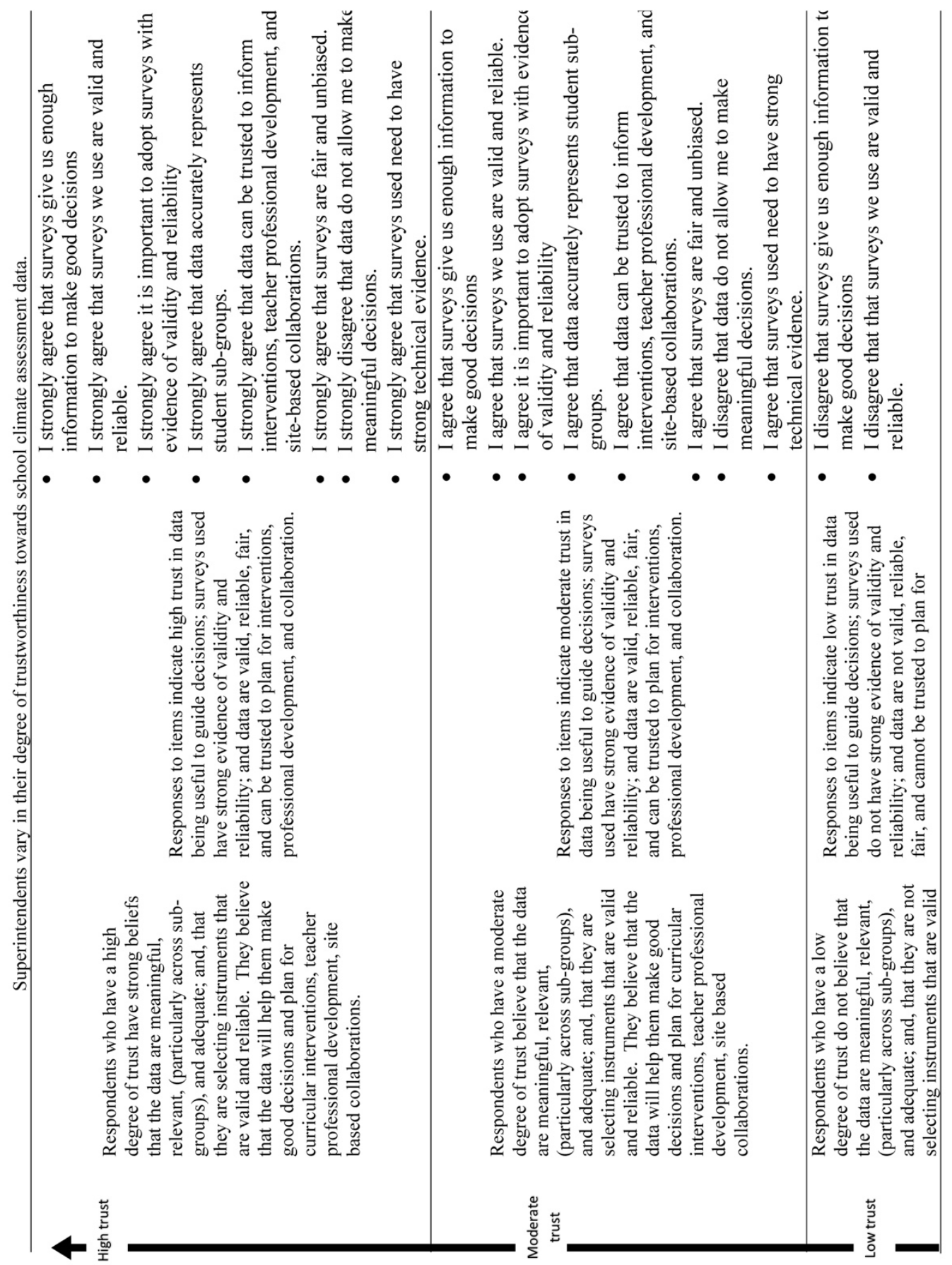




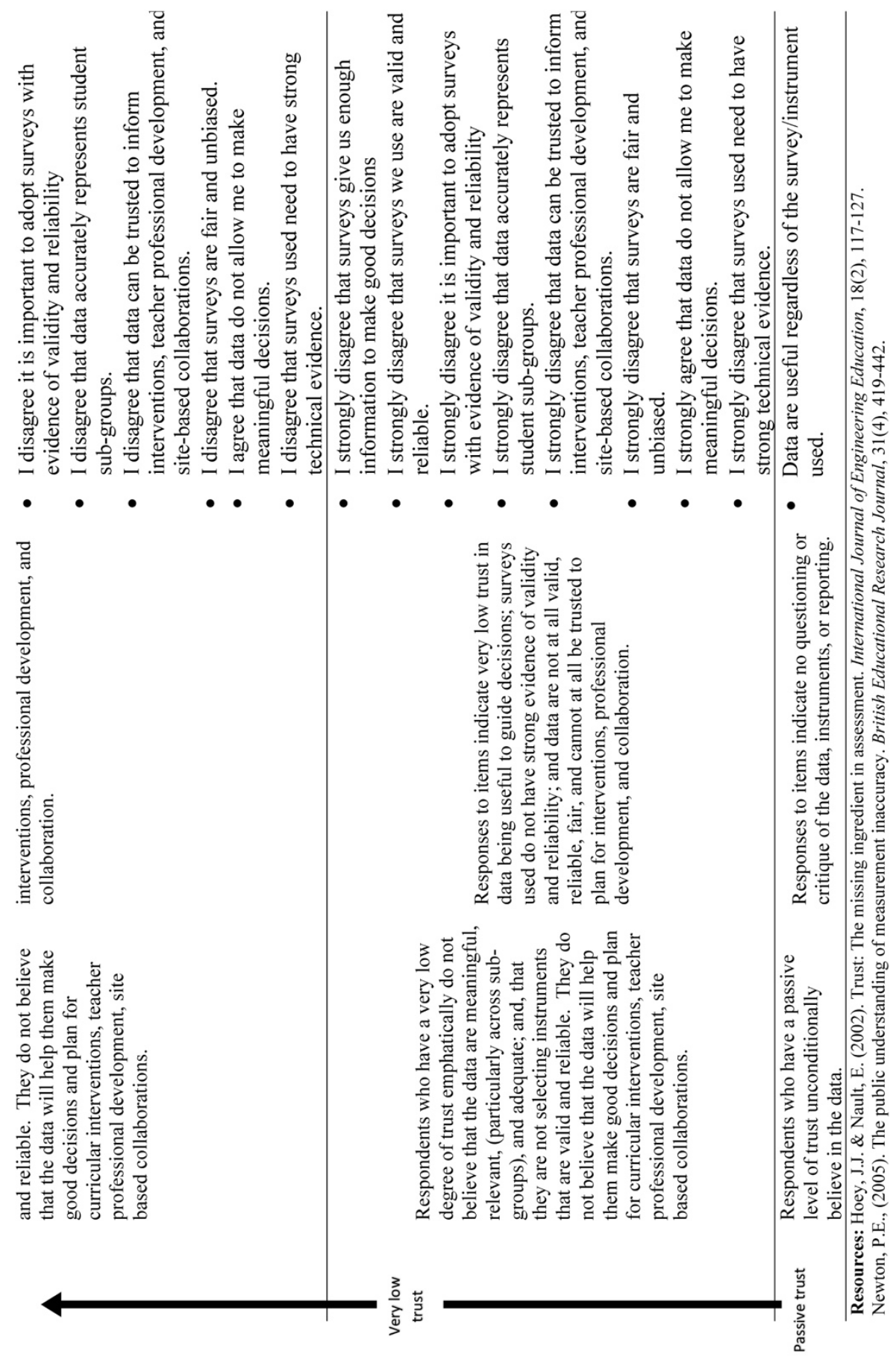




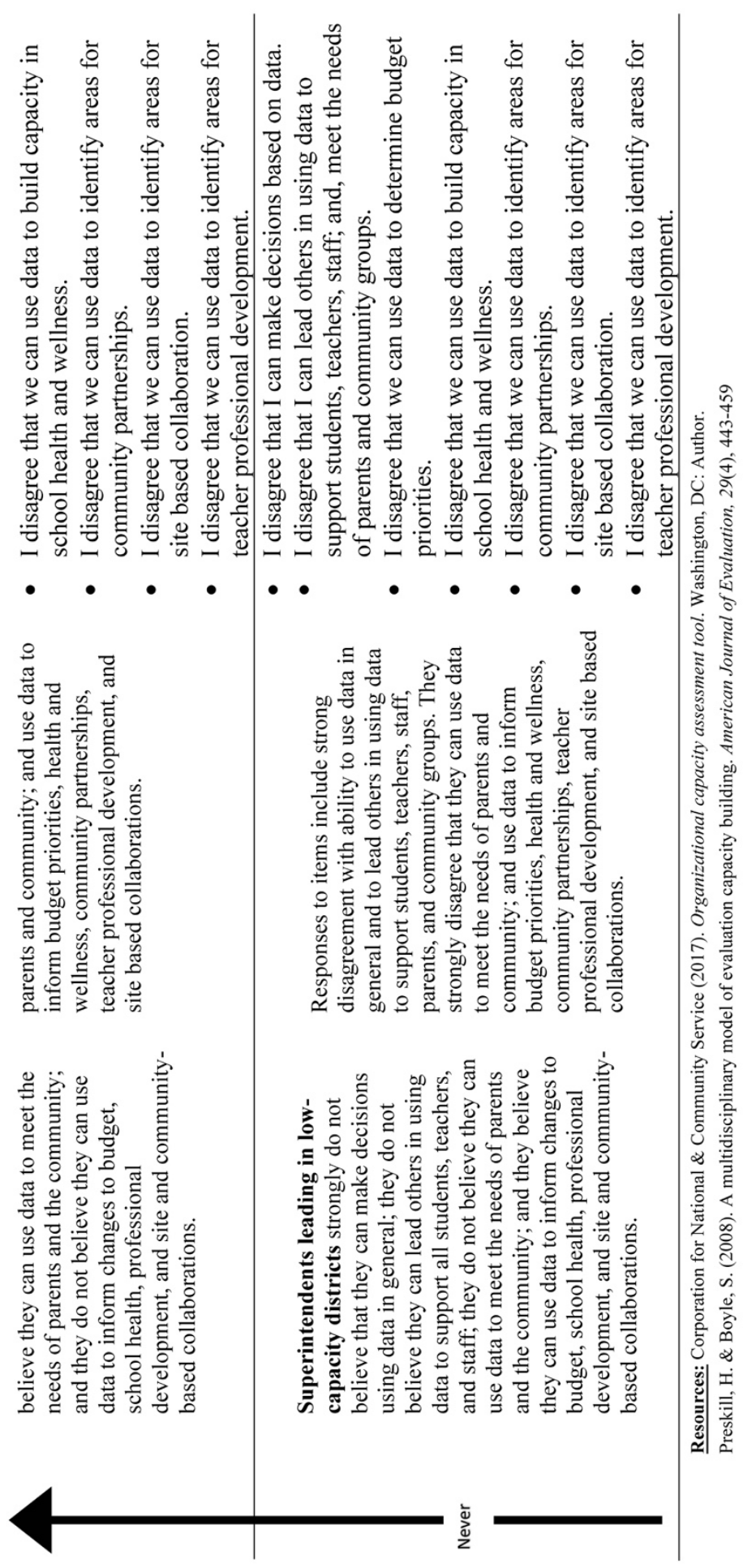









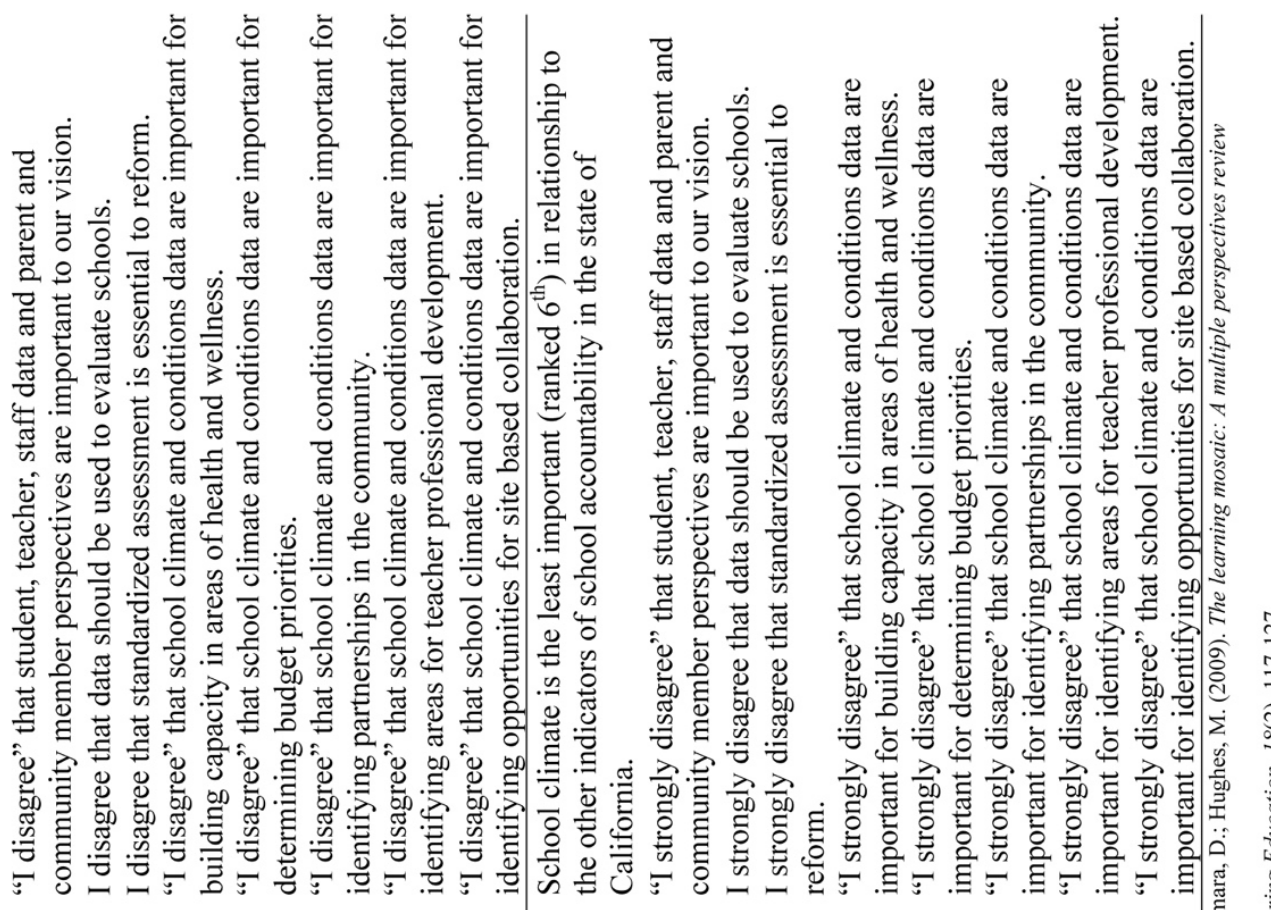

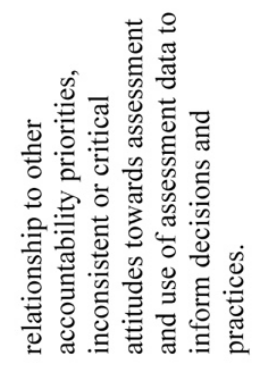

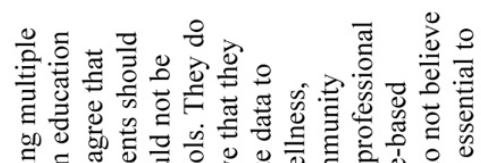

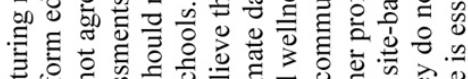

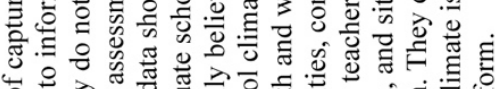

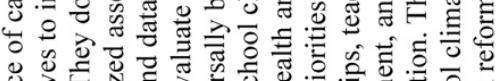

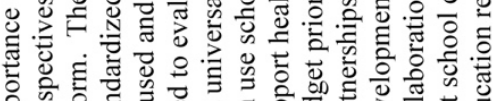

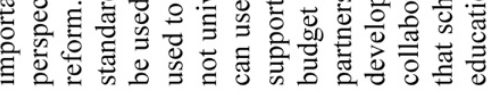

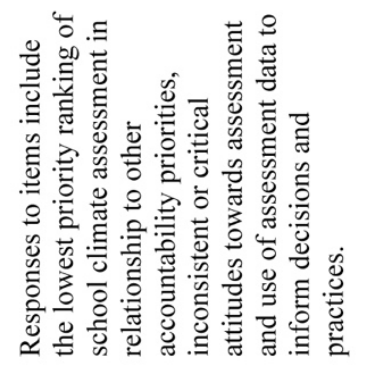

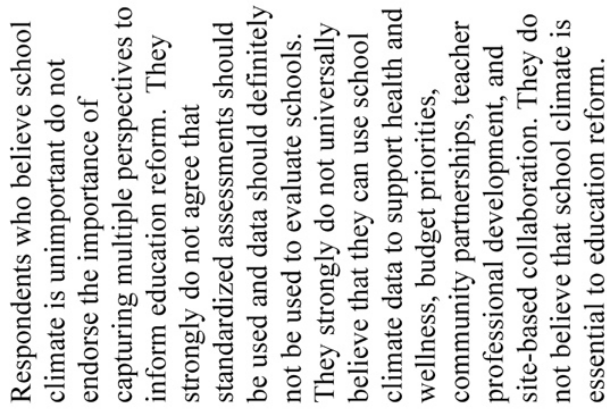

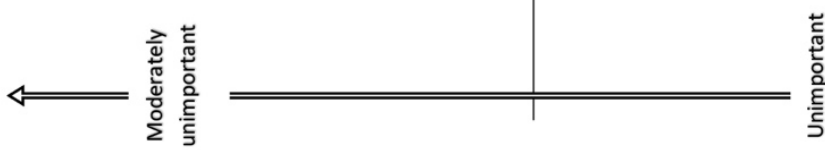




\section{Appendix C: Survey Instrument}

\section{AGREEMENT TO PARTICIPATE IN THE ONLINE SURVEY}

Your completion of the online survey indicates your willingness to voluntarily participate. View and download the consent notice here.

I have read the consent notice and I agree to participate in the online survey.

$\square$ Yes

$\square$ No [prevent from proceeding]

\section{Part One: Superintendent beliefs about importance, capacity, and trustworthiness of} $\underline{\text { data }}$

1. How important is school climate in relationship to the other indicators of school accountability in the state of California? Drag and drop your responses in order from 1 (top priority) to 6 .

a. Priority 1: Basic

b. Priority 2: State Standards

c. Priority 3: Parental Involvement

d. Priority 4: Pupil Achievement

e. Priority 5: Pupil Engagement

f. Priority 6: School Climate

2. School climate is the most important factor in continuous improvement? (Strongly agree, agree, disagree, strongly disagree)

3. To what extent are school climate data about students important to your vision of continuous improvement? (unimportant, somewhat important, very important, extremely important)

4. To what extent are school climate data about teachers important to your vision of continuous improvement? (unimportant, somewhat important, very important, extremely important)

5. To what extent are school climate data about parents important to your vision of continuous improvement? (unimportant, somewhat important, very important, extremely important)

6. To what extent are school climate data about staff important to your vision of continuous improvement? (unimportant, somewhat important, very important, extremely important) 
7. To what extent are community advocacy groups' perspectives on school climate important to your vision of continuous improvement? (unimportant, somewhat important, very important, extremely important)

8. In general, do you believe that it is important to use school climate data to evaluate schools? (unimportant, somewhat important, very important, extremely important)

9. Standardized assessment of school climate is essential to continuous improvement. (Strongly agree, agree, disagree, strongly disagree)

10. How important are data gathered on school climate for building capacity in areas of health and wellness? (unimportant, somewhat important, very important, extremely important)

11. How important are data gathered on school climate for determining budget priorities e.g., curriculum adoption, personnel/hiring, etc.? (unimportant, somewhat important, very important, extremely important)

12. How important are data gathered on school climate for school/community collaboration? (unimportant, somewhat important, very important, extremely important)

13. How important are data gathered on school climate for identifying areas for teacher professional development/training? (unimportant, somewhat important, very important, extremely important)

14. How important are data gathered on school climate for identifying opportunities for site based collaboration e.g. PLC's? (unimportant, somewhat important, very important, extremely important)

15. In general, I can make decisions based on school climate data. (Strongly agree, agree, disagree, strongly disagree)

16. I am able to lead others in using school climate data to support students. (Strongly agree, agree, disagree, strongly disagree)

17. I am able to lead others in using school climate data to support teachers. (Strongly agree, agree, disagree, strongly disagree)

18. I am able to lead others in using school climate data to support staff. (Strongly agree, agree, disagree, strongly disagree)

19. We are able to use school climate data to meet the needs of parents. (Strongly agree, agree, disagree, strongly disagree) 
20. We are able to use school climate data to meet the needs of community advocacy groups. (Strongly agree, agree, disagree, strongly disagree)

21. We can make decisions about the needs of different student sub-groups based on the school climate data. (Strongly agree, agree, disagree, strongly disagree)

22. We can use school climate data for determining budget priorities e.g., curriculum adoption, personnel/hiring, etc. (Strongly agree, agree, disagree, strongly disagree)

23. We can use school climate data for building capacity in areas of health and wellness. (Strongly agree, agree, disagree, strongly disagree)

24. We can use school climate data for identifying areas for partnerships in the community. (Strongly agree, agree, disagree, strongly disagree)

25. We can use school climate data for identifying areas for teacher professional development. (Strongly agree, agree, disagree, strongly disagree)

26. We can use school climate data for identifying areas for identifying opportunities for site based collaboration e.g. PLC's. (Strongly agree, agree, disagree, strongly disagree)

27. School climate survey data give us all the useful information we need to make good decisions for continuous improvement. (Strongly agree, agree, not sure disagree, strongly disagree)

28. School climate surveys, for the most part, are unbiased and fair. (Strongly agree, agree, not sure, disagree, strongly disagree)

29. It is important to adopt a school climate survey that has strong technical evidence, including validity studies, to support appropriate uses. (Strongly agree, agree, not sure disagree, strongly disagree)

30. The school climate data we use accurately depicts the needs of all our student subgroups. (Strongly agree, agree, not sure, disagree, strongly disagree)

31. Any data gathered from school climate surveys are useful to us to improve school climate--regardless of technical evidence e.g., validity studies, reliability, etc. (Strongly agree, agree, not sure, disagree, strongly disagree)

32. School climate data do not allow me to make meaningful decisions for continuous improvement. (Strongly agree, agree, not sure, disagree, strongly disagree) 
33. We can trust the school climate survey data to invest in particular interventions to improve school climate. (Strongly agree, agree, not sure, disagree, strongly disagree)

34. We can trust the school climate survey data to inform the choice of teacher professional development to improve school climate. (Strongly agree, agree, not sure, disagree, strongly disagree)

35. To support appropriate uses with vulnerable populations, school climate survey data must be technically sound e.g., valid, reliable, etc. (Strongly agree, agree, not sure, disagree, strongly disagree)

36. We can trust the school climate survey data to target specific site based collaborations to improve school climate. (Strongly agree, agree, not sure, disagree, strongly disagree)

37. The school climate surveys we use are valid. (Strongly agree, agree, not sure, disagree, strongly disagree)

38. The school climate surveys we use are reliable. (Strongly agree, agree, not sure, disagree, strongly disagree)

\section{Part Two: School climate and conditions instrumentation}

39. Please indicate all the school climate and conditions instruments currently in use. (Check all that apply.)

a. ACT Engage

b. California Healthy Kids

c. Comprehensive School Climate Inventory (CSCI)

d. CORE District Survey

e. DESSA

f. Panorama

g. Positive Behavioral Intervention and Supports (PBIS)

h. School Climate Assessment Instrument (SCAI)

i. Student management system question bank (indicate SMS) [text box]

j. Youth Truth

k. Develop own site based instrument

1. Other (Please specify) [text box]

40. Who currently completes school climate assessments/surveys? (Check all that apply.)

a. Community stakeholders

b. Faculty

c. Parents

d. Staff

e. Students 
41. Who, among the following stakeholders, participates in school climate data analysis and decision making? (Check all that apply.)
a. Community stakeholders
b. Faculty
c. Parents
d. Staff
e. Students

42. Please identify the methods for gathering school climate and conditions data. (Check all that apply.)
a. Interview
b. Observation
c. Survey
d. Other (Please specify) [text box]

43. Please identify the type of disaggregated school climate and conditions data by subgroups. (Check all that apply.)
a. English learner
b. Ethnicity
c. Foster Youth
d. Free and reduced price meals
e. Gender
f. Race
g. Sexual orientation
h. Special education
i. None of the above

44. Please identify the level of disaggregated school climate and conditions data. (Check all that apply.)
a. Individual
b. Classroom
c. Department
d. School
e. None of the above

\section{Part Three: Demographics by District and Respondent}

Demographic data is anonymous and will be reported and analyzed in aggregate. The primary purpose for data collection is to explore patterns and relationships among the dataset. No personal identifiers will be used, consistent with the scope of consent.

45. In what region do you currently lead? [pull down menu]

$\circ$ District 1 (Del Norte, Humboldt, Lake, Mendocino, Shasta, Sonoma) 
- District 2 (Butte, Glenn, Lassen, Modoc, Plumas, Shasta, Siskiyou, Tehama, Trinity)

- District 3 (Alpine, Colusa, El Dorado, Nevada, Placer, Sacramento, Sierra, Sutter, Yolo, Yuba)

- District 4 (Alameda, Contra Costa, Marin, Napa, San Francisco, San Mateo, Solano)

- District 5 (Monterey, San Benito, Santa Clara, Santa Cruz)

- District 6 (Amador, Calaveras, San Joaquin, Stanislaus, Tuolumne)

- District 7 (Fresno, Kings, Madera, Mariposa, Merced, Tulare)

- District 8 (Kern, San Luis Obispo, Santa Barbara, Ventura)

- District 9 (Imperial, Orange, San Diego)

- District 10 (Inyo, Mono, Riverside, San Bernardino)

- District 11 (Los Angeles)

46. Describe your district/county?

$\begin{array}{ll}\circ & \text { Rural } \\ \circ & \text { Suburban } \\ \circ & \text { Urban } \\ \circ & \text { Other (Please specify) [text box] }\end{array}$

47. How many students are enrolled in your school district?

$\circ$ Very small (less than 499)

- Small (500-999)

- Medium (1000-9999)

- Large $(10,000-19,000)$

- Extra large $(20,000$ or more)

48. Estimate your student demographics.

$\circ$ English Learner \%

- Free and reduced priced meals\%

- Special education $\%$

49. Estimate the proportion of schools that are currently in your district/county.

- Charter schools \%

- Traditional public schools $\%$

50. What is your current position?

$\square$ County superintendent

$\square$ District superintendent

- Charter school administrator

$\square$ Other (Please specify)

51. What is the highest degree you have earned?

$\square$ Bachelor's degree 


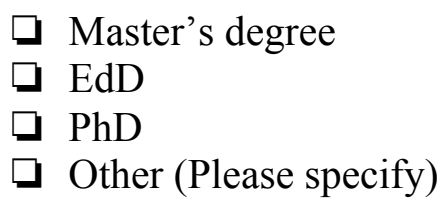

52. What is your gender?
$\square$ Female
$\square$ Male
$\square$ Non-binary
$\square$ Prefer not to state

53. What is your race/ethnicity?
$\square$ American Indian/Alaska Native
$\square$ Asian
$\square$ Black/African American
$\square$ Hispanic or Latinx
$\square$ Native Hawaiian or Pacific Islander
$\square$ White
$\square$ Prefer not to state

54. What is your age?
$\square$ Younger than 30
口 30-39
$\square$ 40-49
口 50-59
$\square$ 60-69
$\square 70$ or older
$\square$ Prefer not to state

55. How many years have you served as a superintendent in this school district/county?
$\square 10$ years or more
$\square$ Five years to less than 10 years
$\square$ three years to less than five years
$\square$ one year to less than 3 years
$\square$ Less than one year

56. How many years have you served as the superintendent in any school district/county?

$\square 10$ years or more

$\square$ Five years to less than 10 years

$\square$ three years to less than five years

$\square$ one year to less than 3 years

$\square$ Less than one year 


\section{Part Four: Exit Questions}

1. Were there any questions on this survey that were unclear? Yes/No Please identify the specific question(s) and explain [Text box]

2. Did you have enough time to complete all of the questions? Yes/No

3. What device/platform did you use to complete the survey? (Smartphone, laptop, desktop, other)

4. Do you have any suggestions for improving the survey? Yes/No Please explain [Text box]

Thank you for your participation! 


\section{Appendix D: Semi-Structured Interview Protocol}

\section{$\underline{\text { Semi structured interview Protocol }}$}

Introduction \& Consent to tape recorded interview

My name is Anji Buckner and I am a graduate student in Educational Leadership at San Jose State University. My research is exploring school climate assessment from the perspective of district leaders across our state. I appreciate that you have taken the time out of your busy schedule to help me continue to explore this topic. Before I begin, I would like to record this interview so I can devote my full attention to our conversation. Portions of this interview and your responses may be included in my dissertation or future publications based on this research, but no identifying characteristics will be included in any published document. Did you receive and review the informed consent that I emailed? Do you have any questions? If you concur, please sign and return that document via email so I have a written record of your consent to voluntarily participate.

May I have your verbal consent for participating in this recorded interview today?

Thank you. Now, I would like to begin with a couple of questions about you.

Demographics

Could I ask you to please state your name?

What is your current position and title?

What is the length of time that you have been in this position?

Thank you. Now, I will be asking you some questions about three different themes related to school climate assessment: importance, capacity, and trustworthiness.

Importance

Context: In the survey I asked several questions about the importance of assessing school climate.

Q: As a district leader, can you explain the importance of understanding and assessing school climate for your vision of continuous improvement?

Probes:

Can you explain?

Can you say more?

Can you give me some examples?

Q: What do you feel are the most important uses of school climate data?

Probes: 
Can you give me some examples.

Do your school climate data inform resources and the budget?

Do your school climate data lead you to changes that are designed to improve health and wellness?

Do your data facilitate collaboration?

Do you feel that we should be using school climate data to rank schools?

Do you feel that schools should be evaluated based on their school climate data?

Capacity

Context: In the survey I asked several questions about your ability to use school climate data for decision making and leadership.

Q: Do you feel that you have the capacity to make decisions based on school climate data?

Probes:

Can you give me some examples?

Can you tell me more?

Q: Do you feel that you have the capacity to lead others in using school climate data?

Probes:

Do you feel that you can adequately help others in using these data to support stakeholders in your schools (e.g. students, teachers, staff)?

Do you feel that you are able to use these data to meet the needs of parents?

Do you feel that you are able to use these data to meet the needs of community advocacy groups?

Do you face any barriers - or challenges - in using data to support any of these stakeholders?

\section{$\underline{\text { Trustworthiness }}$}

Context: In the survey I asked people to evaluate the importance of concepts related to the trustworthiness of the school climate Data.

Q: How important is it to have instruments that are fair, unbiased, valid, and reliable?

Probes

Which of these is most important to you with school climate data?

Why is reliability important?

How can we be sure the school climate instruments are not biased towards an individual or group?

Why does Validity matter to you? 
Is standardization of these instruments important to you? Please explain.

\section{$\underline{\text { Instruments }}$}

Context: Results from my survey suggests that many people are using different instruments across the state.

Currently, what instruments are being used throughout your district to assess school climate?

\section{Probes}

Whose experiences (or perspectives) are the data capturing?

Who is involved in decision making about the uses of the data?

Why do you trust this data?

How do you ensure the data is reliable?

Q: Are the tools that you are using to assess school climate fair and unbiased?

Probes

Who decides which instrument(s) you adopt?

Do you look for specific criteria when selecting an instrument?

Has anyone checked for biases towards particular groups?

How can you be sure that you are getting the valid data that you want?

What principles guide the appropriate uses of the data?

Do you see any possible negative consequences from data use?

\section{$\underline{\text { Closing }}$}

Is there anything else that you would like to share with me about your perspective or experiences in assessing school climate in your district?

Thank you for your time and your willingness to help me with this study. 


\section{Appendix E: Recruitment Emails}

Subject line:

Important study on school climate assessment - your participation is needed

Dear Superintendent $\{$ LastName\},

My name is Anji Buckner and I am a graduate student in Educational Leadership at San Jose State University. This year I am beginning my doctoral research on the implementation of Priority 6 (School Climate) in California's Local Control Funding Formula.

The purpose of this email is to invite you to participate in my study which aims to identify the perceptions and practices of district and county leaders in assessing school climate for state accountability and continuous improvement.

For the last year I have been shadowing the CDE's School Climate and Conditions Work Group led by Glen Price, Deputy Chief Superintendent of Schools. Glen and Superintendent Torlakson support my research which I hope will add more to the conversation around data, capacity and use.

By participating, your voice and experiences will help me better understand what schools are doing and where schools may need additional support in meeting the school climate accountability expectations.

In a few days, you will be receiving an email with a link to the survey sent through the Qualtrics survey platform on my behalf. The survey link can be accessed and used from any device at any time during August 2018. The survey link is anonymous and your name or email address will not be collected.

As an education leader, your knowledge and experiences will provide important information on the practical implications of the new accountability expectation for school climate.

I know you are incredibly busy, but am humbled by individual's commitments to sharing experiences and perspectives to improve our education system. I look forward to hearing from you and capturing your voice in this study.

Thank you for considering this request. If you have any questions, please email me.

Anji Buckner

Doctoral Candidate, San Jose State University 


\section{First link email (7/31/18)}

Subject line: Take the Superintendent Survey on School Climate Assessment practices

Dear Superintendent ___ (name),

I am writing to follow up on my previous email inviting you to participate in my research on school climate assessment in California. As an education leader in our state your perspective, voice, and experiences will offer an important contribution to the discourse that is currently driving policy and practice.

For the past year, I have been shadowing CDE's School Climate and Conditions Work Group led by Glen Price, Chief Deputy Superintendent of Public Instruction. Glen and State Superintendent Torlakson support my research, which I hope will add more to the conversation around data, capacity, and use.

The survey should take approximately 15 minutes to complete and you can access it online here - (link to survey). The survey will be open for the month of August and I will be sending reminders periodically throughout the data collection process in an effort to include as many superintendents as possible.

Your contribution will help to accurately convey the range of practices and beliefs related to school climate reform and offer recommendations for both policy and practice oriented improvements.

If you have any questions about this study, please email anji.buckner@sjsu.edu. Thank you for your time and consideration.

Sincerely, Anji Buckner

Education Doctoral Candidate

San Jose State University

First follow up - 8/7/18

Dear Superintendent (Name)

Last week I invited you to participate in my study on school climate assessment and I wanted to be certain that you received my message. As an education leader your perspective, voice, and experiences will offer an important contribution to the discourse that is currently driving policy and practice.

For the past year, I have been shadowing CDE's School Climate and Conditions Work Group led by Glen Price, Chief Deputy Superintendent of Public Instruction. Glen and 
State Superintendent Torlakson support my research, which I hope will add more to the conversation around data, capacity, and use. (See Torlakson Endorsement.pdf letter).

The survey should take approximately 15-20 minutes to complete and you can access it online here - [Link]- using any device. Once you begin, you can save and return to where you left off at any time, but you will not be able to re-take the survey once you have completed it. The survey will be open for the month of August and I will be sending reminders periodically throughout the data collection process in an effort to include as many superintendents as possible.

Your participation will help to accurately convey the range of practices and beliefs related to school climate and offer recommendations for both policy and practice oriented improvements.

If you have any questions about this study, please email anji.buckner@sjsu.edu. Thank you for your time and consideration.

Sincerely, Anji Buckner Education Doctoral Candidate

San José State University

\section{Second follow up - 8/13/18}

Subject Line: Superintendent school climate survey - add your voice today

Dear Superintendent (name)

Earlier this month I invited you to participate in a statewide survey (link here) of superintendents designed to capture your beliefs and practices related to school climate assessment. The responses that have already been submitted are excellent contributions to this research that will further support meaningful dialogue. However, there are still a lot of perspectives that are not yet included.

As you know, data tell a story and as State Superintendent Torlkason pointed out in the endorsement letter: "Without your experiences, we will not have an accurate picture of what schools are doing and where schools and districts need more support."

I respectfully acknowledge that your schedule is getting busier each day and with that in mind, I encourage you to submit your responses this week.

The survey is available here - $\underline{\text { LINK}}$. 
This study is the first to explore the actual processes and beliefs of education leaders in the state of California and it ambitiously seeks responses from all superintendents in the state. As a local leader, your voice is fundamentally important to capture. Please contribute and help me accurately reflect the landscape of practices and guide the recommendations for future research, practice, and legislation.

Kindly,

Anji

\section{Final follow up email}

Subject Line: Last chance to add your voice on school climate assessment in California public schools

Dear Superintendent (last name),

I know you are very busy and the start of a new school year is upon us, but the school climate survey will be closing soon and I encourage you to add your voice and experiences to the other _ (\# of responses)

I urge you to participate because your experiences will help me gain an accurate picture of what schools are doing that is working well and where schools and districts need support. The findings from this study have the potential to greatly influence the next set of recommendations and legislation to support schools and districts in understanding and improving school climate.

Take 15 minutes to share your perspectives here - LINK. This survey will close at midnight on August 31, 2018.

If you have any questions, please email me.

Sincerely,

Anji Buckner 


\section{Superintendent Participation in School Climate Statewide Study}

I am writing to encourage every superintendent in the state to participate in a statewide study to capture your experiences and perceptions on school climate assessment practices in your district. This survey is part of a research study being conducted by a doctoral candidate in Educational Leadership at San José State University and it is the first of its kind in the State of California.

I urge you to participate because the findings from this study have the potential to influence the next set of recommendations and legislation to support schools and districts in understanding and improving school climate. Without your experiences, we will not have an accurate picture of what schools are doing and where schools and districts need more support.

Your voice and experiences are important and this study offers an unbiased opportunity for us all to learn more. I hope you will each take a few minutes to share your perspectives.

Thank you for all that you are doing to serve children, families, and educators.

Sincerely,

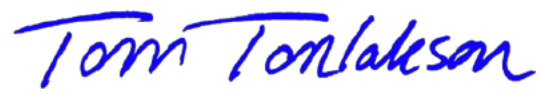

Tom Torlakson

TT:gp 
Subject line: Important study on school climate assessment - interview request

Dear Superintendent

My name is Anji Buckner and I am a graduate student in Educational Leadership at San Jose State University. This year I began my doctoral research on the implementation of Priority 6 (School Climate) in California's Local Control Funding Formula. In the first phase of my research I solicited survey responses from superintendents across the state. In my second phase, I am reaching out to a small representative sample for follow up interviews.

As the superintendent of a ___ (large, medium, small)__ Urban, Rural, Suburban district in the __ (region)__ your perspectives are important. I would like to invite you to participate in a 30-45 minute interview. The purpose of the interview is to explore some of the findings from the survey and to allow participants to further expand on experiences and beliefs about school climate assessment.

To schedule an interview, please respond to this email and indicate days or times that fit your schedule. If you have any questions about this study, please email anji.buckner@sjsu.edu.

Anji Buckner

Doctoral Candidate, San Jose State University

One Washington Square

San Jose, CA 95192

\section{Follow up Voice Message}

My name is Anji Buckner and I am a graduate student in Educational Leadership at San Jose State University. I am reaching out today to invite you to participate in a follow up interview to the survey about school climate assessment from earlier this year.

As the superintendent of a large district in an urban region in California your perspectives are important. I would like to invite you to participate in a 30-45 minute interview. I know you are incredibly busy, but I would be grateful for any time that you might be able to offer. I will follow up with an email with the hope that you could let me know if you are interested and available. 


\section{Appendix F: Wright Maps}

Importance Construct Wright Map

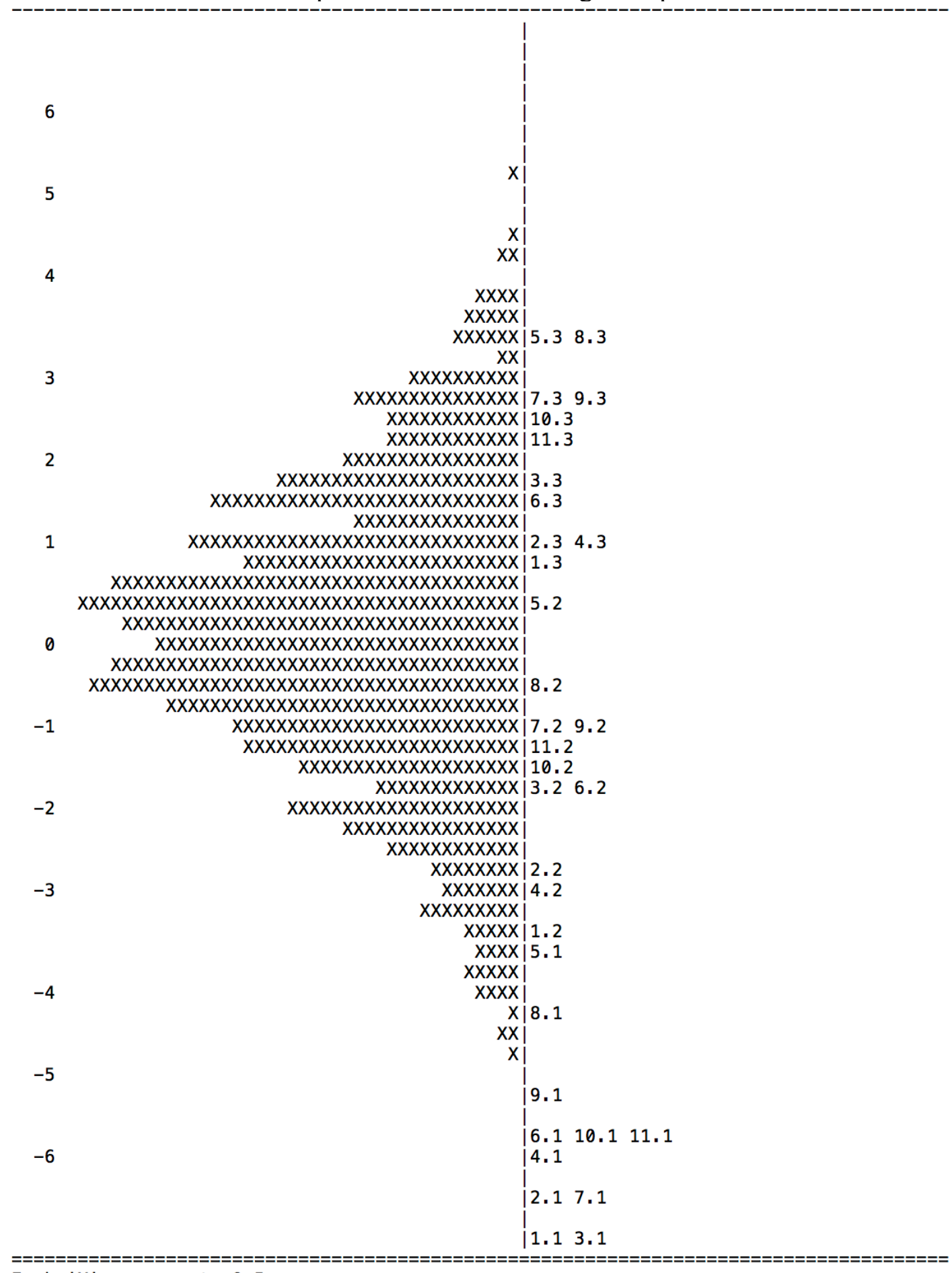

Each ' $X$ ' represents 0.5 cases 


\section{Capacity Construct Wright Map}

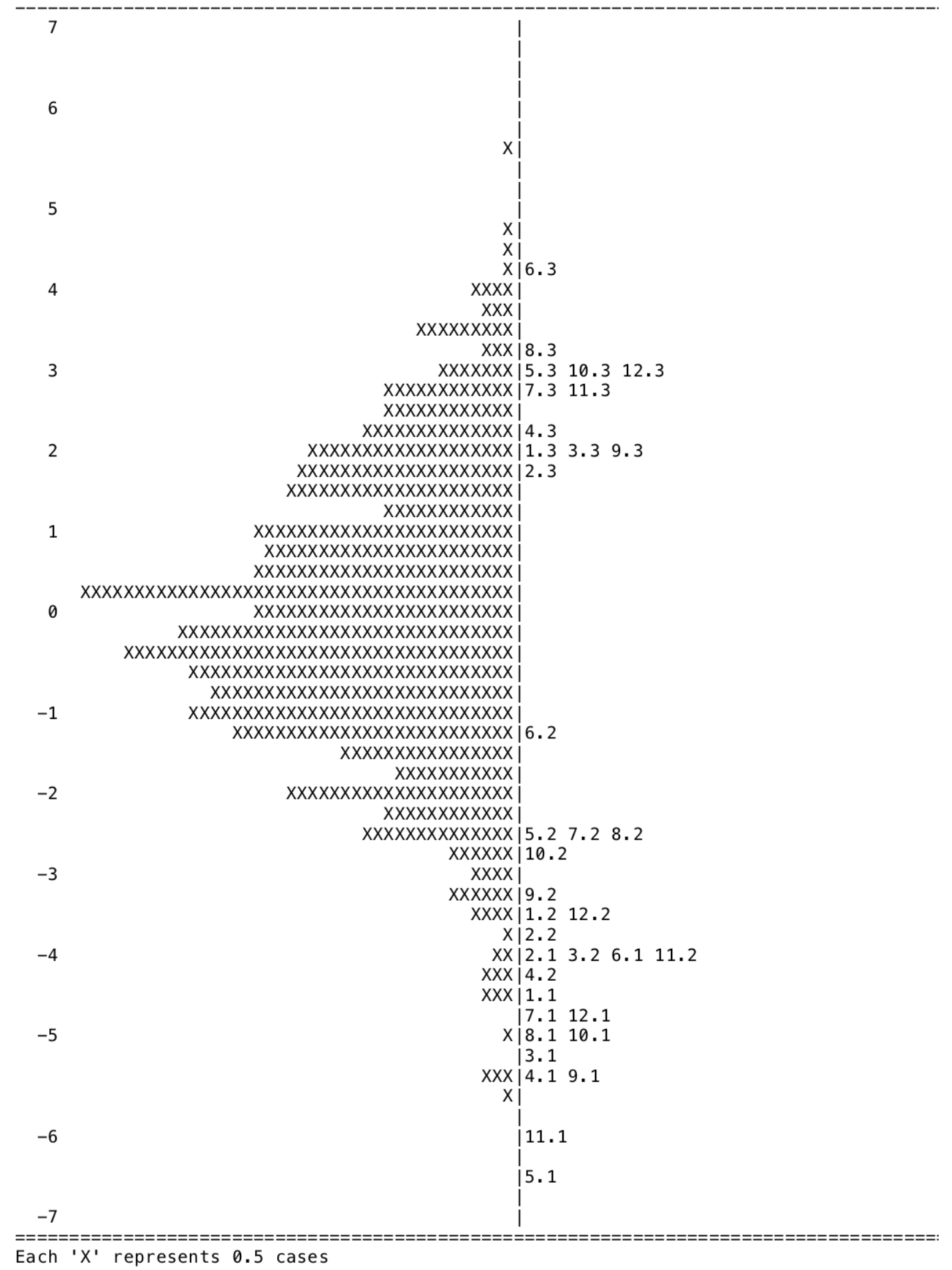


Trustworthiness Construct Wright Map

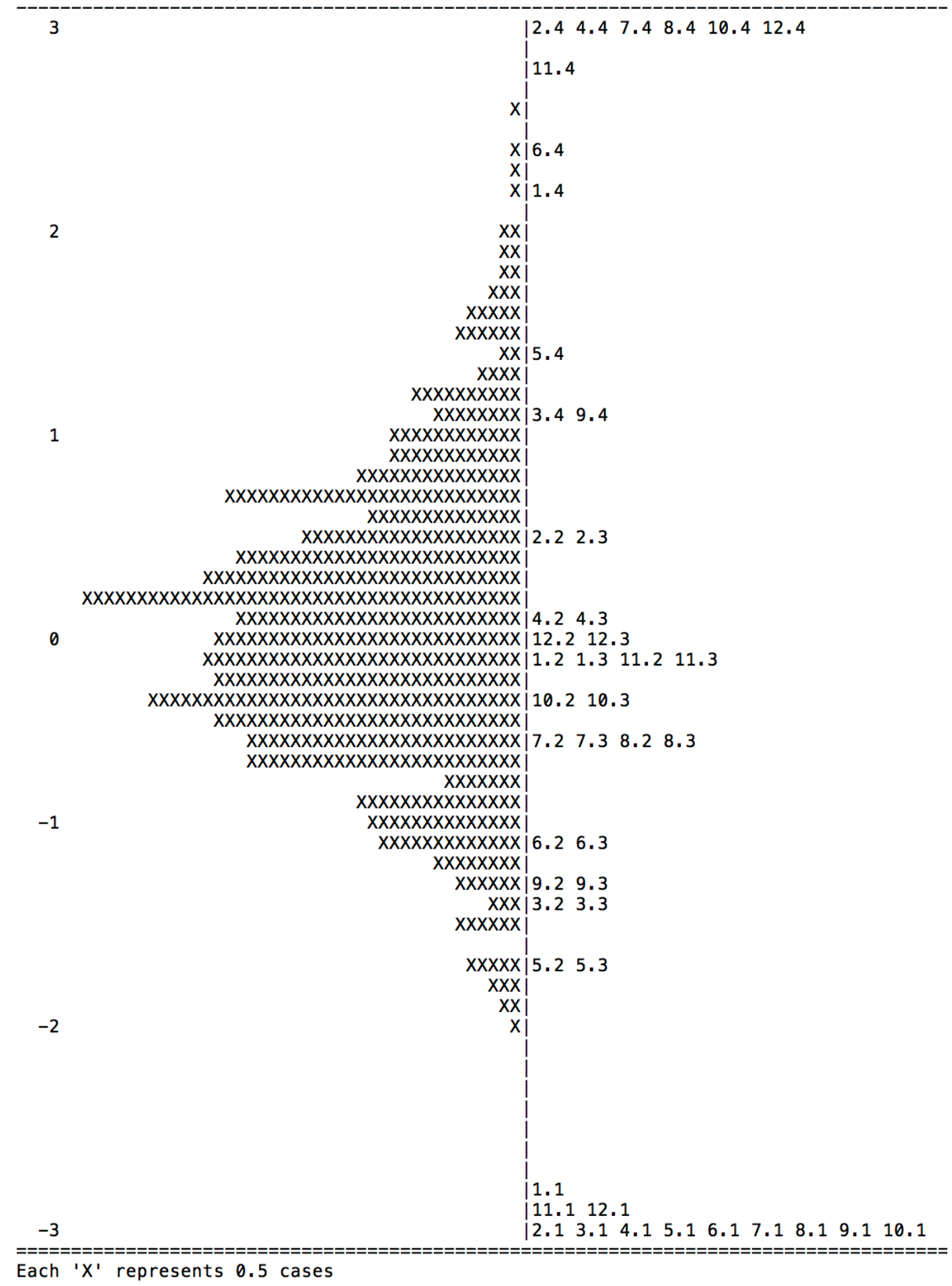




\title{
Appendix F: Regression Analysis Questions
}

\author{
Beliefs of Importance of school climate assessment data for continuous improvement
}

Personal characteristics

1. What is the relationship (if any) between superintendents' strength of belief in the importance of school climate assessment data for continuous improvement and gender?

2. What is the relationship (if any) between superintendents' strength of belief in the importance of school climate assessment data for continuous improvement and age?

3. What is the relationship (if any) between superintendents' strength of belief in the importance of school climate assessment data for continuous improvement and education?

4. What is the relationship (if any) between superintendents' strength of belief in the importance of school climate assessment data for continuous improvement and experience?

\section{School Contexts}

1. What is the relationship (if any) between "urbanicity" and superintendents' beliefs in the importance of school climate assessment data for continuous improvement?

2. What is the relationship (if any) between poverty (estimated using eligibility for free and reduced priced meals as a proxy) and superintendents' beliefs in the importance of school climate assessment data for continuous improvement?

3. What is the relationship (if any) between the percentage of English learner students enrolled and superintendents' beliefs in the importance of school climate assessment data for continuous improvement?

4. What is the relationship (if any) between the percentage of Special Education students and superintendents' beliefs in the importance of school climate assessment data for continuous improvement?

Beliefs towards capacity to use school climate assessment data for continuous improvement

Personal Characteristics

1. What is the relationship (if any) between superintendents' strength of belief in their capacity to use - or lead others in using - school climate assessment data for continuous improvement and gender?

2. What is the relationship (if any) between superintendents' strength of belief in their capacity to use - or lead others in using - school climate assessment data for continuous improvement and age?

3. What is the relationship (if any) between superintendents' strength of belief in their capacity to use - or lead others in using - school climate assessment data for continuous improvement and education?

4. What is the relationship (if any) between superintendents' strength of belief in their capacity to use - or lead others in using - school climate assessment data for continuous improvement and experience?

School Contexts

1. What is the relationship (if any) between "urbanicity" and superintendents' beliefs in their capacity to use school climate assessment data for continuous improvement? 
2. What is the relationship (if any) between poverty and superintendents' beliefs in their capacity to use school climate assessment data for continuous improvement?

3. What is the relationship (if any) between the percentage of English Learner students and superintendents' beliefs in their capacity to use school climate assessment data for continuous improvement?

4. What is the relationship (if any) between the percentage of Special Education students and superintendents' beliefs in their capacity to use school climate assessment data for continuous improvement?

Beliefs towards trust in the data that are obtained

Personal Characteristics

1. What is the relationship (if any) between superintendents' strength of belief in the trustworthiness of school climate assessment data and gender?

2. What is the relationship (if any) between superintendents' strength of belief in the trustworthiness of school climate assessment data and age?

3. What is the relationship (if any) between superintendents' strength of belief in the trustworthiness of school climate assessment data and education?

4. What is the relationship (if any) between superintendents' strength of belief in the trustworthiness of school climate assessment data and experience?

School Contexts

1. What is the relationship (if any) between "urbanicity" and superintendents' beliefs in the trustworthiness of school climate assessment data?

2. What is the relationship (if any) between poverty and superintendents' beliefs in the trustworthiness of school climate assessment data?

3. What is the relationship (if any) between the percentage of English Learner students and superintendents' beliefs in the trustworthiness of school climate assessment data?

4. What is the relationship (if any) between the percentage of Special Education students and superintendents' beliefs in the trustworthiness of school climate assessment data? 


\section{Appendix H: Approved IRB}

\section{\begin{tabular}{l|l|l|l|l|l} 
SAN JOSE STATE & $\begin{array}{l}\text { Office of Research } \\
\text { Division of } \\
\text { Academic Affairs }\end{array}$ & $\begin{array}{l}\text { San José State University } \\
\text { One Washington Square } \\
\text { San Jasé, CA 95192-0025 }\end{array}$ & $\begin{array}{l}\text { TEL: 408-924-2272 } \\
\text { officeofresearch@sjsu.edu } \\
\text { sjsu.edu/research }\end{array}$ \\
UNIVERSITY &
\end{tabular}}

\section{SAN JOSE STATE UNIVERSITY \\ HUMAN SUBJECTS INSTITUTIONAL REVIEW BOARD}

IRB Notice of Approval

Date of Approval: 6/27/2018

Study Title: Assessing School Climate Assessment Processes in California Public Schools: What Superintendents Tell Us about the Collection and Use of School Climate Data in K-12 Settings

Primary Investigator(s): Dr. Brent Duckor

Student(s): Anji Buckner-Capone

Other Team Members:

Funding Source: RSCA

IRB Protocol Tracking Number: S18101

Type of Review

$\triangle \quad$ Exempt Registration: Category of approval $\$ 46.104(\mathrm{~d})(2 \mathrm{iii})$

$\square$ Expedited Review: Category of approval $\$ 46.110(\mathrm{a}) 0$

$\square$ Full Review

Modifications

$\square$ Continuing Review

Special Conditions

$\square$ Waiver of signed consent approved (for survey only; signed consent needed for interviews).

$\square$ Waiver of some or all elements of informed consent approved

$\square$ Risk determination for device:

$\square$ Other:

\section{Continuing Review}

$\square$ Is not required. Principal Investigator must file a status report with the Office of Research one year from the approval date on this notice to communicate whether the research activity is ongoing. Failure to file a status report will result in closure of the protocol and destruction of the protocol file after three years. 
Is required. An annual continuing review renewal application must be submitted to the Office of Research one year from the approval date on this notice. No human subjects research can occur after this date without continuing review and approval.

Approved by Dr. Pamela C. Stacks

Associate Vice President

Institutional Official

Office of Research

San Jose State University

IRB Contact

Alena Filip

Human Protections Analyst

408-924-2479

Alena.Filip@sjsu.edu

\section{Primary Investigator Responsibilities}

- Any significant changes to the research must be submitted for review and approval prior to the implementation of the changes.

- Reports of unanticipated problems, injuries, or adverse events involving risks to participants must be submitted to the IRB within seven calendar days of the primary investigator's knowledge of the event.

- If the continuing review section of this notice indicates that continuing review is required, a request for continuing review must be submitted prior to the date the provided. 


\section{Appendix I: Survey Consent Notification}

$$
10 \begin{array}{lll||}
\text { SAN JOSÉ STATE } & \begin{array}{l}
\text { Ed.D. Leadership Program } \\
\text { Connie L. Lurie } \\
\text { College of Education }
\end{array} & \begin{array}{l}
\text { San José State University } \\
\text { One Washington Square } \\
\text { San José, CA 95192-0064 }
\end{array}
\end{array}
$$

Request for your Participation in Research

Superintendent beliefs about the assessment of school conditions and climate Anji Buckner, Graduate Student and Brent Duckor, Faculty Advisor

\section{PURPOSE}

The purpose of this mixed methods study is to explore the practices and perceptions of district leaders in their efforts to meet Priority 6 of the LCFF.

\section{PROCEDURES}

All California superintendents are invited to participate and will be emailed a link to an online survey that will ask you to respond to questions about your experiences with and opinions about school climate assessment practices. This survey should take between 10-15 minutes to complete. All reported information will be confidential. No personally identifying information will be accessed or reported in the final study. Where data are reported, they will be reported in aggregate with no district identifiable information included.

\section{POTENTIAL RISKS}

There are no identifiable risks associated with this study. This study involves no more risk than what participants would encounter in everyday life.

\section{POTENTIAL BENEFITS}

While we do not anticipate any direct benefits to individual participants the information that is provided may help the researchers better understand the range and scope of instruments in use and the potential usability of school climate data for school planning and legislative purposes.

\section{CONFIDENTIALITY}

Survey responses will be kept confidential. Although the findings of this study may be published, no information that can identify you or your district will be included.

\section{COMPENSATION}

No compensation will be given for participating in this study.

\section{PARTICIPANT RIGHTS}

Your participation in this study is completely voluntary. You can refuse to participate in the entire study or any part of the study without any negative effect on your relations with San Jose State University. You will not waive any rights if you choose not to participate, and there is no penalty for stopping your participation in the study.

\section{QUESTIONS OR PROBLEMS}

You are encouraged to ask questions at any time during this study. 
- For further information about the study, please contact Anji Buckner,

- Complaints about the research may be presented to Dr. Arnold B. Danzig, Director, EdD Leadership Program at San Jose State University, 408-924-3722.

- For questions about participants' rights or if you feel you have been harmed in any way by your participation in this study, please contact Dr. Pamela Stacks, Associate Vice President of the Office of Research, San Jose State University, at 408-924-2479.

AGREEMENT TO PARTICIPATE IN THE ONLINE SURVEY

Your completion of the survey indicates your willingness to participate. Please keep this information for your records and do not write any information that could directly identify you on the survey. 


\section{Appendix J: Interview Consent Form}

$$
\begin{array}{lll||l}
\text { SAN JOSÉ STATE } & \begin{array}{l}
\text { Ed.D. Leadership Program } \\
\text { Connie L. Lurie } \\
\text { college of Education }
\end{array} & \begin{array}{l}
\text { San José State University } \\
\text { One Washington Square } \\
\text { San José, CA 95192-0064 }
\end{array} & \begin{array}{l}
\text { 408-924-4098 } \\
\text { edd-leadership@sjsu.edu }
\end{array}
\end{array}
$$

\section{Request for your Participation in Research}

Assessing school climate assessment processes in California public schools: What superintendents tell us about the collection and use of school climate data in K-12 settings

Anji Buckner, Graduate Student, and Brent Duckor, Faculty Advisor

\section{PURPOSE}

The purpose of this mixed methods study is to explore the practices and perceptions of district leaders in their efforts to meet Priority 6 of the LCFF.

\section{PROCEDURES}

In this voluntary interview, you will be asked to report on various practices and beliefs that you have about school climate assessment instruments that you have used or that schools in your district have used. You may "opt-out" of the interview at any time and you may choose to not answer any question during the interview. All reported information will be confidential. Where data are reported, no personally identifying information will be used and your individual confidentiality will be maintained in any resulting publications. The interview will be audiotaped for transcription. Transcription will be completed by the Graduate Student researcher and a thirdparty vendor contracted with the program. Interviews transcribed by third-party vendor will be edited and identifying information will be deleted before transcription begins.

\section{POTENTIAL RISKS}

There are no identifiable risks associated with this study. This study involves no more risk than what participants would encounter in everyday life.

\section{POTENTIAL BENEFITS}

While we do not anticipate any direct benefits to individual participants the information that is provided may help the researchers better understand the range and scope of instruments in use and the potential usability of school climate data for school planning and legislative purposes.

\section{CONFIDENTIALITY}

Interview responses will be confidential Responses will be reported in the study findings, but confidentiality of individual identity will be maintained. Interviewees may opt for off-site, phone, or online interview locations.

\section{COMPENSATION}

No compensation will be given for participating in this study.

\section{PARTICIPANT RIGHTS}

Your participation in this study is completely voluntary. You can refuse to participate in the entire study or any part of the study without any negative effect on your relations with San Jose State University. You will not waive any rights if you choose not to participate, and there is no penalty for stopping your participation in the study.

\section{QUESTIONS OR PROBLEMS}

You are encouraged to ask questions at any time during this study. 


\section{QUESTIONS OR PROBLEMS}

You are encouraged to ask questions at any time during this study.

- For further information about the study, please contact Anji Buckner,

- Complaints about the research may be presented to Dr. Arnold B. Danzig, Director, EdD Leadership Program at San Jose State University, 408-924-3722.

- For questions about participants' rights or if you feel you have been harmed in any way by your participation in this study, please contact Dr. Pamela Stacks, Associate Vice President of the Office of Research, San Jose State University, at 408-924-2479.

\section{SIGNATURES}

Your signature indicates that you voluntarily agree to be a part of the study, that the details of the study have been explained to you, that you have been given time to read this document, and that your questions have been answered. You will receive a copy of this consent form for your records.

\section{Participant Signature}

$\overline{\text { Participant's Name (printed) }} \overline{\text { Participant's Signature Date }}$

\section{Researcher Statement}

I certify that the participant has been given adequate time to learn about the study and ask questions. It is my opinion that the participant understands his/her rights and the purpose, risks, benefits, and procedures of the research and has voluntarily agreed to participate. 